Chemical Technology

Division

Chemical Technology

Division

Chemical Technology

Division

Chemical Technology

Division

Chemical Technology

Division

Chemical Technology

Division

Chemical Technology

Division

Chemical Technology

Division

Chemical Technology

Division

Chemical Technology

Division

Chemical Technology

Division

Chemical Technology

Division

Chemical Technology

Oivision

Chemical Technology

Division

Chemical Technology

Division

Chemical Technology

Division

Chemical Technology

Division

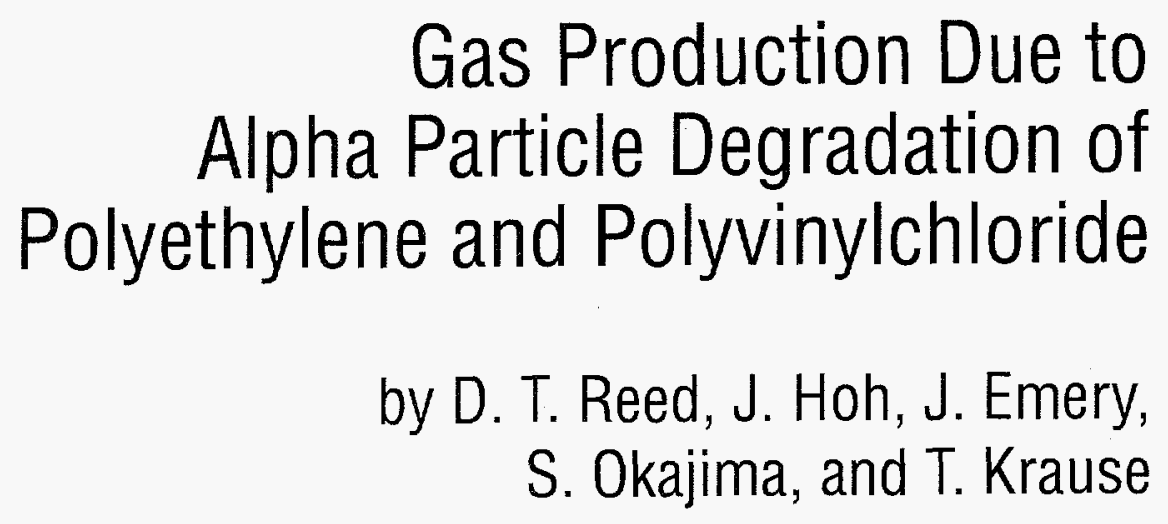

RECEIVED

SEP 151998

OSTI

DISTRBUTION OF THS DOCUMENT IS UMUMTED
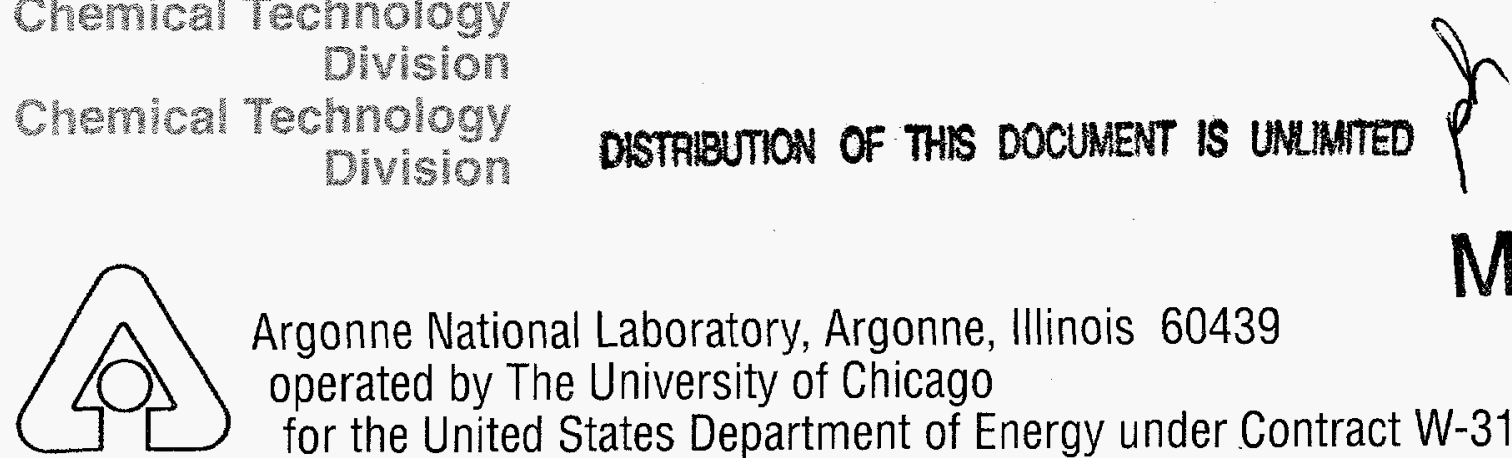

Argonne National Laboratory, Argonne, Illinois 60439

MASTER operated by The University of Chicago

for the United States Department of Energy under Contract W-31-109-Eng-38

Chemical Technology

Division

Chemical Technology

Division

Chemical Technology

Division

Chemical Technology

Division 
Argonne National Laboratory, with facilities in the states of Illinois and Idaho, is owned by the United States government, and operated by The University of Chicago under the provisions of a contract with the Department of Energy.

\section{DISCLAIMER}

This report was prepared as an account of work sponsored by an agency of the United States Government. Neither the United States Government nor any agency thereof, nor any of their employees, makes any warranty, express or implied, or assumes any legal liability or responsibility for the accuracy, completeness, or usefulness of any information, apparatus, product, or process disclosed, or represents that its use would not infringe privately owned rights. Reference herein to any specific commercial product, process, or service by trade name, trademark, manufacturer, or otherwise, does not necessarily constitute or imply its endorsement, recommendation, or favoring by the United States Government or any agency thereof. The views and opinions of authors expressed herein do not necessarily state or reflect those of the United States Government or any agency thereof.

Reproduced from the best available copy.

Available to DOE and DOE contractors from the Office of Scientific and Technical Information F.O. Box 62

Oak Ridge, TN 37831

Prices available from (423) 576-8401

Available to the public from the National Technical Information Service

U.S. Department of Commerce 5285 l?ort Royal Road Springfield, VA 22161 


\section{DISCLAIMER}

Portions of this document may be illegible in electronic image products. Images are produced from the best available original document. 
Distribution Category:

Environmental Process and Transport (UC-603)

\author{
$\overline{\mathrm{ANL}-97 / 7}$ \\ ARGONNE NATIONAL LABORATORY \\ 9700 South Cass Avenue \\ Argonne, Illinois 60439

\section{GAS PRODUCTION DUE TO ALPHA PARTICLE DEGRADATION OF POLYETHYLENE AND POLYVINYLCHLORIDE} \\ by \\ D. T. Reed, J. Hoh, J. Emery, S. Okajima, and T. Krause
}

Chemical Technology Division

July 1998 


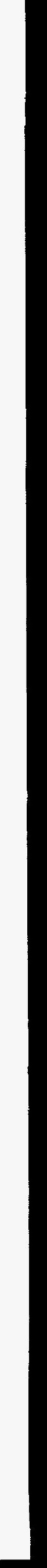




\section{TABLE OF CONTENTS}

Page

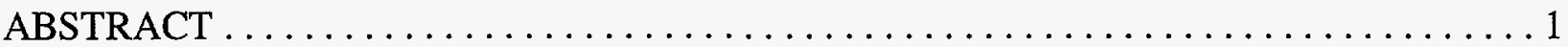

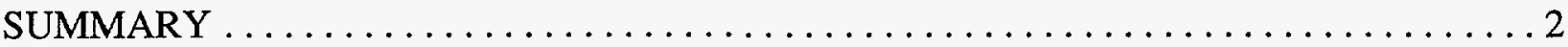

I. INTRODUCTION $\ldots \ldots \ldots \ldots \ldots \ldots \ldots \ldots \ldots \ldots \ldots \ldots \ldots \ldots \ldots \ldots \ldots$

A. Project Objectives and Rationale $\ldots \ldots \ldots \ldots \ldots \ldots \ldots \ldots \ldots \ldots \ldots$

B. Interaction of Ionizing Radiation with

Polyethylene and Polyvinylchloride Plastics $\ldots \ldots \ldots \ldots \ldots \ldots \ldots \ldots \ldots$

C. Overview of Alpha Degradation Studies of TRU Waste $\ldots \ldots \ldots \ldots \ldots \ldots \ldots \ldots$

II. EXPERIMENTAL PROCEDURE, DOSIMETRY, AND DATA ANALYSIS $\ldots \ldots \ldots 7$

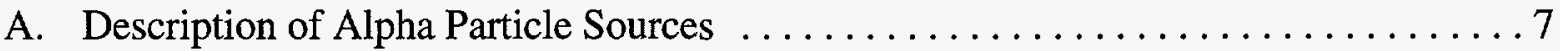

B. Alpha Particle Dosimetry $\ldots \ldots \ldots \ldots \ldots \ldots \ldots \ldots \ldots \ldots \ldots \ldots \ldots \ldots$

C. Sample Preparation, Configuration, and Irradiation $\ldots \ldots \ldots \ldots \ldots \ldots \ldots \ldots$

D. Gas Phase and Sample Analyses $\ldots \ldots \ldots \ldots \ldots \ldots \ldots \ldots \ldots \ldots \ldots \ldots \ldots \ldots$

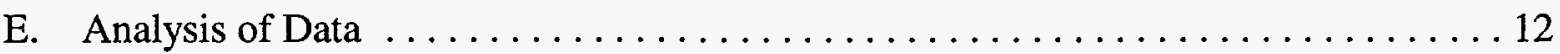

III. ALPHA PARTICLE IRRADIATION OF POLYETHYLENE AND

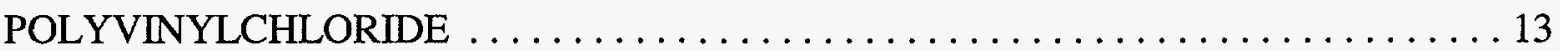

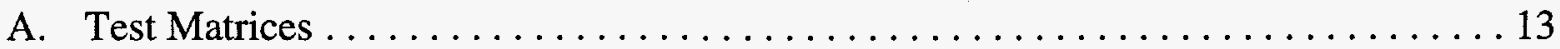

B. Gas Generation Due to Alpha Particle Degradation

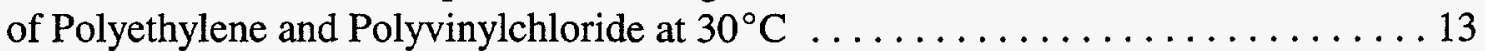

1. Variable Dose Rate Irradiation of $\mathrm{PE}$ at $30^{\circ} \mathrm{C} \ldots \ldots \ldots \ldots \ldots \ldots \ldots \ldots \ldots$

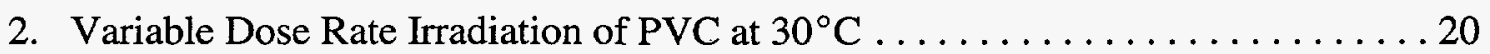

3. Material-Specific High-Absorbed-Dose Experiments at $30^{\circ} \mathrm{C}$

C. Gas Generation Due to Alpha Particle Degradation of Polyethylene and Polyvinylchloride at $60^{\circ} \mathrm{C}$

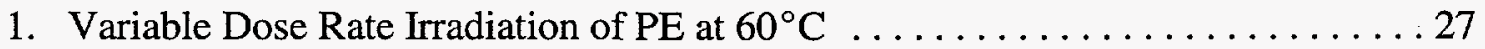

2. Variable Dose Rate Irradiation of $\mathrm{PVC}$ at $60^{\circ} \mathrm{C} \ldots \ldots \ldots \ldots \ldots \ldots \ldots \ldots$

D. Gas Generation Due to Alpha Particle Degradation of Polyethylene and Polyvinylchloride at $100^{\circ} \mathrm{C}$ 


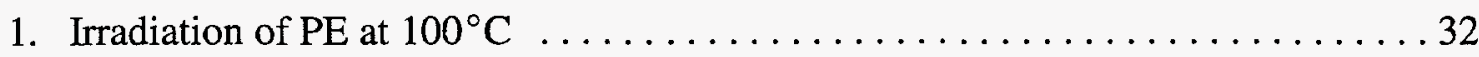

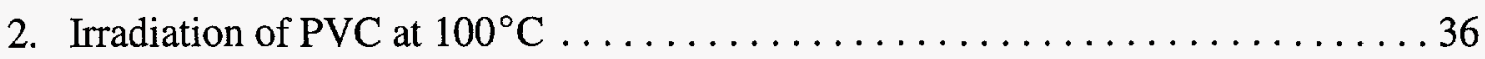

IV. SUMMARY OF OBSERVATIONS ANIJ DISCUSSION $\ldots \ldots \ldots \ldots \ldots \ldots \ldots . \ldots$
A. Buildup of Pressure Due to Irradiation
of Polyethylene and Polyvinylchloride

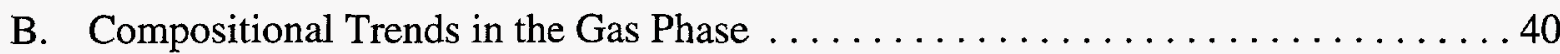

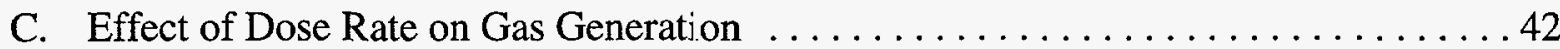
D. Effect of Temperature on Gas Generation $\ldots \ldots \ldots \ldots \ldots \ldots \ldots \ldots \ldots \ldots$
E. Gas Generation as a Function of Plastic Material Variability ................................ 44

V. FUTURE DIRECTION OF THE WORK $\ldots \ldots \ldots \ldots \ldots \ldots \ldots \ldots \ldots \ldots \ldots$

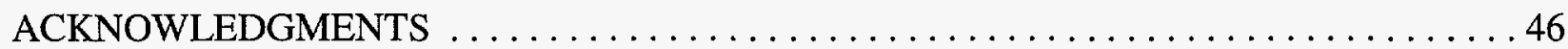

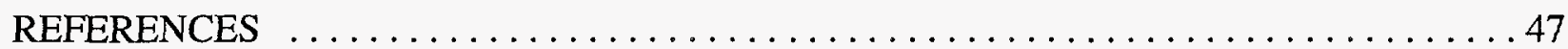

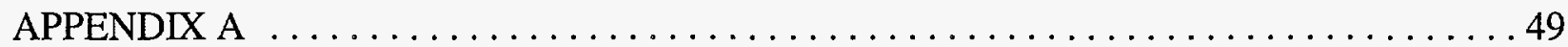




\section{LIST OF FIGURES}

No.

Title

$\underline{\text { Page }}$

1. Configuration of the Alpha Particle Foil and Plastic Sample $\ldots \ldots \ldots \ldots \ldots \ldots$

2. Diagram of Irradiation Vessel Used in the Plastic Material Degradation Studies $\ldots . .10$

3. Concentration of Hydrogen as a Function of Dose Rate for Polyethylene at $30^{\circ} \mathrm{C} \ldots \ldots 19$

4. Concentration of Carbon Dioxide as a Function of Dose Rate for Polyethylene at $30^{\circ} \mathrm{C}$

5. Gas Chromatograms Showing the Relative Organic Content of the Gas Phase

for Polyethylene at $30^{\circ} \mathrm{C}$

6. Concentration of Hydrogen as a Function of Dose Rate for Polyvinylchloride at $30^{\circ} \mathrm{C}$

7. Concentration of Carbon Dioxide as a Function of Dose Rate for Polyvinylchloride at $30^{\circ} \mathrm{C}$.

8. Gas Chromatograms Showing the Relative Organic Content of the Gas Phase for Polyvinylchloride at $30^{\circ} \mathrm{C}$

9. Gas Concentrations as a Function of Time for the $30^{\circ} \mathrm{C}$

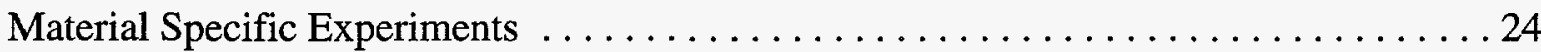

10. Concentration of Hydrogen and Carbon Dioxide for Irradiated Polyethylene at $60^{\circ} \mathrm{C}$

11. Gas Chromatograms Showing the Relative Organic Content of the Gas Phase for Polyethylene at $60^{\circ} \mathrm{C}$

12. Concentration of Hydrogen and Carbon Dioxide for Irradiated Polyvinylchloride at $60^{\circ} \mathrm{C}$.

13. Gas Chromatograms Showing the Relative Organic Content of the Gas Phase for Polyvinylchloride at $60^{\circ} \mathrm{C}$ 
LIST OF FIGURES (Contd.)

No.

Title

$\underline{\text { Page }}$

14. Concentration of Hydrogen and Carbon Dioxide for Irradiated

Polyethylene at $100^{\circ} \mathrm{C}$

15. Gas Chromatograms Showing the Relative Organic Content of the Gas Phase for Polyethylene at $100{ }^{\circ} \mathrm{C}$.

16. Concentration of Hydrogen and Carbon Dioxide for Irradiated Polyvinylchloride at $100^{\circ} \mathrm{C}$

17. Gas Chromatograms Showing the Relative Organic Content of the Gas Phase for Polyvinylchloride at $100^{\circ} \mathrm{C}$ 38 


\section{LIST OF TABLES}

No.

Title

$\underline{\text { Page }}$

1. Range of Alpha Particles and Energies for Air and Water at Different Energies Relevant to the WSRC . . . . . . . . . . . . . . . . .

2. Ethylene Dosimetry of Alpha Foils $\ldots \ldots \ldots \ldots \ldots \ldots \ldots \ldots \ldots \ldots$

3. Average Dose Rate Values for the Am-241 Foils $\ldots \ldots \ldots \ldots \ldots \ldots \ldots$

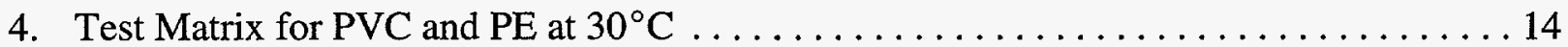

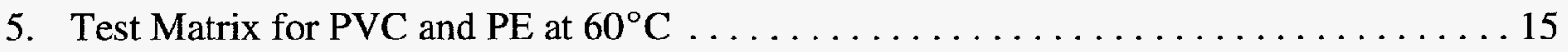

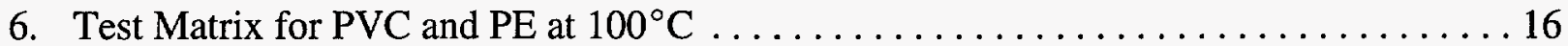

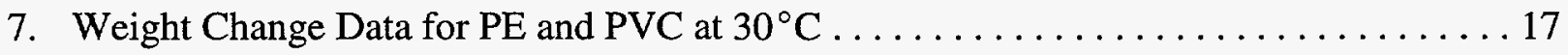

8. Apparent Yield of Molecular Products for both PVC and PE at $30^{\circ} \mathrm{C} \ldots \ldots \ldots \ldots$

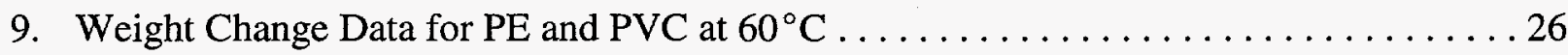

10. Apparent Yield of Molecular Products for both PVC

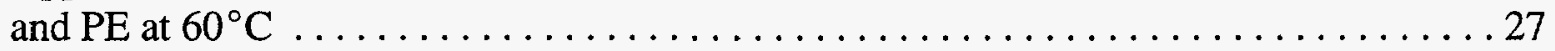

11. Weight Change Data for Polyethylene and Polyvinylchloride at $100^{\circ} \mathrm{C} \ldots \ldots \ldots 33$

12. Apparent Yield of Molecular Products for both PVC and PE at $100^{\circ} \mathrm{C} \ldots \ldots \ldots 34$

13. Best Value Radiolytic Yields for Hydrogen, Carbon Dioxide, and Hydrochloric Acid as a Function of Irradiation Conditions

A.1. Summary of Ethylene Dosimetry Data for the Various Am-241 Alpha Particle Foils Tested

A.2. Final Gas Phase Analysis of the Blank (Unirradiated) Experiments . . . . . . . . 50 


\section{LIST OF TABLES (Contd.)}

No.

$\underline{\text { Title }}$

$\underline{\text { Page }}$

A.3. Gas Phase Composition for Polyethylene at $30^{\circ} \mathrm{C}$ with

6-mCi Am-241 Foils: Experiments WSRC-1 and WSRC-2

A.4. Gas Phase Composition for Polyethylene at $30^{\circ} \mathrm{C}$ with

3-mCi Am-241 Foils: Experiments WSRC-3 and WSRC-4

A.5. Gas Phase Composition for Polyethylene at $30^{\circ} \mathrm{C}$ with

0.6-mCi Am-241 Foils: Experiments WSRC-5 and WSRC-6

A.6. Gas Phase Composition for Polyethylene at $30^{\circ}$ with

0.3-mCi Am-241 Foils: Experiments WSRC-7 and WSRC-8

A.7. Gas Phase Composition for Polyvinylchloride at $30^{\circ} \mathrm{C}$

with 6-mCi Am-241 Foils: Experiments WSRC-10 and WSRC-11

A.8. Gas Phase Composition of Polyvinylchloride at $30^{\circ}$ with

3-mCi Am-241 Foils: Experiments WSRC-12 and WSRC-13

A.9. Gas Phase Composition for Polyvinylchloride at $30^{\circ} \mathrm{C}$

with 0.6-mCi Am-241 Foils: Experiments WSRC-14 and WSRC-15 . . . . . . . 54

A.10. Gas Phase Composition for Polyvinylchloride at $30^{\circ} \mathrm{C}$ with

0.3-mCi Am-241 Foils: Experiments W/SRC-16 and WSRC-17

A.11. Gas Phase Composition of Polyethylene- 1 at $30^{\circ} \mathrm{C}$ with

6-mCi Am-241 Foils: Experiments WSRC-19 and WSRC-20

A.12. Gas Phase Composition of Polyethylene- 2 at $30^{\circ} \mathrm{C}$ with

6-mCi Am-241 Foils: Experiments WSRC-21 and WSRC-22

A.13. Gas Phase Composition for Material-Specific Irradiation

of Polyvinylchloride- 1 at $30^{\circ} \mathrm{C}$ with 6-mCi Am-241 Foils:

Experiments WSRC-23 and WSRC-24

A.14. Gas Phase Composition for Material-Specific Irradiation

of Polyvinylchloride- 2 at $30^{\circ} \mathrm{C}$ with $6-\mathrm{mCi} \mathrm{Am}-241$ Foils:

Experiments WSRC-25 and WSRC-26

A.15. Gas Phase Composition for Polyethylene at $60^{\circ} \mathrm{C}$ with

6-mCi Am-241 Foils: Experiments WSRC-27 and WSRC-28 58 


\section{LIST OF TABLES (Contd.)}

No.

Title

Page

A.16. Gas Phase Composition for Polyethylene at $60^{\circ} \mathrm{C}$ with 0.6-mCi Am-241 Foils: Experiments WSRC-29 and WSRC-30

A.17. Gas Phase Composition for Polyvinylchloride at $60^{\circ} \mathrm{C}$ with 6-mCi Am-241 Foils: Experiments WSRC-32 and WSRC-33

A.18. Gas Phase Composition for Polyvinylchloride at $60^{\circ} \mathrm{C}$ with 0.6-mCi Am-241 Foils: Experiments WSRC-34 and WSRC-35

A.19. Gas Phase Composition for Polyethylene at $100^{\circ} \mathrm{C}$ with 6-mCi Am-241 Foils: Experiments WSRC-37 and WSRC-38

A.20. Gas Phase Composition for Polyethylene at $100^{\circ} \mathrm{C}$ with 3-mCi Am-241 Foils: Experiments WSRC-39 and WSRC-40

A.21. Gas Phase Composition for Polyethylene at $100^{\circ} \mathrm{C}$ with 0.6-mCi Am-241 Foils: Experiments WSRC-41 and WSRC-42

A.22. Gas Phase Composition for Polyethylene at $100^{\circ} \mathrm{C}$ with 0.3-mCi Am-241 Foils: Experiments WSRC-43 and WSRC-44

A.23. Gas Phase Composition for Polyvinylchloride at $100^{\circ} \mathrm{C}$ and 6-mCi Am-241 Foils: Experiments WSRC-46 and WSRC-47

A.24. Gas Phase Composition for Polyvinylchloride at $100^{\circ} \mathrm{C}$ and 3-mCi Am-241 Foils: Experiments WSRC-48 and WSRC-49

A.25. Gas Phase Composition for Polyvinylchloride at $100^{\circ} \mathrm{C}$ with 0.6-mCi Am-241 Foils: Experiments WSRC-50 and WSRC-51

A.26. Gas Phase Composition for Polyvinylchloride at $100^{\circ} \mathrm{C}$ with $0.3-\mathrm{mCi}$ Am-241 Foils: Experiments WSRC-52 and WSRC-53 


\title{
GAS PRODUCTION DUE TO ALPHA PARTICLE DEGRADATION OF POLYETHYLENE AND POLYVINYLCHLORIDE
}

by

D. T. Reed, J. Hoh, J. Emery, S. Okajima, and T. Krause

\begin{abstract}
Alpha particle degradation experiments were performed on polyethylene (PE) and polyvinylchloride (PVC) plastic samples typical of Westinghouse Savannah River Company (WSRC) transuranic (TRU) waste. This was done to evaluate the effects of sealing TRU waste during shipment. Experiments were conducted at three temperatures using low dose rates. Predominant products from both plastics were hydrogen, carbon dioxide, and various organic species, with the addition of hydrochloric acid from PVC. In all experiments, the total pressure decreased. Irradiation at $30^{\circ}$ and $60^{\circ} \mathrm{C}$ and at various dose rates caused small changes for both plastics, but at $100^{\circ} \mathrm{C}$ coupled thermal-radiolytic effects included discoloration of the material as well as large differences in the gas phase composition.
\end{abstract}




\section{SUMMARY}

Gas Pressure Buildup

Total pressure in all systems investigated decreased as a result of irradiation because oxygen depletion in the air atmosphere proceeded at a faster rate than the generation of hydrogen, carbon oxides, and volatile organics.

\section{Gas Generation from PE}

Hydrogen and carbon dioxide were generated at constant rate at temperatures of 30 and $60^{\circ} \mathrm{C}$. Yields for hydrogen production were approximately $2 \mathrm{molec} / 100 \mathrm{eV}$ and were not affected by dose rate. Carbon dioxide yield was $2.5 \mathrm{molec} / 100 \mathrm{eV}$. At $100^{\circ} \mathrm{C}$, the yield trends were not always linear and coupled radiolytic-thermal effects were noted. Apparent hydrogen yield increased to over $3 \mathrm{molec} / 100 \mathrm{eV}$ and the apparent carbon dioxide yield was over $10 \mathrm{molec} / 100 \mathrm{eV}$. Little discoloration of the material, even at elevated temperature was observed. Weight gain in the plastic material was observed under all irradiated conditions tested and attributed to oxygen uptake.

\section{Gas Generation from PVC}

Hydrogen and carbon dioxide formation were linear with time at 30 and $60^{\circ} \mathrm{C}$. The formation of hydrochloric acid, measured as chloride in a vessel rinse, was also determined. Yields for hydrogen, carbon dioxide, and hydrochloric acid were approximately $0.6,1.0$, and 0.4 to $1.0 \mathrm{molec} / 100 \mathrm{eV}$, respectively. At $100^{\circ} \mathrm{C}$ the thermal and radiolytic decomposition processes were strongly coupled with thermal processes being the most predominant. Apparent yields for hydrogen increased to $1.0 \mathrm{molec} / 100 \mathrm{eV}$, carbon dioxide increased to over 10 molec $/ 100 \mathrm{eV}$ and $\mathrm{HCl}$ increased to over $20 \mathrm{molec} / 100 \mathrm{eV}$. Compared to polyethylene, a wider variety of trace organics were observed in these systems. Weight loss, rather than gain, occurred in the PVC plastic material.

\section{Gas Generation as a Function of Plastic Variability}

A few experiments were done at $30^{\circ} \mathrm{C}$ to investigate gas generation from two different types of polyethylenes and polyvinylchlorides. The initial yields of both hydrogen and carbon dioxide varied by up to a factor of two depending on plastic material type. The magnitude of this effect was experimentally significant but small. 


\section{INTRODUCTION}

The production of gas due to the interaction of high LET (i.e., alpha particle) ionizing radiation with organic materials in transuranic (TRU) waste is potentially an important issue during both the initial storage and subsequent transport of the waste to the Waste Isolation Pilot Plant (WIPP) site. Current guidelines provide for a period of up to 60 days during which the shipping container, which is normally vented, will be sealed while the waste is transported to the WIPP.

Westinghouse Savannah River Company (WSRC), one of the major generators of TRU waste, has identified the need to quantify the rate of gas generation due to alpha particle degradation of TRU waste. These data are needed to evaluate gas generation during the 60 -day shipping period to help qualify waste for safe shipment to the WIPP. The yield data determined in this project will, therefore, in models along with other data, be used to predict gas generation and meet the regulatory guidelines established for waste shipment.

The results of a study to investigate the effects and dose rate and temperature on gas generation from polyethylene and polyvinylchloride are presented in this report. Tests were conducted at temperatures up to $100^{\circ} \mathrm{C}$ to a bounding case since there was a possibility that some of the waste packages may reach these temperatures during shipment. Polyethylene and polyvinylchloride were chosen because they are common plastic materials used by WSRC to package TRU waste.

\section{A. Project Objectives and Rationale}

Our overall project objectives are to (1) establish the technical needs related to the gas generation in TRU waste during transport to the WIPP, (2) measure the gas generation yield for materials prevalent in WSRC TRU waste and, (3) measure gas generation in actual Pu-waste mixtures.

There are two primary benefits in completing this work. First, a comprehensive experimental strategy for demonstrating compliance with existing regulations will be developed from the perspective of radiolytic gas generation. Although this work is specific to WSRC waste, we expect that this will be applicable to the several TRU waste generators within the DOE complex. Second, data from both material-specific alpha particle interactions and simulated plutonium-waste mixtures will be obtained. These data will provide needed input to model radiolytic gas generation and, eventually, validate the models developed to support waste qualification.

In this study, we emphasized the determination of gas generation yields under well-defined radiolytic condition. Polyvinylchloride and polyethylene plastics were irradiated using alpha particle sources. The yields of hydrogen, carbon dioxide, and hydrochloric acid (from PVC only) were determined as functions of dose rate, temperature, and plastic material type. Qualitative information was also obtained about the composition of volatile organic compounds (VOCs) in the gas phase. Macroscopic changes in the weight and coloration of each material irradiated were also determined. 


\section{B. Interaction of Ionizing Radiation with Polyethylene and Polyvinylchloride Plastics}

The alpha particle degradation of polyethylene and polyvinylchloride has not been extensively studied. A number of studies have been performed, however, with low LET (gamma and beta particle) irradiation. Reviews of this work have been published elsewhere [1-4]. Hydrogen gas $\left[\mathrm{G}\left(\mathrm{H}_{2}\right)=3.5\right.$ to $\left.5.0 \mathrm{molec} / 100 \mathrm{eV}\right]$ and lesser arnounts of hydrocarbons are the radiolytically-induced degradation products of PE. Hydrogen and hydrochloric acid (up to $13 \mathrm{molec} / 100 \mathrm{eV}$ ) are generated from PVC [2]. The replacement of beta and gamma ionizing radiation by alpha particles was expected to affect the relative amounts of products observed in the low LET systems but not the nature of the products generated.

Ionizing radiation has been widely used to alter the physical properties of polymeric material and, to a much lesser extent, to initiate the polymerization of monomeric materials. Low LET (gamma and beta) radiation has been used for irradiation processing of plastic materials because they are highly penetrating, which makes them more suitable for bulk processing. This is an important difference from the alpha degradation studies we performed, since 3.9-4.75 MeV alpha particles, which have a relative LET of $>250$ times that of gamma or beta, were utilized. Net irradiation damage per Mrad is therefore expected to be higher in our experiments compared to those published in the literature.

There are predominantly three processes that occur as the result of the interaction of ionizing radiation with polymeric materials: (1) main-chain scission, which lowers the average molecular weight of the polymer; (2) cross-linking and network formation, which results in the formation of carbon-carbon bonds; and (3) changes in the elemental composition of the polymer via either increased unsaturation, accompanied by gas evolution, or the incorporation of elements present in the irradiation environment into the polymer matrix.

Main-chain scission (fragmentation), which lowers the average molecular weight of the polymer, can have significant effects on the physical properties of the polymer, even at absorbed doses as low as $1 \mathrm{Mrad}$. This process involves the breaking of carbon-carbon bonds, resulting in increased unsaturation or the addition/incorpcration of non-polymeric species.

Crosslinking, which is the formation of carbon-carbon bonds between adjacent polymer molecules, is an important radiation-induced phenomenon in the irradiation processing of plastic materials. This carbon-carbon bonding results in the evolution of gas molecules. Relatively high absorbed doses are needed at room temperature before macroscopic effects, due to crosslinking, are noted ( $>1000 \mathrm{Mrad}$ is not unusual), although detectable changes in the physical properties of the plastic can be observed after a few Mrad. This irradiation effect is very temperature-dependent and accelerates rapidly above the melt temperature of the plastic (typically $80-120^{\circ} \mathrm{C}$ for plastics commonly used to package TRU waste). The means by which species present in the environment become incorporated into the plastic is not fully understood. The formation of unsaturation in the plastic material appears, however, to be an important step in this process. This occurs by the elimination of hydrogen or HX (analogous to crosslinking), with a yield that is typically comparable to that of the crosslinking process. Unsaturation promotes the incorporation of species such as oxygen and sulfur by providing sites for relatively long-lived but reactive free radicals. These sites 
can react with species diffusing into the plastic resulting in their incorporation into the polymer matrix.

Substantial evidence exists that the irradiation environment has a significant effect on the extent and nature of radiolytic alteration observed. Significant differences have been noted in the physical properties of polymers (reflecting chemical change in the polymer) irradiated in aqueous versus gaseous environments. Irradiation to the same total dose at different dose rates gave different results, which were interpreted as the result of increased environmental interaction (i.e., longer experiments were performed).

Specific studies on the irradiation degradation of PE and PVC have been reported in the literature; their results are summarized in the reviews previously mentioned. The irradiation degradation/alteration of polyethylene has been the most extensively investigated of all plastic materials. The principal gaseous degradation product of polyethylene was hydrogen (typically $>95 \%$ ) with a small amount of $\mathrm{C} 1-\mathrm{C} 3$ alkanes present. Hydrogen yields reported vary with $\mathrm{G}\left(\mathrm{H}_{2}\right)$ ranging from 3.5 to 5.0 molec $/ 100 \mathrm{eV}$. Cross-linking yields are in the range of $\mathrm{G}$ (cross-linking) = $1-4 \mathrm{molec} / 100 \mathrm{eV}$ and unsaturation yields are in the range of $\mathrm{G}$ (unsaturation) $=1-2 \mathrm{molec} / 100 \mathrm{eV}$.

The yields just noted are affected by the irradiation environment and the process used to make the plastic (elemental composition, plasticizer present). Irradiation of polyethylene without a plasticizer in an evacuated system gave reproducible results. Hydrogen evolution, with $\mathrm{G}\left(\mathrm{H}_{2}\right)$ of $3 \mathrm{molec} / 100 \mathrm{eV}$, accompanied by weight loss was the primary radiolytic effect. In the presence of oxygen, however, oxygen diffused into the polymer matrix and reacted with the radiolyticallyproduced active sites within the polymer. Oxygen uptake $\mathrm{G}\left(-\mathrm{O}_{2}\right)=10 \mathrm{molec} / 100 \mathrm{eV}$ was reported [5-7], resulting in weight gain and the formation of carbonyl groups on the polymer. Similar results were observed when irradiation was performed in a carbon dioxide atmosphere [8].

Less work has been done to investigate the irradiation degradation of PVC. The gas evolved is almost exclusively hydrogen chloride. Yields are very sensitive to the polymer brand (because of the plasticizer present and the chloride substitution); $\mathrm{G}(\mathrm{HCl})$ ranges from 0.25 to as high as $13 \mathrm{molec} / 100 \mathrm{eV}$ at room temperature. Heavy irradiation causes the polymer to become very hard and brittle. Environmental effects, primarily in the presence of oxygen, were also noted. The dominant process in vacuum irradiation of polyvinylchloride was crosslinking, resulting in very strong discoloration. In the presence of oxygen, however, this was suppressed in favor of fragmentation processes (main-chain scission), resulting in significantly less discoloration. No irradiations in a carbon dioxide atmosphere were reported but this will presumably have similar effects.

\section{Overview of Alpha Degradation Studies of TRU Waste}

In addition to the more fundamental studies just summarized, other studies on gas generation issues relevant to TRU and low-level nuclear waste management have been made. Extensive work was performed in connection with the WIPP project in the mid to late 1970s [9-13]. Issues related to long-term storage of TRU waste have also been investigated [14,15]. More recently, gas generation has resurfaced as an issue for long-term performance of the planned WIPP repository 
[16-19]. The results of our initial set of experiments, which are described in this report, have also been published [20].

The work performed by Kosiewicz ard Zerwekh [9-12] for the WIPP project is the most relevant to our project. For reasons that are discussed more fully in Section 4.2, however, many of the results cannot be directly compared with our data because they were addressing different technical issues. In their experiments, mixtures of plutonium-waste and cellulosic and plastic materials were monitored for gas pressure buildup. Yields were determined based on gas pressure buildup and an assumed distribution of the plutonium (alpha particle source). Experiments were performed at temperatures up to $100^{\circ} \mathrm{C}$ with absorbed doses in excess of $3 \times 10^{26} \mathrm{eV} / \mathrm{g}\left(5 \times 10^{6}\right.$ Mrad) in what was essentially an anoxic system since the oxygen initially present in the air was rapidly depleted.

In this series of experiments, hydrogea was the predominant product, with lesser amounts of carbon dioxide and carbon monoxide noted. G(gas) was initially $2 \mathrm{molec} / 100 \mathrm{eV}$ but decreased to 0.4 with increased absorbed dose. No $\mathrm{HCl}$ was observed when polyvinyl-chloride was irradiated. The organic content of the gas phase was small relative to total gas production with little details reported. Overall they did not report any dose rate effects and did not provide detailed gas generation data at elevated temperatures.

The early work performed by the WIPP was summarized by Molecke [13] and interpreted with respect to gas generation issues relevant: to the long-term performance of the WIPP. It was concluded that gas generation, due to direct interaction between ionizing radiation and TRU waste, would not be a significant component of net gas generation in the WIPP when the long times associated with repository performance and other potential sources of gas generation are taken into account. Corrosion and microbial degradation of cellulosics were established as the predominant contributors to gas generation. This view has been reaffirmed in more recent analyses $[16,17]$. Other potential radiolytic effects, such as direct irradiation of brine and the conversion of nonbiodegradable material to biodegradable material, are still being investigated experimentally $[18,19]$. In terms of net gas generation, radiolytic processes remain a significant but lesser contributor to the overall gas generation rates.

The issue of waste acceptance and qualification for shipment is becoming increasingly important. From the perspective of gas generation, this differs in three important ways from work that has already been done. First, the time period of consideration is $60 \mathrm{~d}$ rather than several thousand years. It will therefore be easier to more accurately predict and establish radiolytic alteration. Secondly, the environment will be air rather than an anoxic hydrogen, carbon dioxide and nitrogen mixture; this will significantly affect the total pressures and relative yields of the various products observed. Lastly, the temperatures of interest are potentially higher (up to $100^{\circ} \mathrm{C}$ rather than $30^{\circ} \mathrm{C}$ for the WIPP) because of the existence of high-activity ${ }^{238} \mathrm{Pu}$-containing waste. 


\section{EXPERIMENTAL PROCEDURE, DOSIMETRY, AND DATA ANALYSIS}

All of the experiments were performed using the same experimental approach. This section describes the alpha particle source and plastic/foil configuration, and the dosimetry results.

\section{A. Description of Alpha Particle Sources}

Gold-plated $5 \mathrm{~cm}^{2} \mathrm{Am}-241$ foils that were special-ordered provided the ionizing radiation in the experiments. Four activity loadings were used to vary the dose rate: $6,3,0.6$ and $0.3 \mathrm{mCi} /$ foil $\left(2.22 \times 10^{11}, 1.11 \times 10^{11}, 2.22 \times 10^{10}\right.$, and $\left.1.11 \times 10^{10} \mathrm{Dis} / \mathrm{s} / \mathrm{foil}\right)$. The alpha foil was active on only one side: the active side had a thin gold plating that allowed approximately $85 \%$ of the alpha particles emitted towards the gold coating to escape. The other side had a silver backing that prevented the alpha particle from escaping.

The alpha particle emitted from Am-241 has an average energy of $5.46 \mathrm{MeV} /$ decay. The gold coating attenuated this energy to approximately $4.75 \mathrm{MeV}$. A $4.75-\mathrm{MeV}$ alpha particle has a track average linear energy transfer (LET) that is 150-200 times higher than gamma and beta particles of comparable energy. For alpha particles, interaction with matter is primarily through inelastic scattering, and energy loss is approximately linear with penetration depth. The estimated ranges for selected media are summarized in Table 1 since these data are important considerations in experimental design. In air, the range is $1.7,3.3$ and $4 \mathrm{~cm}$ for $3,4.8$, and $5.5 \mathrm{MeV}$ particles, respectively. The alpha energy attenuates $9 \%$ at a distance of approximately $3 \mathrm{~mm}$ from the Am-241 source. Thus, with our experimental configuration, over $90 \%$ of the alpha particle energy that escaped from the alpha foil was deposited in the plastic material of interest, typically 3 to 5 mils $(0.076$ to $0.127 \mathrm{~cm})$.

\begin{tabular}{|c|c|c|c|c|}
\hline \multirow{2}{*}{$\begin{array}{c}{ }^{241} \mathrm{Am} \\
\text { Alpha Energy }(\mathrm{MeV})\end{array}$} & \multicolumn{4}{|c|}{ Range, microns } \\
\hline & Air & Water & $\begin{array}{c}\rho=0.93 \mathrm{~g} / \mathrm{cm}^{3} \\
\text { PE }\end{array}$ & $\begin{array}{c}\rho=1.406 \mathrm{~g} / \mathrm{cm}^{3} \\
\text { PE }\end{array}$ \\
\hline Incident (5.46) & 40,000 & 41 & 43 & 32 \\
\hline Foil Average (4.75) & 32,000 & 33 & 35 & 25 \\
\hline $3 \mathrm{~mm}$ Gap (4.3) & 28,000 & 27 & 28 & 21 \\
\hline
\end{tabular}

\section{B. Alpha Particle Dosimetry}

The energy deposition rate (EDR), defined as the total alpha particle energy emitted per hour from the surface of the alpha foil, was determined for each of the four Am-241 activity loadings. This quantity was determined, instead of the absorbed dose because it is a function of only the foil (e.g., activity loading and thickness of the gold layer) and is independent of the absorbing material. 
The energy deposition rate was measured by ethylene dosimetry [4]. The foil was placed with the active surface up in a vessel that was filled with 800 torr of ethylene gas. Hydrogen buildup in the gas phase was monitored using gas chromatography. The energy deposition rate under these conditions is given by

$$
E D R=\frac{\text { [molecules of } \mathrm{H}_{2} \text { generated] }}{\mathrm{G}\left(\mathrm{H}_{2}\right) \quad \text { [irradiation time] }}
$$

For $\mathrm{G}\left(\mathrm{H}_{2}\right)=1.35 \mathrm{molec} / 100 \mathrm{eV}$, a vessel volume of $0.325 \mathrm{~L}$, and an ethylene gas pressure of 800 torr, this becomes

$$
\text { EDR (in MeV/h) }=\frac{6.305 \times 10^{15}\left(\frac{\mathrm{MeV}}{\mathrm{h} \cdot \mathrm{mol} \%}\right) \text { [mol \% of Hydrogen] }}{\text { [time in hours] }}
$$

Both the time-dependence of hydrogen buildup for a particular alpha particle foil and the foilto-foil reproducibility of the EDR measurements were evaluated. The initial dosimetry measurements made are summarized in Table 2. Here, for the time intervals checked, there was no significant variation in the rate of hydrogen buildup.

All the dosimetry data are summarized in Table A.1 in the appendix. Alpha particle dosimetry was performed for each of the highest activity $6-\mathrm{mCi}\left(2.22 \times 10^{11}\right.$-Dis/s) Am-241 foils utilized and each of the lowest activity $(0.3-\mathrm{mCi})$ foils utilized. However, it was only determined for three of the 0.6 and $3.0-\mathrm{mCi}$ foils. The average EDR determinations obtained are summarized in Table 3. The average EDR rates were $4.9 \pm 0.3 \times 10^{10}, 9.5 \pm 0.3 \times 10^{10}, 4.6 \pm 0.9 \times 10^{11}$ and $1.0 \pm$ $0.1 \times 10^{12} \mathrm{MeV} / \mathrm{h}$ for the $0.3,0.6,3$, and 6-mCi foils, respectively. As expected, the EDR rate measured was proportional to the curie content of the alpha particle foil.

The absorbed dose for a particular plastic material is calculated from the amount of energy deposited in the mass of irradiated material in the range of the average energy alpha particle. The absorbed dose rate in polyethylene and polyvinylchloride for the various EDR rates were also given in Table 3. These ranged in value from 8900 to $2 \times 10^{5} \mathrm{rad} / \mathrm{h}(89$ to $2000 \mathrm{~Gy} / \mathrm{h}$ ). 


\begin{tabular}{|c|c|c|c|c|c|c|c|}
\hline \multirow{2}{*}{$\begin{array}{c}\text { Nominal } \\
\text { Foil } \\
\text { Activity, } \\
\text { mCi } \\
\end{array}$} & \multirow[b]{2}{*}{ Vessel } & \multicolumn{2}{|c|}{ Irradiation } & \multicolumn{3}{|c|}{ Concentration, $\mathrm{mol} \%$} & \multirow{2}{*}{$\begin{array}{c}\text { Energy } \\
\text { Deposition } \\
\text { Rate, } \\
\text { MeV/h } \\
\end{array}$} \\
\hline & & $\begin{array}{c}\text { Time, } \\
\text { h }\end{array}$ & $\begin{array}{c}\text { Pressure, } \\
\text { torr }\end{array}$ & $\mathrm{H}_{2}$ & Et & $\begin{array}{l}\mathbf{H}_{2} / \mathrm{Et} \\
\text { Ratio } \\
\end{array}$ & \\
\hline \multirow[t]{3}{*}{0.3} & 2 & 93.3 & 793 & 0.0009 & 99.999 & 0.0009 & $5.56 \mathrm{E}+10$ \\
\hline & 2 & 190 & 793 & 0.0023 & 99.998 & 0.0023 & $6.93 E+10$ \\
\hline & 2 & 190 & 793 & 0.002 & 99.998 & 0.002 & $6.12 \mathrm{E}+10$ \\
\hline \multirow[t]{4}{*}{0.6} & 23 & 94.75 & 801 & 0.0019 & 99.998 & 0.0019 & $1.2 \mathrm{E}+11$ \\
\hline & 23 & 95 & 701 & 0.0015 & 99.999 & 0.0015 & $7.96 \mathrm{E}+10$ \\
\hline & 23 & 191 & 698 & 0.0031 & 99.997 & 0.0031 & $8.24 \mathrm{E}+10$ \\
\hline & 23 & 191 & 698 & 0.0041 & 99.996 & 0.0041 & $1.1 E+11$ \\
\hline \multirow[t]{4}{*}{3} & 24 & 94 & 803 & 0.0067 & 99.993 & 0.0067 & 4.18E+11 \\
\hline & 24 & 95.25 & 797 & 0.0066 & 99.993 & 0.0066 & $4.04 \mathrm{E}+11$ \\
\hline & 24 & 191 & 792 & 0.0131 & 99.987 & 0.0131 & $3.94 \mathrm{E}+11$ \\
\hline & 24 & 191.5 & 792 & 0.0132 & 99.987 & 0.0132 & $3.96 \mathrm{E}+11$ \\
\hline \multirow[t]{4}{*}{6} & 25 & 94.8 & 786 & 0.0163 & 99.984 & 0.0163 & $9.84 \mathrm{E}+11$ \\
\hline & 25 & 92.5 & 797 & 0.0152 & 99.985 & 0.0153 & $9.56 \mathrm{E}+11$ \\
\hline & 25 & 191 & 778 & 0.0319 & 99.968 & 0.0319 & $9.45 \mathrm{E}+11$ \\
\hline & 25 & 191.5 & 778 & 0.0319 & 99.968 & 0.0319 & $9.44 \mathrm{E}+11$ \\
\hline
\end{tabular}

\begin{tabular}{|c|c|c|c|c|c|}
\hline \multirow{2}{*}{$\begin{array}{l}\text { Foil Activity, } \\
\left(\mu \mathrm{Ci} / \mathbf{i n}^{2}\right) / \mathbf{m C i}\end{array}$} & \multirow{2}{*}{$\begin{array}{l}\text { Number } \\
\text { Foils } \\
\text { Tested } \\
\end{array}$} & \multirow{2}{*}{$\begin{array}{c}\text { Energy } \\
\text { Deposition } \\
\text { Rate, } \\
\text { MeV/h/ } \\
\text { per foil }\end{array}$} & \multirow[b]{2}{*}{ Ratio } & \multicolumn{2}{|c|}{$\begin{array}{l}\text { Estimated Absorbed Dose Rate } \\
\text { eV/gh }(\mathrm{rad} / \mathrm{h})\end{array}$} \\
\hline & & & & PE & PVC \\
\hline $1500 / 6$ & 20 & $1.0 \pm .1 \times 10^{12}$ & 20 & $1.2 \times 10^{19}\left(2.0 \times 10^{5}\right)$ & $1.1 \times 10^{19}\left(1.8 \times 10^{5}\right)$ \\
\hline $750 / 3$ & 3 & $4.6 \pm .9 \times 10^{11}$ & 9.4 & $5.7 \times 10^{18}\left(9.0 \times 10^{4}\right)$ & $5.2 \times 10^{18}\left(8.4 \times 10^{4}\right)$ \\
\hline $150 / 0.6$ & 3 & $9.5 \pm .3 \times 10^{10}$ & 1.9 & $1.2 \times 10^{18}\left(1.9 \times 10^{4}\right)$ & $1.1 \times 10^{18}\left(1.7 \times 10^{4}\right)$ \\
\hline $75 / 0.3$ & 8 & $4.9 \pm .3 \times 10^{10}$ & 1.0 & $6.0 \times 10^{17}\left(9.6 \times 10^{3}\right)$ & $5.6 \times 10^{17}\left(8.9 \times 10^{3}\right)$ \\
\hline
\end{tabular}




\section{Sample Preparation, Configuration, and Iradiation}

The polyethylene and polyvinylchloride plastic materials were received from Westinghouse Savannah River Company (WSRC). Four materials were selected for the test matrix: polyethylene bottles (PE-1), polyethylene bags (PE-2), polyvinylchloride bags (PVC-1), and polyvinylchloride sheeting (PVC-2). These materials were selected because they are commonly used as waste packaging in TRU waste drums and are often irl direct contact with alpha-producing waste. The bags and bottles are often used to package waste during bag-out procedures, and the PVC sheeting is normally used in preparing huts or other containment applications.

The plastic was cut into sheets approximately $6.1 \mathrm{~cm} \mathrm{x} 6.1 \mathrm{~cm}$ and mounted $3 \mathrm{~mm}$ from the alpha particle source (Am-241 foil). This assembly is shown in Figs. 1 and 2. The foil-plastic assembly was placed in the irradiation vessel. The vessel was sealed, leak-checked, attached to a vacuum manifold, and evacuated to $<10 \mathrm{mtorr}$. Water vapor was added to the vessel by expanding

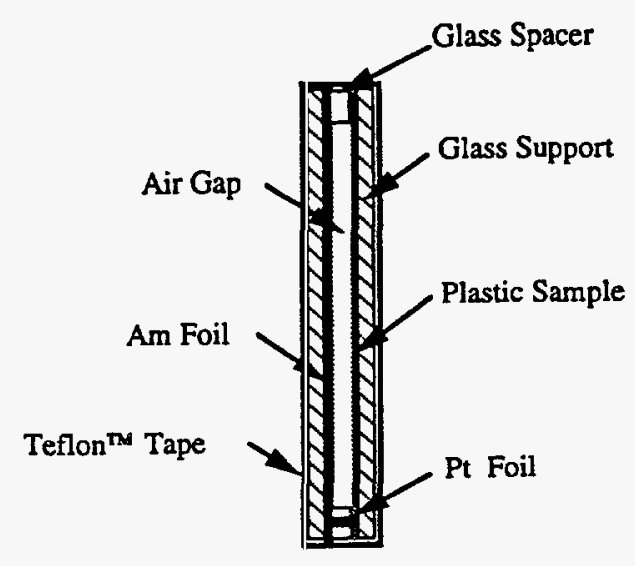

Fig. 1. Configuration of the Alpha Particle Foil and Plastic Sample

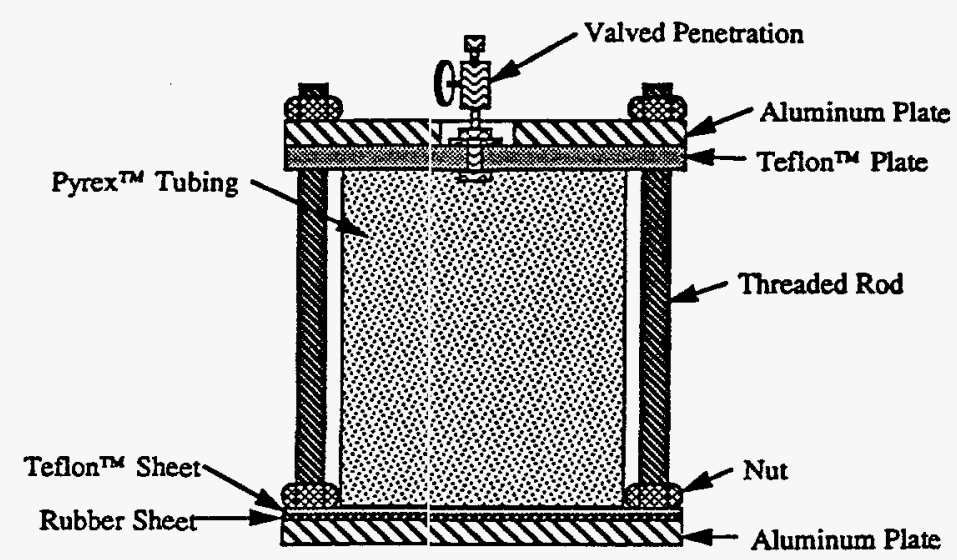

Fig. 2. Diagram of Irradiation Vessel Used in the Plastic Material Degradation Studies 
previously degassed liquid water into the vacuum manifold to a total water vapor pressure of approximately 14 torr. This was measured directly by an MKS Baratron Type 220 pressure gauge that was calibrated to NIST-traceable standards. A Panametrics hygrometer was also used to confirm that the pressure measured was due to water vapor and not air present in the system. Breathing air $\left(21.5 \pm 0.2 \% \mathrm{O}_{2}, 78.5 \pm 0.2 \% \mathrm{~N}_{2}\right.$, and typically $<0.01 \%$ carbon dioxide) was added to the vessel to a total pressure of $760 \pm 10$ torr.

Once prepared, the vessels were placed in ovens at 30,60 , or $100^{\circ} \mathrm{C}$. Oven temperature was continuously monitored and recorded on a data logger throughout the course of the experiments. The vessels were periodically removed, cooled to room temperature and sampled to establish the bulk composition of the gas phase.

\section{Gas Phase and Sample Analyses}

Gas analyses were performed on a Varian model 3300 or 3400 gas chromatograph. Sampling was done by attaching the vessel directly to the sample volume area of the gas chromatograph and expanding the contents of the vessel into the pre-evacuated sample tube for injection into the chromatograph. The pressure in the vessel was also recorded at this time. The sampling process itself caused a small reduction in the total pressure, approximately 3-4 torr for each expansion. Hydrogen analyses were performed using argon as the carrier gas and a thermal conductivity detector. Oxygen, nitrogen, and carbon dioxide were determined using a thermal conductivity detector with helium as the carrier gas. The trace organic composition was determined using a flame ionization detector with helium as the carrier gas. In this analysis, the composition of the trace organics was only qualitatively established. For our column, we could readily detect alkanes (C2-C6), alkenes (C2-C6), alcohols (C2 and C3) and acetone (large peak typically observed at 15-16 minutes retention time). Approximate retention times for the alkenes and alkanes were $\mathrm{C} 2-$ 2 minutes, C3 - 3 minutes, C4 - 4 minutes, C5 - 5.5 minutes, and C6 - 14-16 minutes. Gas phase concentrations of these gases were estimated by comparison with a $1 \%$ gas phase standard of the C2-C6 alkenes and alkanes.

For the PVC samples, a vessel rinse was made after test termination and analyzed for chloride content using ion chromatography to determine the $\mathrm{HCl}$ yield. In developmental experiments, we determined that the $\mathrm{HCl}$ generated was condensing on the vessel wall (glass and Teflon) and the stainless steel valve. $\mathrm{No} \mathrm{HCl}$ was found in the gas phase using mass spectrometry but our sensitivity was only at the $100 \mathrm{ppm}$ level. Only a small percentage $(<10 \%)$ of the $\mathrm{HCl}$ was on the PVC material or the gold-plated Am-241 alpha foil.

Weight change was measured on both PE and PVC plastic materials. They were weighed to five places before and after irradiation to NIST-traceable standards. Bulk changes in the appearance of the plastics were also noted (e.g., coloration, loss of plasticity). Only the PVC material at $100^{\circ} \mathrm{C}$ showed strong discoloration due to both radiolytic and thermal effects. No surface analyses were performed on the irradiated plastics. 


\section{E. Analysis of Data}

The data generated during the course of performing the experiments were (1) the pressure and bulk gas composition as a function of time, (2) qualitative analyses of the trace organic composition of the gas phase and, (3) at the end of the run, weight change measurement and vessel rinse for chloride (PVC only).

To evaluate and establish radiolytic yields, the concentrations of various components of the gas phase were plotted versus irradiation time. In cases where the increase in the mol \% of the gas phase was linear with time, the yield of that component was calculated from the slope of the plot according to the following equation:

$$
G \text { (gaseous species) }=\frac{[\text { mole } \% / d]]}{E D R / \text { in eV/d) }}
$$

Here $\mathrm{mol} \% / \mathrm{d}$ is the slope of the mol \% vs. time plot, $\mathrm{PVA}_{\mathrm{o}} / \mathrm{RT}$ is the total number of molecules of gas present in the vessel, and EDR is the energy deposition rate in the plastic material.

In a number of cases, particularly at $100^{\circ} \mathrm{C}$, the buildup of gaseous species was not linear with time due to coupled radiolytic-thermal effects. Under these circumstances the radiolytic yield, that is, gas generation due solely to ionizing radiation, is not clearly defined. In these cases, the data are presented from the perspective of compositional changes rather than radiolytic yields. Although we can qualitatively account for gas generation due to thermal processes from the blank experiments (i.e., no alpha particle source), we noted that it was not possible to completely uncouple the radiolytic and thermal effects based solely on the data we obtained. For this reason the term "apparent yield" is used to differentiate between gas production due to coupled thermal-radiolytic effects and radiolytic yields that correspond to radiolytic processes only. 


\section{ALPHA PARTICLE IRRADIATION OF POLYETHYLENE AND POLYVINYLCHLORIDE}

The results obtained for the work we performed are summarized in this section. The data are organized by irradiation temperature and plastic type.

\section{A. Test Matrices}

The test matrices for the experiments completed are given in Tables 4, 5 and 6 for the experiments performed at 30,60 and $100^{\circ} \mathrm{C}$, respectively. At $30^{\circ} \mathrm{C}$, two sets of experiments were performed. First, both PVC and PE were irradiated at four different dose rates to establish the effect of dose rate. Second, higher absorbed-dose experiments using the highest activity foils were done using two different PE and PVC plastic materials. The objectives of these tests were to better establish the longer-term yields and to examine the effect of material variability on gas generation due to alpha particle degradation of the plastic material.

An abbreviated set of experiments was performed at $60^{\circ} \mathrm{C}$. The objective was to provide data at an intermediate temperature to establish thermal trends. The highest temperature investigated was $100^{\circ} \mathrm{C}$. These experiments were performed at all dose rates and were directly comparable to the variable dose rate experiments performed at $30^{\circ} \mathrm{C}$.

All experiments were performed in duplicate. Blank experiments, which were experiments that were similar in all aspects except for the presence of an alpha particle source, were also performed for each plastic at each temperature.

\section{B. Gas Generation Due to Alpha Particle Degradation of Polyethylene and Polyvinylchloride at $30^{\circ} \mathrm{C}$}

The experiments performed at $30^{\circ} \mathrm{C}$ focused on the effect of dose rate on gas generation. A few experiments were also done to investigate the effect of irradiating different materials of the same plastic type.

At $30^{\circ} \mathrm{C}$, there was little net alteration of the gas phase. A small reduction in the total pressure was observed because oxygen depletion was greater than the buildup of hydrogen, carbon oxides, and organics in the gas phase. At this temperature, no PE or PVC sample was more than slightly discolored by the ionizing radiation. Relatively few organic species were observed in the gas phase as degradation products. The total organic content in the gas phase was typically less than $0.01 \mathrm{~mol} \%$.

Weight change data for all the experiments performed at $30^{\circ} \mathrm{C}$ are tabulated in Table 7 . The yield values determined are tabulated in Table 8.

\section{Variable Dose Rate Irradiation of PE at $30^{\circ} \mathrm{C}$}

The variable dose rate experiments performed with polyethylene (PE-1) correspond to experiments WSRC-1 to WSRC-9. The gas phase data for these experiments are tabulated in 
Table A.2 (blank) and Tables A.3 to A.6 in the appendix. The objective of these experiments was to determine the rate of gas generation as a function of absorbed dose and dose rate.

\begin{tabular}{|c|c|c|c|}
\hline $\begin{array}{l}\text { Test } \\
\text { No. }\end{array}$ & $\begin{array}{c}\text { Sample } \\
\text { ID }\end{array}$ & $\begin{array}{l}\text { Foil Activity, } \\
\mu \mathrm{Ci} / \mathbf{i n}^{2}(\mathrm{mCi})\end{array}$ & $\begin{array}{c}\text { Duration, } \\
\text { Months }\end{array}$ \\
\hline WSRC-1 & PE1-01 & $1500(6)$ & 1.0 \\
\hline WSRC-2 & PE1-02 & $1500(6)$ & 1.0 \\
\hline WSRC-3 & PE1-03 & $750(3)$ & 2.0 \\
\hline WSRC-4 & PE1-04 & $750(3)$ & 2.0 \\
\hline WSRC-5 & PE1-05 & $150(.6)$ & 6.0 \\
\hline WSRC- 6 & PE1-06 & $150(.6)$ & 6.0 \\
\hline WSRC-7 & PE1-07 & $75(.3)$ & 6.0 \\
\hline WSRC-8 & PE1-08 & $75(.3)$ & 6.0 \\
\hline WSRC-9 & PE1-09 & 0 & 6.0 \\
\hline WSRC- 10 & PVC1-01 & $1500(6)$ & 1.0 \\
\hline WSRC-11 & PVC1-02 & $1500(6)$ & 1.0 \\
\hline WSRC- 12 & PVC1-03 & $750(3)$ & 2.0 \\
\hline WSRC-13 & PVC1-04 & $750(3)$ & 2.0 \\
\hline WSRC-14 & PVC1-05 & $150(.6)$ & 6.0 \\
\hline WSRC-15 & PVC1-06 & $150(.6)$ & 6.0 \\
\hline WSRC-16 & PVC1-07 & $75(.3)$ & 6.0 \\
\hline WSRC-17 & PVC1-08 & $75(.3)$ & 6.0 \\
\hline WSRC-18 & PVC1-09 & 0 & 6.0 \\
\hline WSRC-19 & PE1-10 & $1500(6)$ & 4.0 \\
\hline WSRC-20 & PE1-11 & $1500(6)$ & 4.0 \\
\hline WSRC-21 & PE2-01 & $1500(6)$ & 4.0 \\
\hline WSRC-22 & PE2-02 & $1500(6)$ & 4.0 \\
\hline WSRC-23 & PVC1-10 & $1500(6)$ & 4.0 \\
\hline WSRC-24 & PVC1-11 & $1500(6)$ & 4.0 \\
\hline WSRC-25 & PVC2-01 & $1500(6)$ & 4.0 \\
\hline WSRC-26 & PVC2-02 & $1500(6)$ & 4.0 \\
\hline
\end{tabular}




\begin{tabular}{|c|c|c|c||}
\hline \multicolumn{4}{|c|}{ Table 5. Test Matrix for PVC and PE at 60 ${ }^{\circ} \mathbf{~}$} \\
\hline $\begin{array}{c}\text { Test } \\
\text { No. }\end{array}$ & Sample ID & $\begin{array}{c}\text { Foil Activity, } \\
\mu \text { Ci/in. }{ }^{2}(\mathbf{m C i})\end{array}$ & $\begin{array}{c}\text { Duration, } \\
\text { Months }\end{array}$ \\
\hline WSRC-27 & PE1-12 & $1500(6)$ & 1.0 \\
\hline WSRC-28 & PE1-13 & $1500(6)$ & 1.0 \\
\hline WSRC-29 & PE1-14 & $150(.6)$ & 6.0 \\
\hline WSRC-30 & PE1-15 & $150(0.6)$ & 6.0 \\
\hline WSRC-31 & PE1-16 & 0 & 6.0 \\
\hline WSRC-32 & PVC1-12 & $1500(6)$ & 1.0 \\
\hline WSRC-33 & PVC1-13 & $1500(6)$ & 1.0 \\
\hline WSRC-34 & PVC1-14 & $150(0.6)$ & 6.0 \\
\hline WSRC-35 & PVC1-15 & $150(0.6)$ & 6.0 \\
\hline WSRC-36 & PVC1-16 & 0 & 6.0 \\
\hline \hline
\end{tabular}

The major changes in the bulk composition of the gas phase were oxygen depletion coupled with the formation of hydrogen and carbon dioxide. The concentration of hydrogen and carbon dioxide as functions of time and dose rate are shown in Figs. 3 and 4, respectively. The gas chromatograms representing the organic content of the gas phase are shown in Fig. 5.

In the absence of ionizing radiation, polyethylene is stable at $30^{\circ} \mathrm{C}$. There was no significant change in weight in the blank (WSRC-9) system after 8 months of contact with the 70\% RH air atmosphere. No hydrogen buildup or trace organics and only $0.022 \mathrm{~mol} \%$ carbon dioxide were found.

In the presence of ionizing radiation, hydrogen was produced at a constant rate with a yield of $2.3+0.3 \mathrm{molec} / 100 \mathrm{eV}$ that was independent of dose rate (see Fig. 3). The invariance of the yield over time (i.e., for the same absorbed doses but different experiment durations), along with the lack of hydrogen production in the unirradiated experiment, indicated that there was no significant thermal contribution to hydrogen formation.

Carbon dioxide was produced at a rate that was nearly constant, although some evidence of accelerated production at longer times was present. The apparent yield of carbon dioxide increased as the dose rate decreased from $2.5+0.2 \mathrm{molec} / 100 \mathrm{eV}$ to over $3 \mathrm{molec} / 100 \mathrm{eV}$. The slight increase was attributed to thermal contributions to the production of carbon dioxide. This contention is supported by (1) the oxygen concentration data in that the apparent $\mathrm{G}\left[-\mathrm{O}_{2}\right]$ increases with experiment duration and (2) the observation that some carbon dioxide was produced at a low rate due to thermal processes. As the dose rate is lowered and experiment duration is increased, the rate of oxygen removal increases from an apparent $\mathrm{G}\left(-\mathrm{O}_{2}\right)$ of 10 to over $20 \mathrm{molec} / 100 \mathrm{eV}$. At high dose rates, the thermal contribution is negligible. 
The overall rate of oxygen depletion was 2-5 times greater than the buildup of other gases in the systems, resulting in a net reduction in the total system pressure. The fate of oxygen was twofold. First, it contributed to the formation of carbon dioxide and a lesser amount of carbon monoxide, both accounting for $10-20 \%$ of the oxygen lost. Most of the oxygen, however, was reacted with the polyethylene itself, resulting in weight gain. (See Table 7.) This weight gain is radiolytically-induced, since oxygen uptake did not occur in the unirradiated sample. Weight gain also correlated well with absorbed dose, but not with exposure time.

\begin{tabular}{|c|c|c|c|}
\hline $\begin{array}{l}\text { Test } \\
\text { No. }\end{array}$ & Sample ID & $\begin{array}{l}\text { Foil Activity, } \\
\mu \mathrm{Ci} / \mathbf{i n}^{2} \text { (mCi) }\end{array}$ & $\begin{array}{c}\text { Duration, } \\
\text { Months }\end{array}$ \\
\hline WSRC-37 & PE1-17 & $1500(6)$ & 1.0 \\
\hline WSRC-38 & PE1-18 & $1500(6)$ & 1.0 \\
\hline WSRC-39 & PE1-19 & $750(3)$ & 2.0 \\
\hline WSRC-40 & PE1-20 & $750(3)$ & 2.0 \\
\hline WSRC-41 & PE1-21 & $150(.6)$ & 6.0 \\
\hline WSRC-42 & PE1-22 & $150(.6)$ & 6.0 \\
\hline WSRC-43 & PE1-23 & $75(.3)$ & 6.0 \\
\hline WSRC-44 & PE1-24 & $75(.3)$ & 6.0 \\
\hline WSRC-45 & PE1-25 & 0 & 6.0 \\
\hline WSRC-46 & PVC1-17 & $1500(6)$ & 1.0 \\
\hline WSRC-47 & PVC1-18 & $1500(6)$ & 1.0 \\
\hline WSRC-48 & PVC1-19 & $750(3)$ & 2.0 \\
\hline WSRC-49 & PVC1-20 & $750(3)$ & 2.0 \\
\hline WSRC-50 & PVC1-21 & $150(.6)$ & 6.0 \\
\hline WSRC-51 & PVC1-22 & $150(.6)$ & 6.0 \\
\hline WSRC-52 & PVC-23 & $75(.3)$ & 6.0 \\
\hline WSRC-53 & PVC1-24 & $75(.3)$ & 6.0 \\
\hline WSRC-54 & PVC1-25 & 0 & 6.0 \\
\hline
\end{tabular}




\begin{tabular}{|c|c|c|c|c|}
\hline Test No. & Plastic & Before (g) & After (g) & Gain or Loss (g) \\
\hline WSRC-1 & $\mathrm{PE}$ & 0.68153 & 0.68649 & 0.00496 \\
\hline WSRC-2 & $\mathrm{PE}$ & 0.66965 & 0.67303 & 0.00338 \\
\hline WSRC-3 & $\mathrm{PE}$ & 0.66718 & 0.67026 & 0.00308 \\
\hline WSRC-4 & $\mathrm{PE}$ & 0.67620 & 0.67950 & 0.00330 \\
\hline WSRC-5 & $\mathrm{PE}$ & 0.66955 & 0.67181 & 0.00226 \\
\hline WSRC- 6 & $\mathrm{PE}$ & 0.67744 & 0.67992 & 0.00248 \\
\hline WSRC-7 & $\mathrm{PE}$ & 0.66882 & 0.67005 & 0.00123 \\
\hline WSRC- 8 & PE & 0.68480 & 0.68612 & 0.00132 \\
\hline WSRC- 9 & PE (BLANK) & 0.67003 & 0.66968 & -.00035 \\
\hline WSRC-10 & $\mathrm{PVC}$ & 1.51284 & 1.50888 & -0.00396 \\
\hline WSRC-11 & $\mathrm{PVC}$ & 1.50503 & 1.50179 & -0.00324 \\
\hline WSRC-12 & PVC & 1.54746 & 1.54190 & -0.00556 \\
\hline WSRC-13 & PVC & 1.51198 & 1.50740 & -0.00458 \\
\hline WSRC-14 & PVC & 1.50403 & 1.50148 & -0.00255 \\
\hline WSRC-15 & PVC & 1.55488 & 1.55204 & -0.00284 \\
\hline WSRC-16 & PVC & 1.47402 & 1.47257 & -0.00145 \\
\hline WSRC-17 & PVC & 1.50711 & 1.50554 & -0.00157 \\
\hline WSRC-18 & PVC (BLANK) & 1.51461 & 1.51429 & -0.00032 \\
\hline WSRC-19 & $\mathrm{PE}$ & 0.65902 & 0.66280 & 0.00378 \\
\hline WSRC-20 & $\mathrm{PE}$ & 0.68065 & 0.68484 & 0.00419 \\
\hline WSRC-21 & $\mathrm{PE}$ & 5.38797 & 5.39519 & 0.00722 \\
\hline WSRC-22 & $\mathrm{PE}$ & 5.48106 & 5.48688 & 0.00582 \\
\hline WSRC-23 & PVC & 1.47374 & 1.46628 & -0.00746 \\
\hline WSRC-24 & PVC & 1.51167 & 1.50107 & -0.01060 \\
\hline WSRC-25 & PVC & 0.82812 & 0.82365 & -0.00447 \\
\hline WSRC-26 & PVC & 0.79354 & 0.78731 & -0.00623 \\
\hline
\end{tabular}




\begin{tabular}{|c|c|c|c|c|c|c|}
\hline \multirow{2}{*}{$\begin{array}{l}\text { Experiment } \\
\text { Designation }\end{array}$} & \multirow{2}{*}{ Material } & \multirow{2}{*}{$\begin{array}{c}\text { Energy } \\
\text { Deposition } \\
\text { Rate, } \\
\mathrm{MeV} / \mathrm{h} \\
\end{array}$} & \multicolumn{4}{|c|}{ Apparent Yield, Molec/100eV } \\
\hline & & & $\mathrm{G}\left(\mathrm{H}_{2}\right)$ & $\mathrm{G}\left(\mathrm{CO}_{2}\right)$ & $\mathrm{G}\left(-\mathrm{O}_{2}\right)$ & $\mathrm{G}(\mathrm{HCl})$ \\
\hline WSRC-1 & PE1 & $1.0 \times 10^{12}$ & $2.4 \pm .5$ & $2.5 \pm 0.2$ & 11 & NA \\
\hline WSRC-2 & PE1 & $1.0 \times 10^{12}$ & $2.2 \pm .2$ & $2.6 \pm 0.1$ & 10 & NA \\
\hline WSRC-3 & PE1 & $4.6 \times 10^{11}$ & $2.3 \pm .2$ & $3.1 \pm 0.4$ & 15 & NA \\
\hline WSRC-4 & PE1 & $4.6 \times 10^{11}$ & $2.6 \pm .2$ & $3.5 \pm 0.5$ & 16 & NA \\
\hline WSRC-5 & PE1 & $9.5 \times 10^{10}$ & $1.5 \pm 0.2$ & $3.6 \pm 0.3$ & 20 & NA \\
\hline WSRC- 6 & PE1 & $9.5 \times 10^{10}$ & 2.1. \pm 0.1 & $3.9 \pm 0.2$ & 20 & NA \\
\hline WSRC-7 & PE1 & $4.9 \times 10^{10}$ & $2.4 \pm .2$ & $2.6 \pm 0.3$ & 16 & NA \\
\hline WSRC-8 & PE1 & $4.9 \times 10^{10}$ & $2.8 \pm .2$ & $3.5 \pm 0.2$ & 30 & NA \\
\hline WSRC-9 & PE1 & Blank Test & NA & NA & NA & NA \\
\hline WSRC-10 & PVC1 & $1.0 \times 10^{12}$ & $0.64 \pm .02$ & $.90 \pm .03$ & 6 & $0.50 \pm .05$ \\
\hline WSRC-11 & PVC1 & $1.0 \times 10^{12}$ & $0.58 \pm 0.05$ & $.69 \pm .10$ & 4 & $0.42 \pm .05$ \\
\hline WSRC-12 & PVC1 & $4.6 \times 10^{11}$ & $0.71 \pm .10$ & $1.0 \pm .05$ & 5 & $0.30 \pm .03$ \\
\hline WSRC- 13 & PVC1 & $4.6 \times 10^{11}$ & $0.48 \pm .13$ & $1.1 \pm .07$ & 2 & $0.23 \pm .03$ \\
\hline WSRC-14 & PVC1 & $9.5 \times 10^{10}$ & $0.42 \pm .06$ & $0.82 \pm .06$ & 5 & $0.55 \pm .05$ \\
\hline WSRC- 15 & PVC1 & $9.5 \times 10^{10}$ & $0.44 \pm .06$ & $0.68 \pm .22$ & 5 & $0.55 \pm .05$ \\
\hline WSRC-16 & PVC1 & $4.9 \times 10^{10}$ & $0.44 \pm 0.04$ & $1.3 \pm 0.2$ & 18 & ND \\
\hline WSRC- 17 & PVC1 & $4.9 \times 10^{10}$ & $0.32 \pm .04$ & $1.1 \pm 0.1$ & 9 & $0.78 \pm .08$ \\
\hline WSRC-18 & PVC1 & Blank Test & NA & NA & NA & $\mathrm{NA}$ \\
\hline WSRC-19 & PE1 & $1.0 \times 10^{12}$ & $1.2 \pm .1$ & $3.0 \pm .1$ & 10 & NA \\
\hline WSRC-20 & PE1 & $1.0 \times 10^{12}$ & $1.1 \pm .1$ & $2.5 \pm .1$ & 9 & NA \\
\hline WSRC-21 & PE2 & $1.0 \times 10^{12}$ & $1.9 \pm .1$ & $4.6 \pm .1$ & 18 & NA \\
\hline WSRC-22 & PE2 & $1.0 \times 10^{12}$ & $1.7 \pm .1$ & $3.9 \pm .1$ & 14 & NA \\
\hline WSRC-23 & PVC1 & $1.0 \times 10^{12}$ & $0.55 \pm .01$ & $0.85 \pm .011$ & 4 & $0.38 \pm .04$ \\
\hline WSRC-24 & PVC1 & $1.0 \times 10^{12}$ & $0.55 \pm .02$ & $0.87 \pm .011$ & 4 & $0.47 \pm .05$ \\
\hline WSRC-25 & PVC2 & $1.0 \times 10^{12}$ & $0.34 \pm .03$ & $0.82 \pm .02$ & 5 & ND \\
\hline WSRC-26 & PVC2 & $1.0 \times 10^{12}$ & $0.39 \pm .02$ & $1.1 \pm 0.1$ & 6 & $0.39 \pm .04$ \\
\hline
\end{tabular}




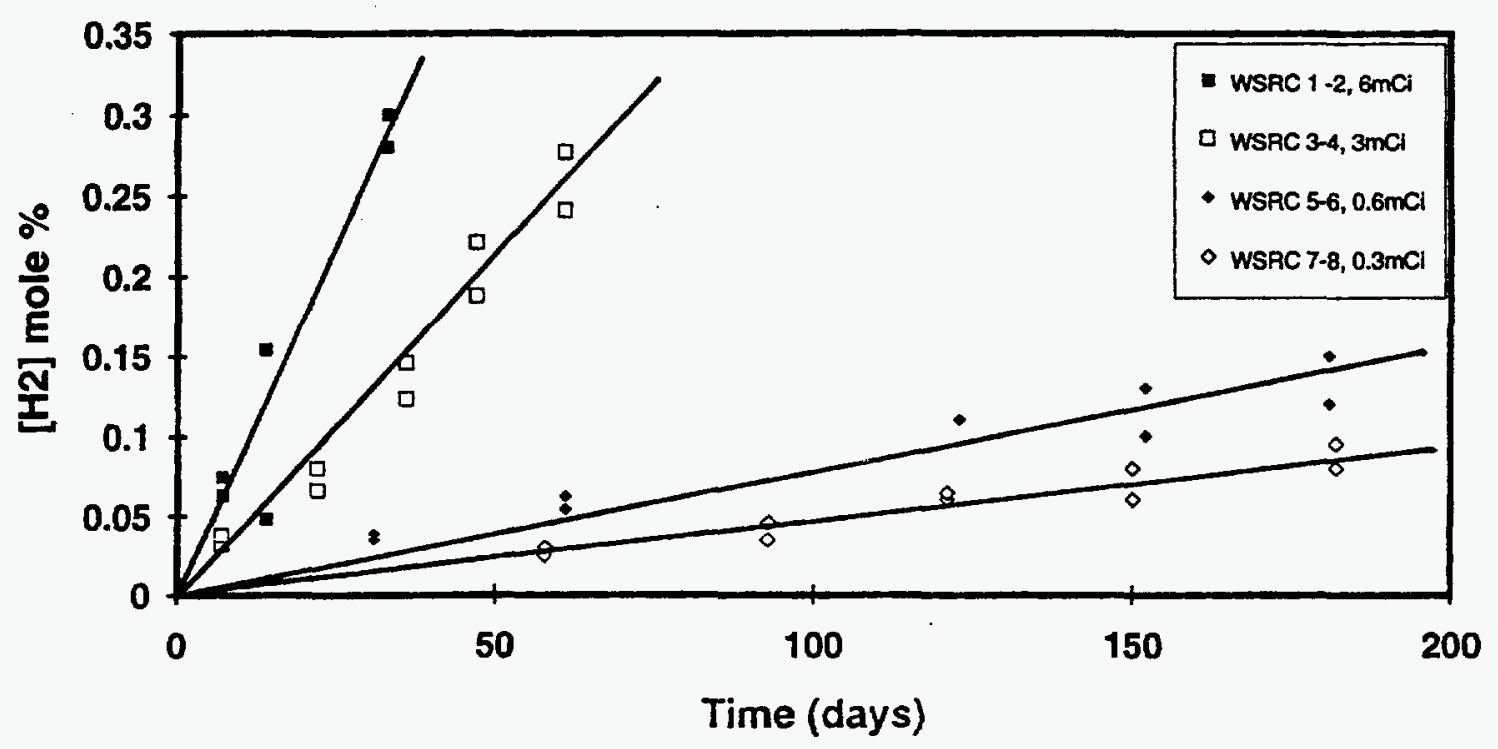

Fig. 3. Concentration of Hydrogen as a Function of Dose Rate for Polyethylene at $30^{\circ} \mathrm{C}$

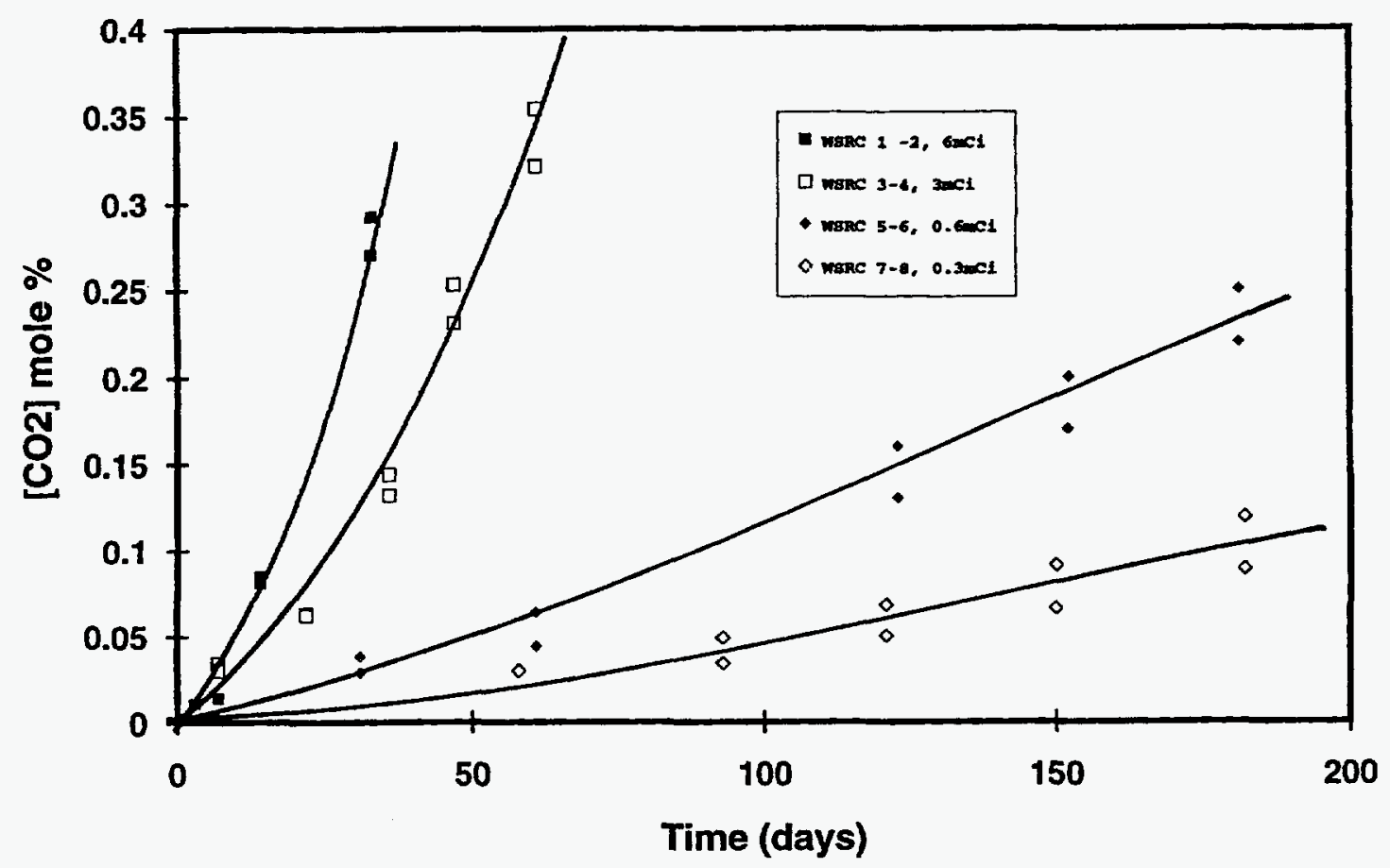

Fig. 4. Concentration of Carbon Dioxide as a Function of Dose Rate for Polyethylene at $30^{\circ} \mathrm{C}$ 
(a)

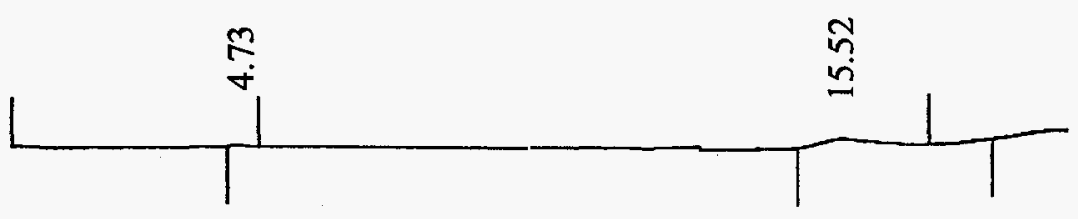

(b)

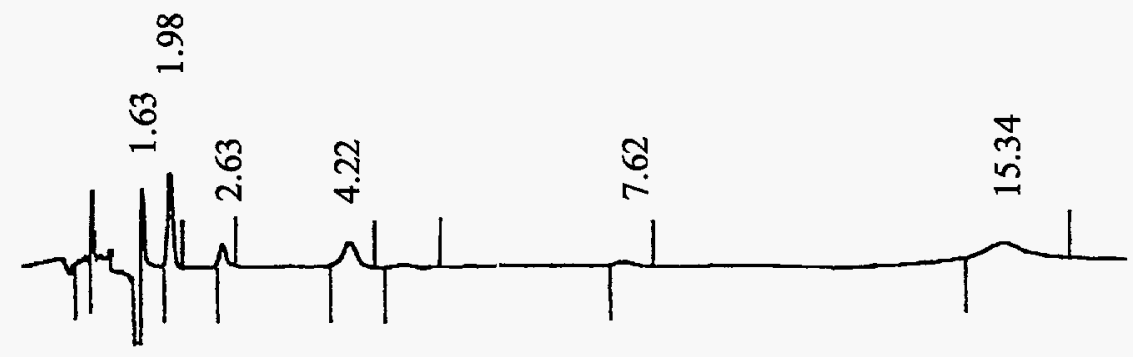

Fig. 5. Gas Chromatograms Showing the Relative Organic Content of the Gas Phase for Polyethylene at $30^{\circ} \mathrm{C}$. (a) Unirradiated Test, (b) Irradiated for 1 Month with a 6-mCi Am241 Foil.

Lastly, the organic content of the gas phase was monitored as a function of absorbed dose. (See Fig. 5.) Whereas no volatile organics are detected in the unirradiated system, small quantities of organics are noted in the irradiated systems that are correlated with absorbed dose. The overall concentration of organics in the gas phase, however, was less than $0.01 \mathrm{~mol} \%$ following irradiation.

\section{Variable Dose Rate Irradiation of $\mathrm{PVC}$ at $30^{\circ} \mathrm{C}$}

The same set of variable dose rate experiments that were done with polyethylene were also done with polyvinylchloride (PVC-1) at $30^{\circ} \mathrm{C}$. These PVC experiments correspond to experiments WSRC-10 to WSRC-18. The gas phase data are tabulated in Table A.2 (blank experiment) and Tables A.7 to A.10. Overall gas generation was less than that observed with PE. Only small changes in the bulk composition of the gas phase occurred, and no significant discoloration was noted. Irradiation resulted in a slight decrease in the total gas pressure.

In the blank experiment (WSRC-18), PVC was stable at $30^{\circ} \mathrm{C}$ for a period of over eight months. No hydrogen was formed, no organics were detected in the gas phase, and only 
$0.020 \mathrm{~mol} \%$ of carbon dioxide was generated. This amount of carbon dioxide was comparable to that observed in the PE blank experiment. No significant weight change in the plastic material occurred.

The apparent yields for hydrogen formation, carbon dioxide formation, and oxygen depletion were given in Table 8. Plots of the concentration of these two species are shown in Figs. 6 and 7 respectively. The gas chromatograms of the organic composition of the gas phase are shown in Fig. 8.

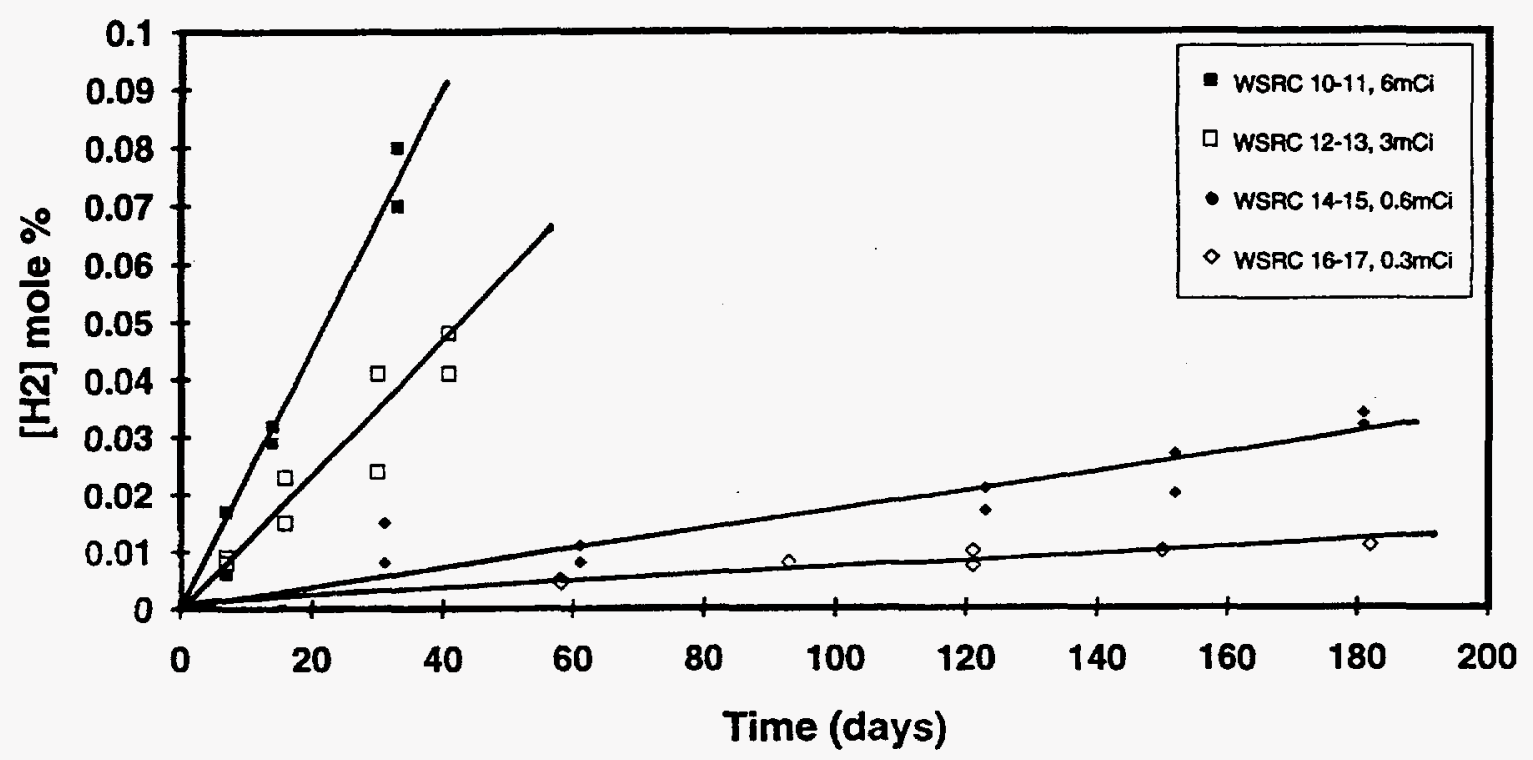

Fig. 6. Concentration of Hydrogen as a Function of Dose Rate for Polyvinylchloride at $30^{\circ} \mathrm{C}$

An apparent small dose rate effect was noted in the hydrogen generation data: the yield decreased from $0.60 \pm 0.03 \mathrm{molec} / 100 \mathrm{eV}$ to $0.35 \pm 0.03 \mathrm{molec} / 100 \mathrm{eV}$ as the dose rate was decreased. The amount of hydrogen generated was the same in the two six-month experiment sets, although the absorbed dose differed by a factor of two, which suggests that thermal, not radiolytic contributions, caused the differences in yield noted.

The carbon dioxide yield data (Table 8) are more scattered than the hydrogen yield data and do not show a significant trend with dose rate or irradiation time. The best interpretation of these data is that the yield does not vary with dose rate and has an average value of $0.95 \pm$ $0.2 \mathrm{molec} / 100 \mathrm{eV}$. The large scatter in the carbon dioxide data is also reflected in the oxygen depletion data. The apparently large increase in oxygen depletion rates reported for experiments WSRC-16 and 17 are not considered significant since the overall change in the oxygen concentration was small. 


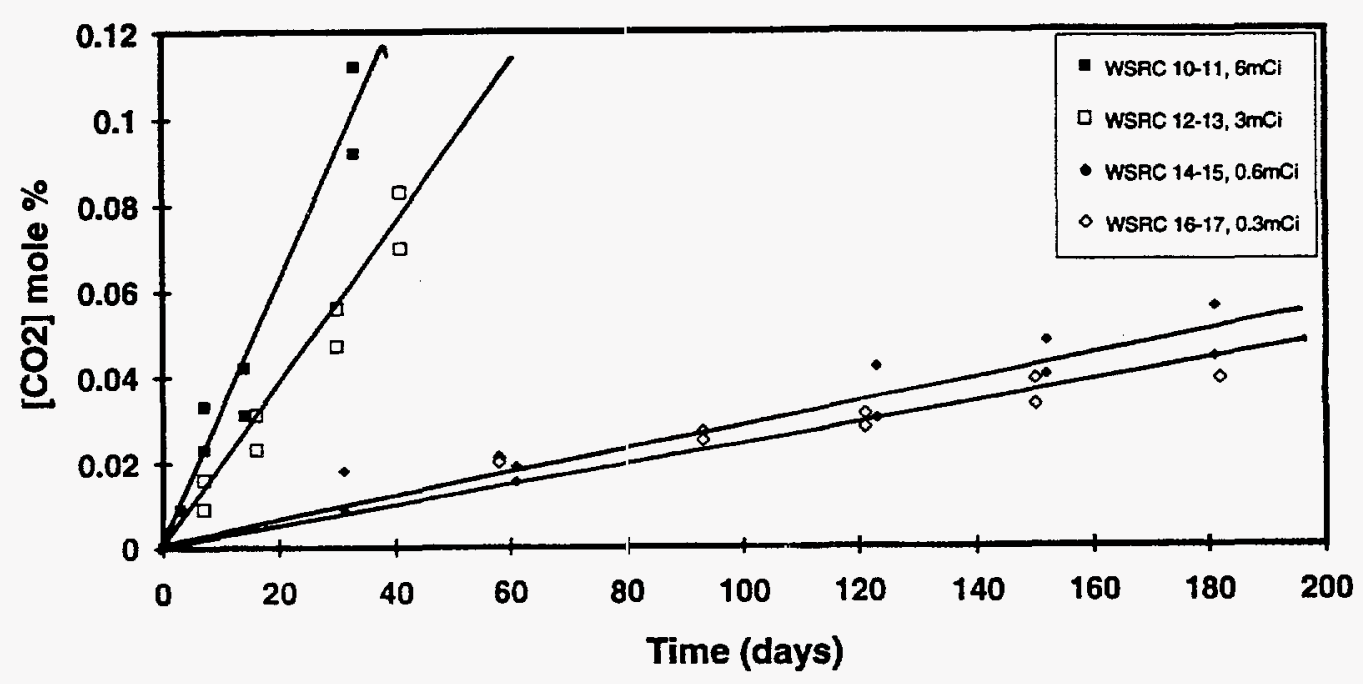

Fig. 7. Concentration of Carbon Dioxide as a Function of Dose Rate for Polyvinylchloride at $30^{\circ} \mathrm{C}$

The yield of hydrochloric acid, based on an end-of-the-experiment vessel rinse, ranged from 0.2 to $0.8 \mathrm{molec} / 100 \mathrm{eV}$. We canrot establish the dependence of the yield on irradiation time, since only one data point per experiment was obtained. Yields for hydrochloric acid appeared to increase with irradiation time for comparable absorbed doses and to decrease with dose rate for comparable irradiation times. This trend is the opposite of what was expected.

For all PVC samples irradiated at $30^{\circ} \mathrm{C}$, weight loss, not gain, was observed. These data were summarized in Table 7. The weight loss was not only dependent on the dose rate, but was affected by both dose rate and experiment duration. In experiments WSRC-10,11 and WSRC-12,13, which were irradiated to the same absorbed dose but for different lengths of time (one vs. two months), the net weight loss was almost $50 \%$ greater for the two-month experiment. In experiments WSRC-14,15 and WSRC-16,17, which were irradiated to different absorbed doses but for the same duration in time, weight loss was lower in the lower absorbed dose experiment. This, however, was not directly proportional to the dose rate.

The concentration of volatile organics in the PVC system was affected by absorbed dose. (See Fig. 8.) The overall gas production, however, remained low and was less than $0.01 \mathrm{~mol} \%$ of the total in all experiments. Net production of VOCs, relative to the irradiation of PE at the same conditions, was slightly greater for PVC. 
(a)

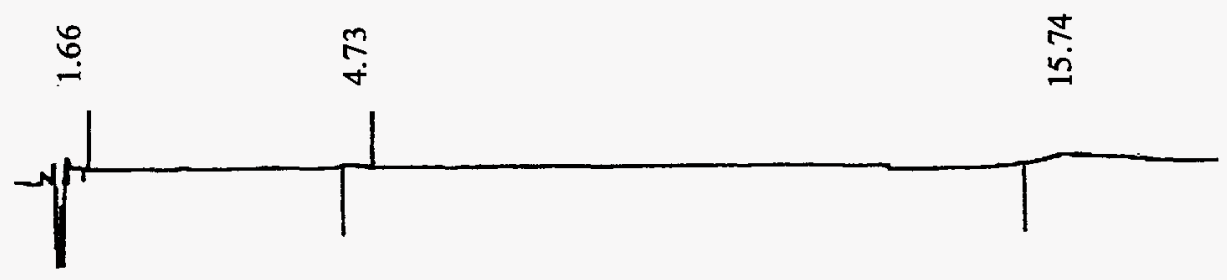

(b)

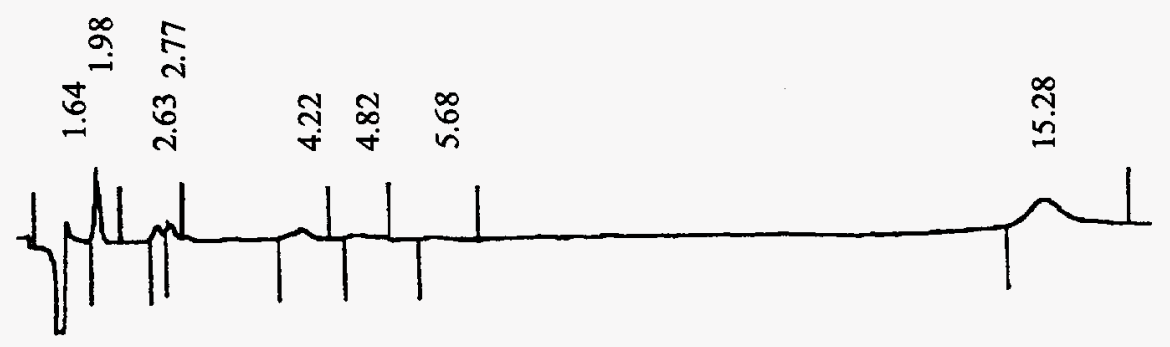

Fig. 8. Gas Chromatograms Showing the Relative Organic Content of the Gas Phase for Polyvinylchloride at $30^{\circ} \mathrm{C}$. (a) Unirradiated Test, (b) Irradiated for 1 Month with a 6-mCi Am-241 Foil.

\section{Material-Specific High-Absorbed-Dose Experiments at $30^{\circ} \mathrm{C}$}

Eight experiments were performed using 6-mCi alpha particle sources (highest dose rate) for a duration of four months. These were duplicate samples of PE-1, PE-2, PVC-1, and PVC-2 and corresponded to the experiments designated WSRC-19 to 26. The objective of these experiments was to extend the high dose rate results to higher absorbed dose and begin to look at the effect of plastic type variability on gas generation.

The gas phase data for these experiments are reported in Tables A.11 to A.14. The yields and weight change date were tabulated in Tables 7 and 8 , respectively. The major changes in the gas phase composition due to radiolysis were qualitatively the same as observed in the variable dose rate experiments. Net oxygen depletion (in the range of $2-7 \mathrm{~mol} \%$ compared to $<1 \mathrm{~mol} \%$ ) was greater than that observed in the one-month experiments. Carbon dioxide formation and oxygen depletion were linear with time. The hydrogen and carbon dioxide concentration data, as a function of irradiation time, are shown in Fig. 9. 
(a)

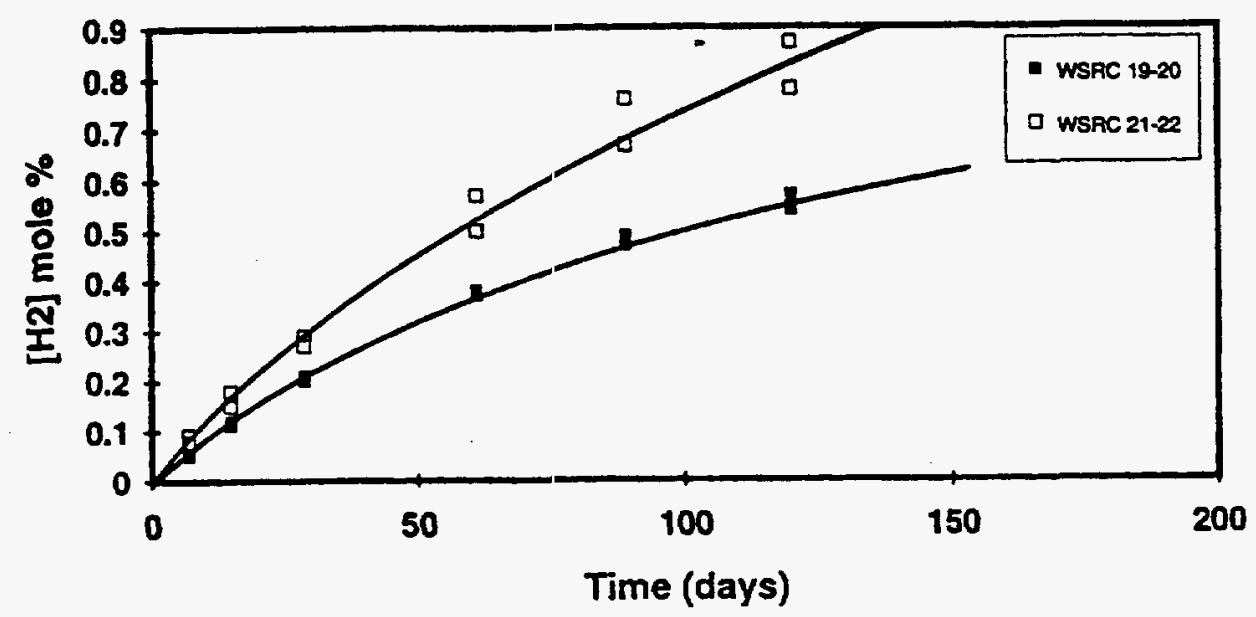

(b)

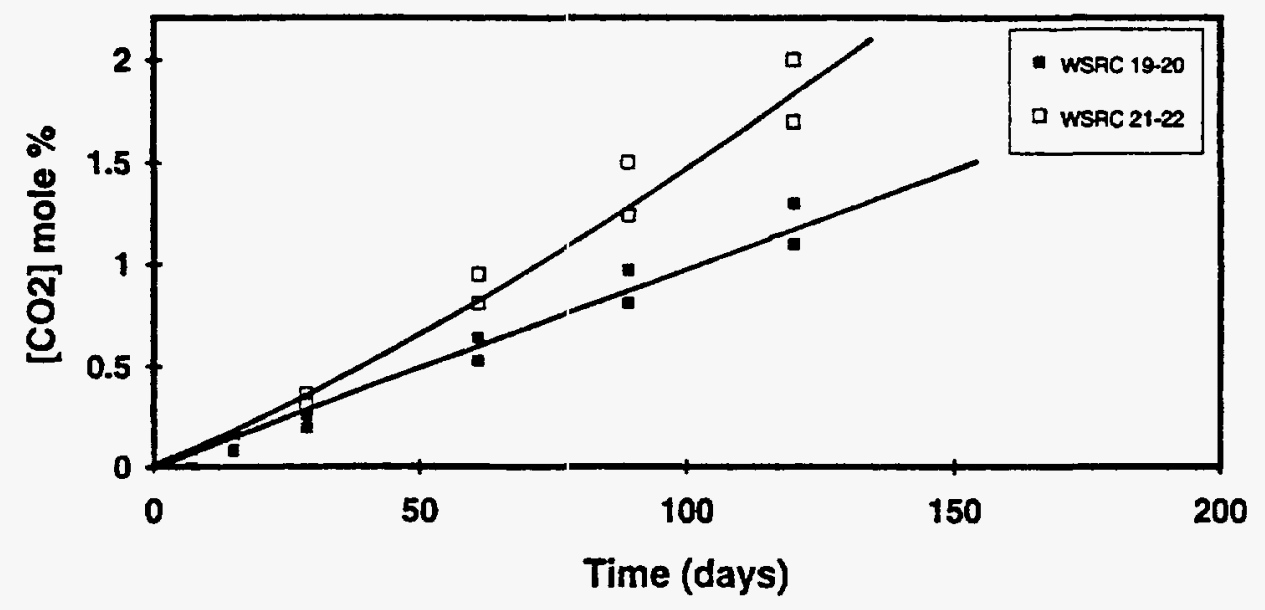

Fig. 9. Gas Concentration as a Function of Time for the $30^{\circ} \mathrm{C}$ Material Specific Experiments.

(a) Hydrogen for PE1 and PE2, (b) Carbon Dioxide for PE1 and PE2, (c) Hydrogen for PVC 1 and PVC 2, (d) Carbon Dioxide for PVC 1 and PVC 2. 
(c)

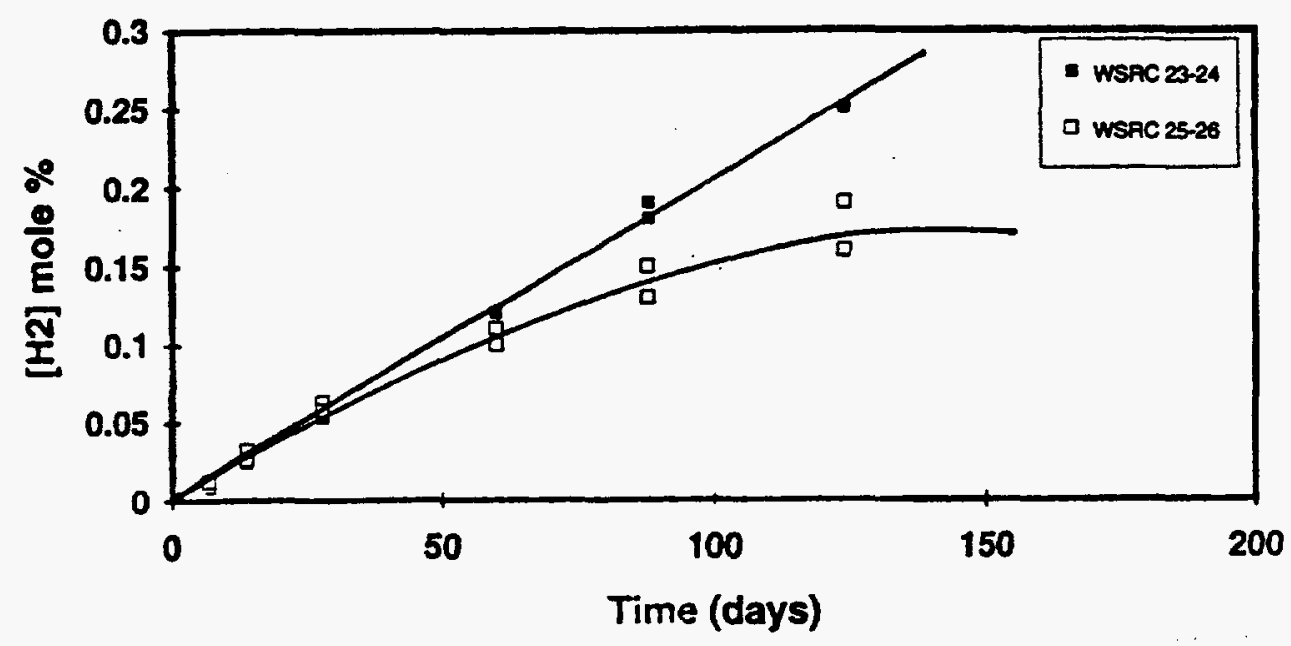

(d)

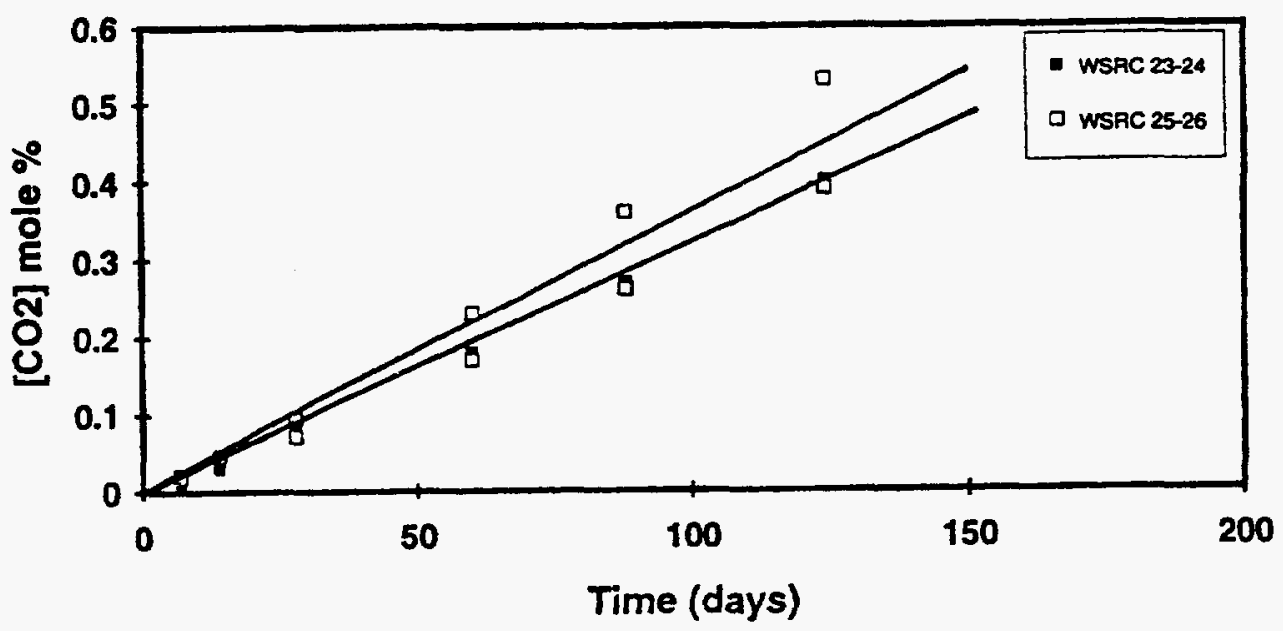

Fig. 9. (contd.)

Apparent yields measured for carbon dioxide formation were 2.8, 4.2, 0.86 and $0.92 \mathrm{molec} / 100 \mathrm{eV}$ for PE-1, PE-2, PVC-1 and PVC-2, respectively. Results for PE-1 (bag material) showed 50\% less carbon dioxide formation than PE-2 (sheet material). This finding correlated with the decrease in the oxygen concentration and the material weight gain observed. The two PVC samples showed the same carbon dioxide formation. This result also correlated well qualitatively with the oxygen data but not with the weight loss data. Oxygen depletion was about four times higher than the rate of carbon dioxide formation.

The apparent yield of hydrogen was $1.2,1.8,0.55$ and $.036 \mathrm{molec} / 100 \mathrm{eV}$ for PE-1, PE-2, PVC-1, and PVC-2, respectively. There was a 50\% increase in hydrogen formation from PE-1 to PE-2. There was also a 50\% difference in the yield when PVC-1 and PVC-2 were compared. 
These changes, though small, are experimentally significant and relate to the radiation chemistry of the plasticizer present in the material.

The organic composition of the gas phase increased with absorbed dose, as expected. The key organics detected were ethylene and acetone with the overall organic component still less than $0.01 \mathrm{~mol} \%$. Weight gain in the polyethylene samples was the same as observed in the onemonth experiment although the absorbed dose was four time higher, suggesting that the component responsible for the observed weight gain, perhaps the plasticizer present, may have been depleted after one month. Weight loss in the PVC samples increased by almost a factor of three relative to the one-month experiment, indicating that depletion had not occurred.

\section{Gas Generation Due to Alpha Particle Degradation of Polyethylene and Polyvinylchloride at $60^{\circ} \mathrm{C}$}

A smaller matrix of experiments, shown in Table 5, was performed at $60^{\circ} \mathrm{C}$. They are comparable to the variable-dose rate experiments done at $30^{\circ} \mathrm{C}$, except that only two dose rates (6-mCi and $0.6-\mathrm{mCi}$ alpha particle foils) were used. A blank experiment was also performed for each material. Net change in the bulk gas phase composition was small and comparable to that observed at $30^{\circ} \mathrm{C}$. The PE samples remained clear in all experiments, but very slight yellowish coloration was observed on some of the PVC samples. As observed at $30^{\circ} \mathrm{C}$, there was a small reduction in the total pressure due to irradiation in these systems.

The weight change data, for experiments performed at $60^{\circ} \mathrm{C}$, are summarized in Table 9 . The yield data for both PVC and PE experiment sets are summarized in Table 10.

\begin{tabular}{||c|c|c|c|c||}
\hline \multicolumn{5}{|c|}{ Table 9. Weight Change Data for PE and PVC at 60 ${ }^{\circ} \mathbf{C}$} \\
\hline \hline Test Number & Plastic & Before (g) & After (g) & Gain or Loss (g) \\
\hline WSRC-27 & PE & 0.69562 & 0.70520 & 0.00958 \\
\hline WSRC-28 & PE & 0.68838 & 0.69285 & 0.00447 \\
\hline WSRC-29 & PE & 0.67756 & 0.68154 & 0.00398 \\
\hline WSRC-30 & PE & 0.67180 & 0.67542 & 0.00362 \\
\hline WSRC-31 & PE (BLANK) & 0.69293 & 0.69252 & -0.00041 \\
\hline WSRC-32 & PVC & 1.52822 & 1.52380 & -0.00442 \\
\hline WSRC-33 & PVC & 1.52597 & 1.51961 & -0.00636 \\
\hline WSRC-34 & PVC & 1.49796 & 1.49454 & -0.00342 \\
\hline WSRC-35 & PVC & 1.60479 & 1.60030 & -0.00449 \\
\hline WSRC-36 & PVC (BLANK) & 1.55128 & 1.55070 & -0.00058 \\
\hline
\end{tabular}




\begin{tabular}{|c|c|c|c|c|c|c|}
\hline \multirow[b]{2}{*}{$\begin{array}{l}\text { Experiment } \\
\text { Designation }\end{array}$} & \multirow[b]{2}{*}{ Material } & \multirow{2}{*}{$\begin{array}{c}\text { Energy } \\
\text { Deposition } \\
\text { Rate, } \\
\mathrm{MeV} / \mathrm{h}\end{array}$} & \multicolumn{4}{|c|}{ Apparent Yield, molec $/ 100 \mathrm{eV}$} \\
\hline & & & $\mathrm{G}\left(\mathbf{H}_{2}\right)$ & $\mathrm{G}\left(\mathrm{CO}_{2}\right)$ & $\mathrm{G}\left(-\mathrm{O}_{2}\right)$ & $\mathrm{G}(\mathrm{HCl})$ \\
\hline WSRC-27 & PE1 & $1.0 \times 10^{12}$ & $1.8 \pm 0.4$ & $2.5 \pm 0.2$ & 17 & NA \\
\hline WSRC-28 & PE1 & $1.0 \times 10^{12}$ & $1.9 \pm 0.2$ & $2.6 \pm 0.4$ & 17 & NA \\
\hline WSRC-29 & PE1 & $9.5 \times 10^{10}$ & $1.4 \pm 0.2$ & $2.9 \pm 0.2$ & 27 & NA \\
\hline WSRC-30 & PE1 & $9.5 \times 10^{10}$ & $1.2 \pm 0.2$ & $2.6 \pm 0.2$ & 26 & NA \\
\hline WSRC-31 & PE1 & Blank Test & NA & NA & NA & NA \\
\hline WSRC-32 & PVC1 & $1.0 \times 10^{12}$ & $0.47 \pm .05$ & $1.0 \pm 0.1$ & 5 & $0.9 \pm .1$ \\
\hline WSRC-33 & PVC1 & $1.0 \times 10^{12}$ & $0.55 \pm .02$ & $0.92 \pm .05$ & 9 & $0.8 \pm .1$ \\
\hline WSRC-34 & PVC1 & $9.5 \times 10^{10}$ & $0.25 \pm .08$ & $1.2 \pm 0.1$ & 7 & $1.9 \pm .1$ \\
\hline WSRC-35 & PVC1 & $9.5 \times 10^{10}$ & $0.47 \pm .05$ & $1.5 \pm 0.1$ & 16 & $2.1 \pm .1$ \\
\hline WSRC-36 & PVC1 & Blank Test & $\mathrm{NA}$ & NA & NA & NA \\
\hline
\end{tabular}

\section{Variable Dose Rate Irradiation of PE at $60^{\circ} \mathrm{C}$}

Experiments WSRC-27 to 31 correspond to the irradiation of polyethylene at $60^{\circ} \mathrm{C}$. The gas phase compositions, as a function of time, are summarized in Table A.2 (blank) and Tables A.15 and A.16 in the appendix. The yield of hydrogen and carbon dioxide, versus dose rate, are shown in Fig. 10. Gas chromatograms of the organic composition of the gas phase are shown in Fig. 11 and Table 10.

Polyethylene was stable at $60^{\circ} \mathrm{C}$ in the absence of ionizing radiation (experiments WSRC-31). After eight months (see Table A.15), no hydrogen formation was observed, only three gas chromatography peaks (VOC) were noted that altogether comprised $<0.005 \mathrm{~mol} \%$ of the gas phase, and the carbon dioxide concentration was $0.031 \mathrm{~mol} \%$. Weight change in this experiment was minimal.

The formation of hydrogen was approximately linear with possibly some decrease in the rate of hydrogen formation at long times. With a factor of 10 decrease in dose rate, the yield did not decrease significantly $(1.8 \pm 0.3$ to $1.3 \pm 0.2 \mathrm{molec} / 100 \mathrm{eV})$.

The yield of carbon dioxide was $2.6+0.3 \mathrm{molec} / 100 \mathrm{eV}$ and was also independent of dose rate. Greater oxygen uptake was noted at longer times. This, however, was not well correlated with the weight gain data. Overall, the weight gain was a factor of almost two times higher than that observed at $30^{\circ} \mathrm{C}$. 
(a)

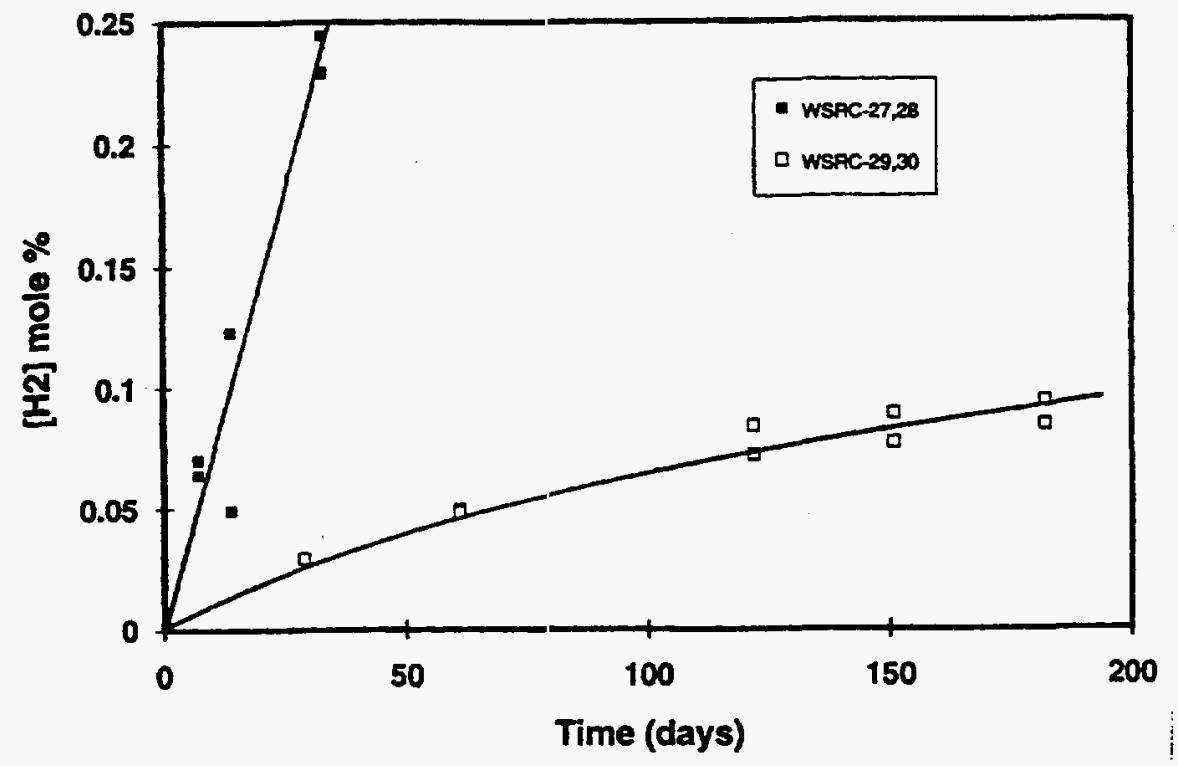

(b)

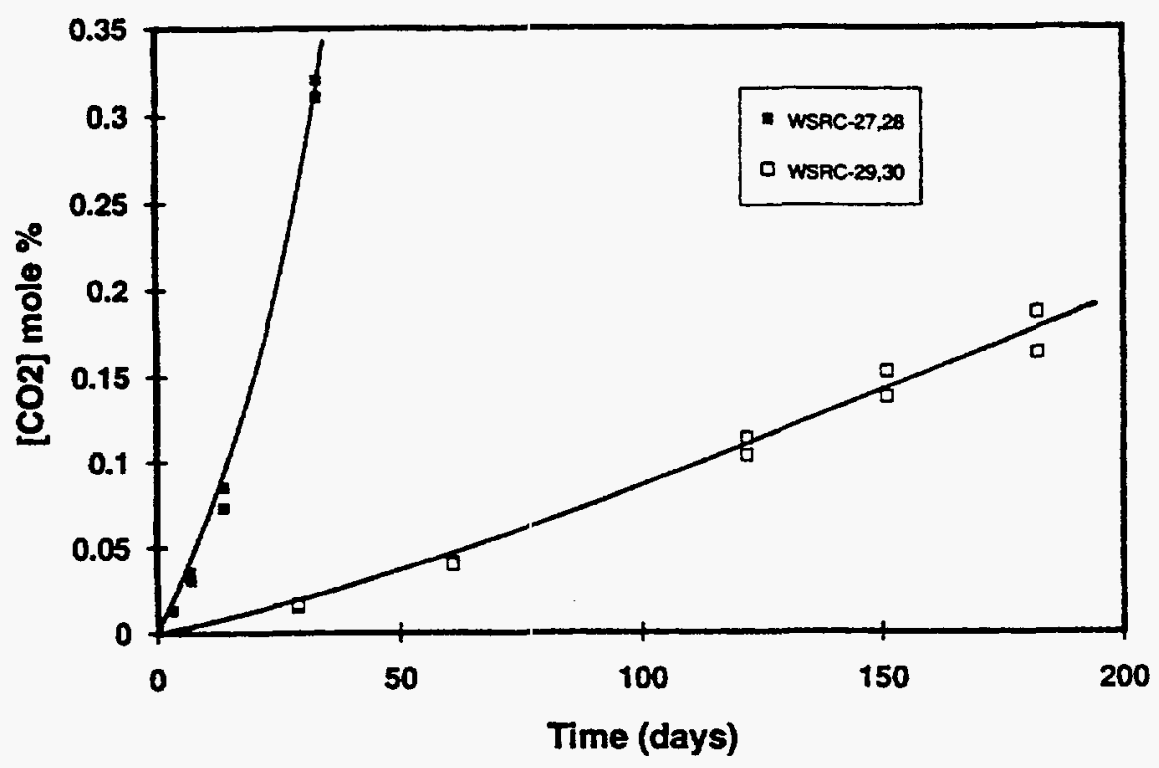

Fig. 10. Concentration of Hydrogen (a) and Carbon Dioxide (b) for Irradiated Polyethylene at $60^{\circ} \mathrm{C}$.

Greater diversity in the organic content of the gas phase was found at $60^{\circ} \mathrm{C}$, (see Fig. 11) relative to $30^{\circ} \mathrm{C}$ but the total amount of gas generation remained small $(<0.01 \mathrm{~mol} \%)$. No systematic trend with dose rate was noted. 'The majority of the organics were at least partially generated by radiolytic processes since significant enhancement in VOC content was observed in the irradiated vs. unirradiated experiments. 
(a)

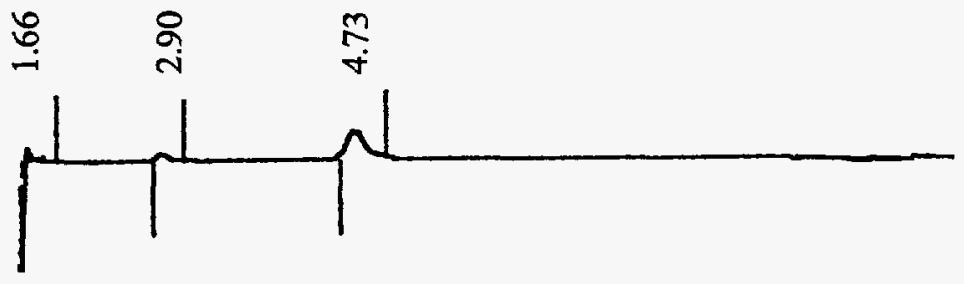

(b)

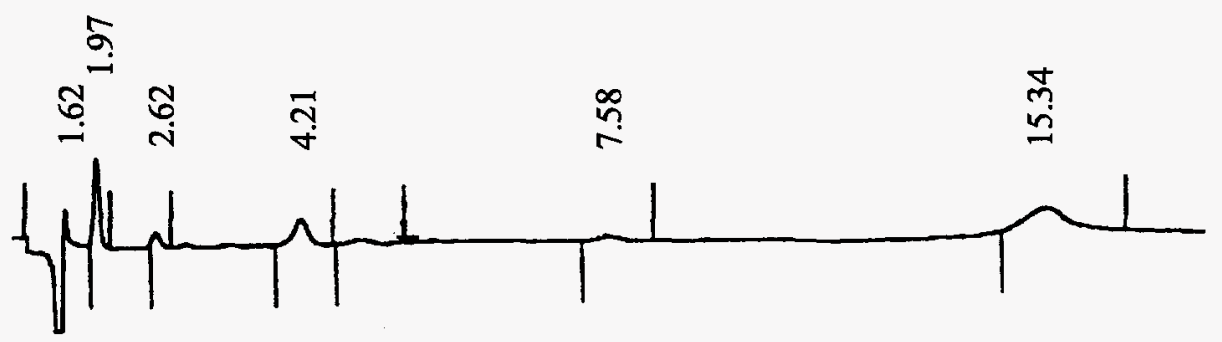

Fig. 11. Gas Chromatograms Showing the Relative Organic Content of the Gas Phase for Polyethylene at $60^{\circ} \mathrm{C}$. (a) Unirradiated and (b) Irradiated for 1 Month with a 6-mCi Am-241 Foil.

\section{Variable Dose Rate Irradiation of PVC at $60^{\circ} \mathrm{C}$}

Experiments WSRC-32 to 36 correspond to the irradiation of polyvinylchloride (PVC-1) at $60^{\circ} \mathrm{C}$. The gas phase compositions, as a function of time, are summarized in Table A.2 (blank) and Tables A.17 and A.18 in the appendix. Hydrogen and carbon dioxide formation, as a function of time, are shown in Fig. 12. Gas chromatograms of irradiated and unirradiated PVC are shown in Fig. 13. 
(a)

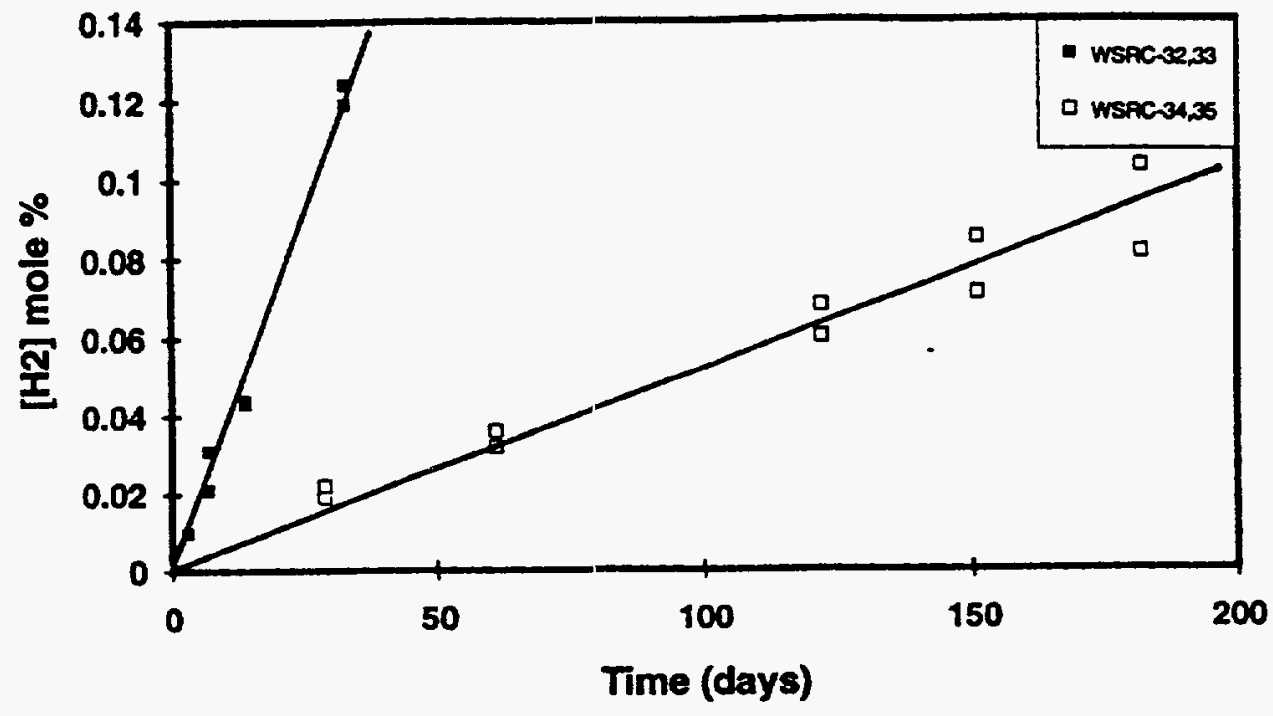

(b)

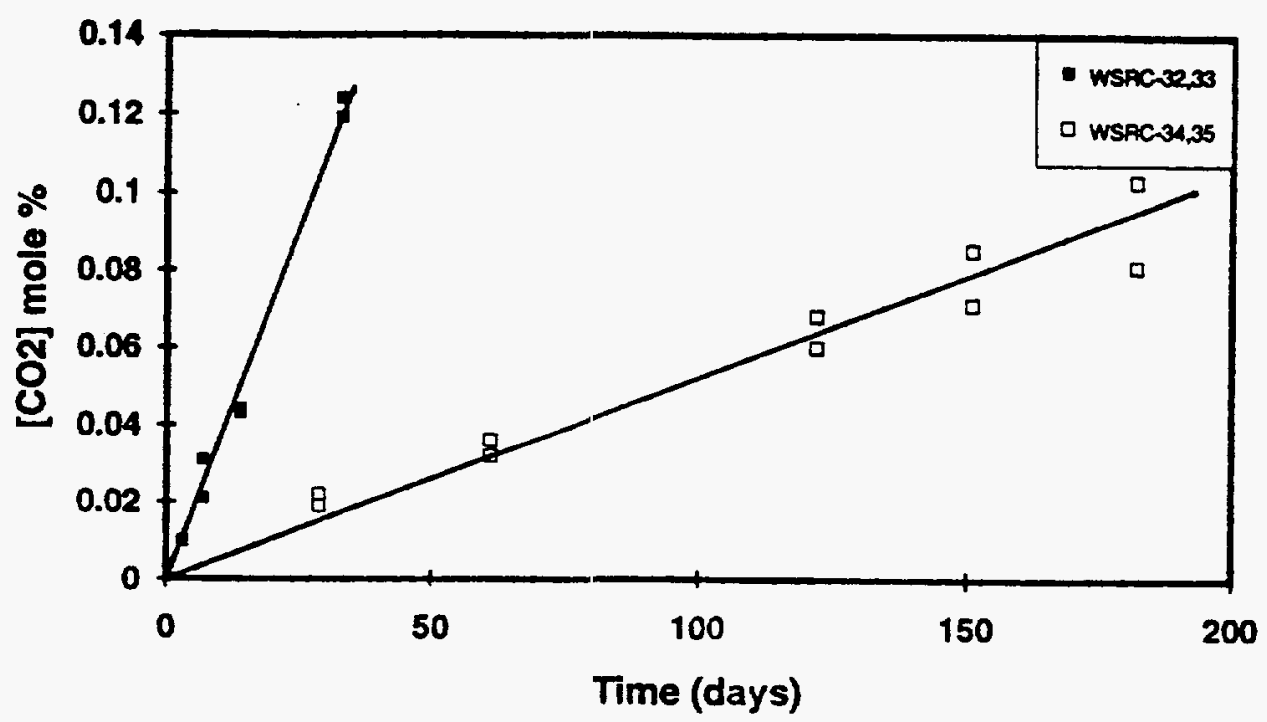

Fig. 12. Concentration of Hydrogen (a) and Carbon Dioxide (b) for Irradiated Polyvinylchloride at $60^{\circ} \mathrm{C}$

The stability of PVC at this temperature was comparable to that observed for PE. No hydrogen production was noted, approximately twice the quantity (total $<0.05 \mathrm{~mol} \%$ ) of organics were generated relative to the polyethylene system, and carbon dioxide production was $0.034 \mathrm{~mol} \%$. Weight loss increased slightly but remained small relative to that observed in the irradiated experiments. 
(a)

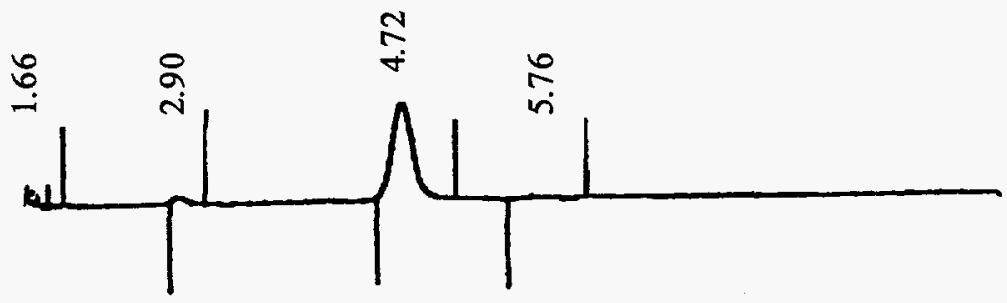

(b)

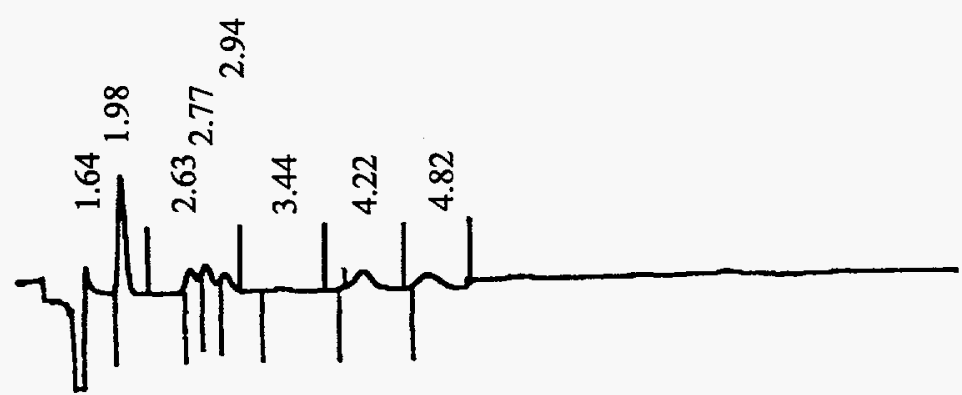

Fig. 13. Gas Chromatograms Showing the Relative Organic Content of the Gas Phase for Polyvinylchloride at $60^{\circ} \mathrm{C}$. (a) Unirradiated and (b) Irradiated for 1 Month with a 6-mCi Am-241 Foil.

The formation of hydrogen was linear with absorbed dose, with a yield of $0.50 \pm$ 0.05 molec/100 eV. (Hydrogen yield in WSRC-34 was not well correlated with time and is ignored in this analysis.) There is, therefore, no dose rate effect on hydrogen formation.

Carbon dioxide formation was linear with time with an apparent yield of $0.9 \pm 0.1$ and $1.4 \pm 0.2 \mathrm{molec} / 100 \mathrm{eV}$ for $6-$ and $0.6-\mathrm{mCi}$ foils, respectively. The apparent increase in yield for the longer, lower dose rate experiments was not purely radiolytic. The enhanced carbon dioxide production due to thermal processes was supported by the increase in oxygen consumption noted and reflected in the weight gain data. This appears to be a truly coupled effect since little carbon dioxide production was noted in the unirradiated experiments. 
The apparent yield of hydrochloric acid was 1.2 and $2.1 \mathrm{molec} / 100 \mathrm{eV}$ at the dose rates corresponding to $6-\mathrm{mCi}$ and $0.6-\mathrm{mCi} \mathrm{Am}-241$ foils. If no true dose rate effect is present, then the radiolytic yield is $1.0 \mathrm{molec} / 100 \mathrm{eV}$ (10\% less) and the thermal contribution is approximately a $10 \%$ enhancement per month for the highest dose rate.

The organic content of the gas phase was qualitatively similar to that observed for polyethylene at the same temperature. The concentration of the various species was somewhat higher, but remained low overall $(<0.05 \mathrm{~mol} \%)$.

\section{Gas Generation Due to Alpha Particle Degradation of Polyethylene and Polyvinylchloride at $100^{\circ} \mathrm{C}$}

The matrix of experiments performed at $100^{\circ} \mathrm{C}$ was identical to that done for the variable dose rate experiments at $30^{\circ} \mathrm{C}$. (See Table 6.) All experiments were done with the PE-1 and PVC-1 plastic samples.

At $100^{\circ} \mathrm{C}$, the initial gas phase was substantially altered. As with the lower temperature experiments, however, a reduction of total pressure occurred because oxygen depletion was greater than the buildup of hydrogen, carbon oxides, and organics in the gas phase. In many of the experiments, over $50 \%$ of the oxygen initially present was depleted and in some experiments as much as $90 \%$ was depleted. At this temperature, all PE samples were slightly discolored, but the PVC samples were all charcoal black in both unirradiated and irradiated systems. The organic composition of the gas phase was significantly more diverse than that noted at lower temperature and was as high as $3-5 \mathrm{~mol} \%$ of the total gas composition.

The weight change data for these experiments are tabulated in Table 11. The yield data for both PVC and PE samples are summarized in Table 12. Many of the results obtained at $100^{\circ} \mathrm{C}$, although reproducible, could not be interpreted in terms of yield values because of the nonlinearities observed in the concentration trends.

\section{Irradiation of $\mathrm{PE}$ at $100^{\circ} \mathrm{C}$}

Experiments WSRC- 37 to -45 correspond to the irradiation of polyethylene at $100^{\circ} \mathrm{C}$. The gas phase compositions for these experiments, as a function of time, are tabulated in Tables A.19 through A.22. Examples of compositional trends are given in Fig. 14. Gas chromatograms, as a function of dose rate, are shown in Fig. 15.

In the blank experiment (WSRC-45), the composition of the gas phase remained airlike (see Table A.2) with little depletion of oxygen even after eight months of exposure at $100^{\circ} \mathrm{C}$. No hydrogen formation was noted and carbon dioxide and carbon monoxide concentrations remained small at $0.05 \mathrm{~mol} \%$ and $0.006 \mathrm{~mol} \%$, respectively. Six hydrocarbon peaks and two acetone/alcohol peaks were noted in the FID chromatogram. Total volatile organic carbon composition was approximately $0.05 \mathrm{~mol} \%$, which is an order of magnitude higher than that observed at $60^{\circ} \mathrm{C}$. Weight gain in the purely thermal system was negligible $(0.0007 \mathrm{~g})$. 


\begin{tabular}{||c|c|c|c|c||}
\hline \multicolumn{6}{|c|}{ Table 11. Weight Change Data for Polyethylene and Polyvinylchloride at 100 ${ }^{\circ}$ C } \\
\hline \hline Test Number & Plastic & Before (g) & After (g) & Gain or Loss (g) \\
\hline WSRC-37 & PE & 0.66716 & 0.69924 & 0.03208 \\
\hline WSRC-38 & PE & 0.66569 & 0.68592 & 0.02023 \\
\hline WSRC-39 & PE & 0.69146 & 0.72248 & 0.03102 \\
\hline WSRC-40 & PE & 0.66993 & 0.70270 & 0.03277 \\
\hline WSRC-41 & PE & 0.69603 & 0.72214 & 0.02611 \\
\hline WSRC-42 & PE & 0.66754 & 0.69165 & 0.02411 \\
\hline WSRC-43 & PE & 0.68359 & 0.71052 & 0.02693 \\
\hline WSRC-44 & PE & 0.69328 & 0.72153 & 0.02825 \\
\hline WSRC-45 & PE (BLANK) & 0.67150 & 0.67220 & 0.0007 \\
\hline WSRC-46 & PVC & 1.49165 & 1.43538 & -0.05627 \\
\hline WSRC-47 & PVC & 1.53871 & 1.48336 & -0.05535 \\
\hline WSRC-48 & PVC & 1.63188 & 1.52940 & -0.10248 \\
\hline WSRC-49 & PVC & 1.52908 & 1.42983 & -0.09925 \\
\hline WSRC-50 & PVC & 1.52381 & 1.36785 & -.15596 \\
\hline WSRC-51 & PVC & 1.64552 & 1.46851 & -0.17701 \\
\hline WSRC-52 & PVC & 1.55503 & 1.44111 & -0.11392 \\
\hline WSRC-53 & PVC & 1.54795 & 1.42988 & -0.11807 \\
\hline WSRC-54 & PVC (BLANK) & 1.51009 & 1.35795 & -0.15214 \\
\hline \hline
\end{tabular}

In the irradiated systems, the formation of hydrogen and carbon dioxide and depletion of oxygen were often reproducible, but they were not linear with time. In all but one of the irradiated experiments, oxygen was rapidly depleted as a function of both dose rate and time (typically over $80 \%$ was depleted) to a value that was constant for the rest of the experiment. It is the depletion of oxygen, combined with increased thermal destabilization of the polyethylene plastic, that contributed most significantly to the mechanistic changes that led to the nonlinear concentration profiles.

In the shorter-term data (one- and two-month experiment set), hydrogen concentration increased with time. The apparent yield was approximately $3 \mathrm{molec} / 100 \mathrm{eV}$. At longer irradiation times, however, the hydrogen concentration increased to a maximum and subsequently decreased. (See Figs. 14 and 15.) This lack of linearity makes it inappropriate to describe the data in terms of yield data (G-values). The inflection point was approximately the point at which oxygen concentration had reached its lowest concentration. This overall effect was reproduced in each of the replicate experiments. 


\begin{tabular}{|c|c|c|c|c|c|c|}
\hline \multirow[b]{2}{*}{$\begin{array}{l}\text { Experiment } \\
\text { Designation }\end{array}$} & \multirow[b]{2}{*}{ Material } & \multirow{2}{*}{$\begin{array}{c}\text { Energy } \\
\text { Deposition } \\
\text { Rate, } \\
\text { MeV/h }\end{array}$} & \multicolumn{4}{|c|}{ Apparent Yield, molec $/ 100 \mathrm{eV}$} \\
\hline & & & $\mathrm{G}\left(\mathrm{H}_{2}\right)$ & $\mathrm{G}\left(\mathrm{CO}_{2}\right)$ & $\mathrm{G}\left(-\mathrm{O}_{2}\right)$ & $\mathrm{G}(\mathrm{HCl})$ \\
\hline WSRC-37 & PE1 & $1.0 \times 10^{12}$ & $3.3 \pm 1.3$ & $27 . \pm 5$ & 190 & $\mathrm{NA}$ \\
\hline WSRC-38 & PE1 & $1.0 \times 10^{12}$ & $2.8 \pm 0.4$ & $8.4 \pm 1.0$ & 54 & $\mathrm{NA}$ \\
\hline WSRC-39 & PE1 & $4.6 \times 10^{11}$ & ND & ND & 228 & $\mathrm{NA}$ \\
\hline WSRC-40 & PE1 & $4.6 \times 10^{11}$ & $3.5 \pm 0.6$ & $37 \pm 7$ & 245 & $\mathrm{NA}$ \\
\hline WSRC-41 & PE1 & $9.5 \times 10^{10}$ & $6.0 \pm 1.7$ & $65 \pm 14$ & 488 & $\mathrm{NA}$ \\
\hline WSRC-42 & PE1 & $9.5 \times 10^{10}$ & $2.8 \pm 1.1$ & $50 \pm 11$ & 386 & NA \\
\hline WSRC-43 & PE1 & $4.9 \times 10^{10}$ & ND & ND & 182 & NA \\
\hline WSRC-44 & PE1 & $4.9 \times 10^{10}$ & ND & ND & 802 & NA \\
\hline WSRC-45 & PE1 & Blank Test & NA & NA & NA & NA \\
\hline WSRC-46 & PVC1 & $1.0 \times 10^{12}$ & $1.1 \pm 0.1$ & $8.1 \pm .5$ & 91 & $26 \pm 3$ \\
\hline WSRC-47 & PVCl & $1.0 \times 10^{12}$ & $1.4 \pm 0.2$ & ND & 105 & $24 \pm 3$ \\
\hline WSRC-48 & PVC1 & $4.6 \times 10^{11}$ & $1.1 \pm 0.2$ & $12 \pm 1$ & 142 & $50 \pm 5$ \\
\hline WSRC-49 & PVC1 & $4.6 \times 10^{11}$ & $0.9 \pm 0.1$ & $10 \pm 1$ & 125 & $35 \pm 4$ \\
\hline WSRC-50 & PVC1 & $9.5 \times 10^{10}$ & ND & ND & 143 & $73 \pm 7$ \\
\hline WSRC-51 & PVC1 & $9.5 \times 10^{10}$ & ND & ND & 193 & $60 \pm 6$ \\
\hline WSRC-52 & PVC1 & $4.9 \times 10^{10}$ & ND & ND & 144 & $140 \pm 14$ \\
\hline WSRC-53 & PVC1 & $4.9 \times 10^{10}$ & ND & ND & 123 & $106 \pm 11$ \\
\hline WSRC-54 & PVC1 & Blank Test & NA & NA & NA & NA \\
\hline
\end{tabular}

Carbon dioxide formation and corresponding oxygen depletion were also not linear with time. Initially, carbon dioxide formation was slow. The rate accelerated greatly to a plateau and essentially remained constant for the rest of the experiment. (See Fig. 14.) The lag time or induction period was a function of absorbed dose as well as temperature. The time at which a significant increase in gas generation was noted increased as the dose rate decreased. It occurred at $20-25 \mathrm{~d}$ for the $6-\mathrm{mCi}$ foil, at $40 \mathrm{~d}$ for the $3-\mathrm{mCi}$ foil, at $90 \mathrm{~d}$ for the $0.6-\mathrm{mCi}$ foil, and at slightly longer than $90 \mathrm{~d}$ for the $0.3-\mathrm{mCi}$ foil. No such acceleration in gas production was noted when ionizing radiation was not present. Overall carbon dioxide gas production was up to ten times greater than at $60^{\circ} \mathrm{C}$, with carbon dioxide comprising over $1 \mathrm{~mol} \%$ of the final atmosphere. Oxygen depletion was still a factor of 3-5 greater than total gas formation in these systems. 
(a)

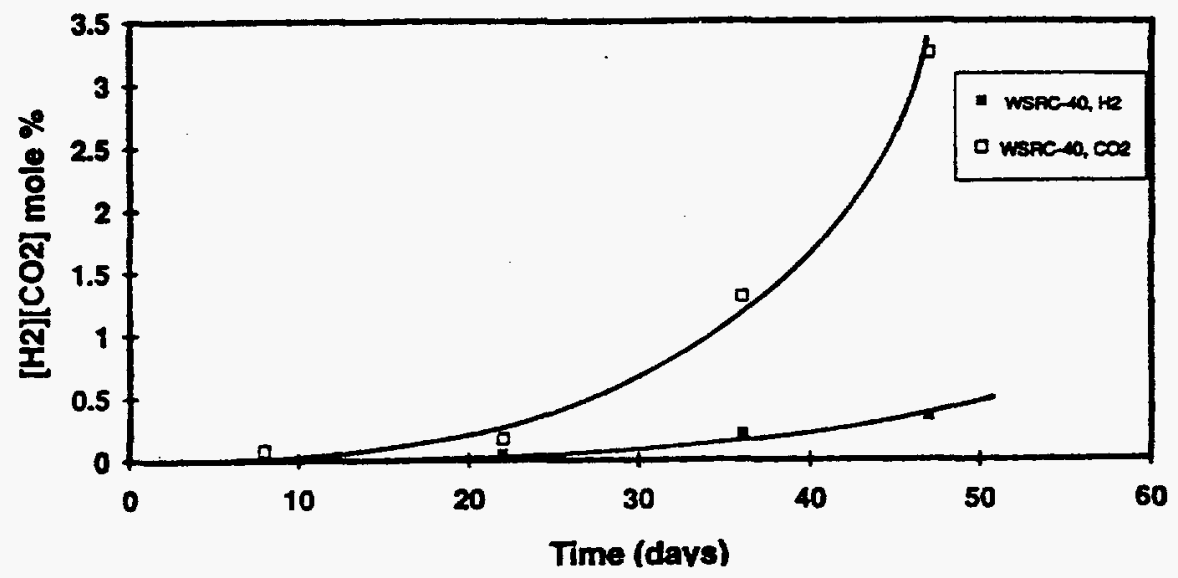

(b)

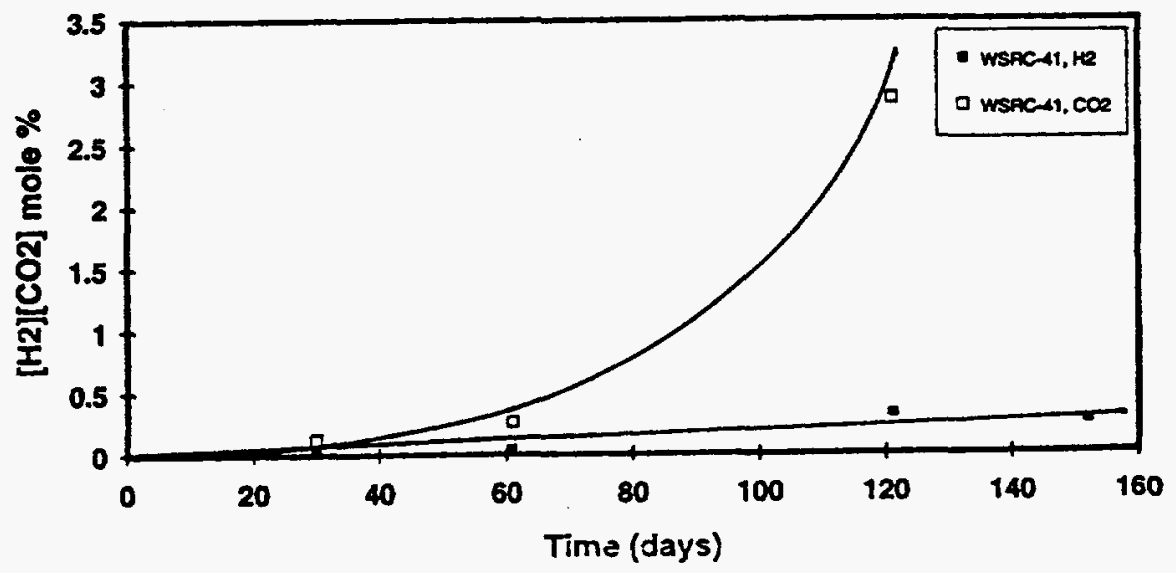

Fig. 14. Concentration of Hydrogen (a) and Carbon Dioxide (b) for Irradiated Polyethylene at $100^{\circ} \mathrm{C}$

Weight gain for all the plastic samples was between 0.02 and $0.033 \mathrm{~g}$, which was up to an order of magnitude larger than that observed at $60^{\circ} \mathrm{C}$. It was caused by truly coupled radiolytic thermal processes, with the thermal contributions dominant at longer times. In the higher dose-rate one- and two-month experiment sets, where the absorbed dose was the same, the weight gain is identical, indicating that the thermal contribution was small. In the six-month experiments, however (i.e., WSRC-41 to 44), the weight gain was also identical, although there was a difference of a factor of two in the absorbed dose. At these dose rates, the thermal contribution appears to be the dominant factor. Since no significant weight change was observed in the blank experiment, radiation was needed to induce the predominantly thermal reaction. More experimental data are needed to fully decouple the effects noted here. 
(a)

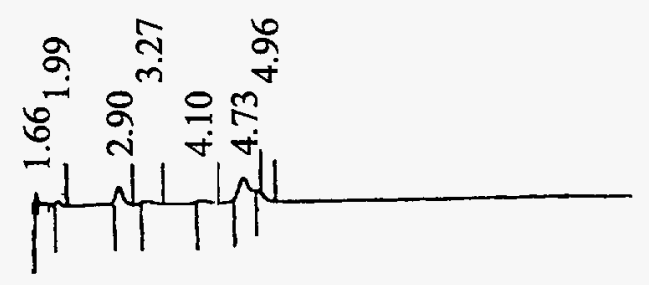

(b)

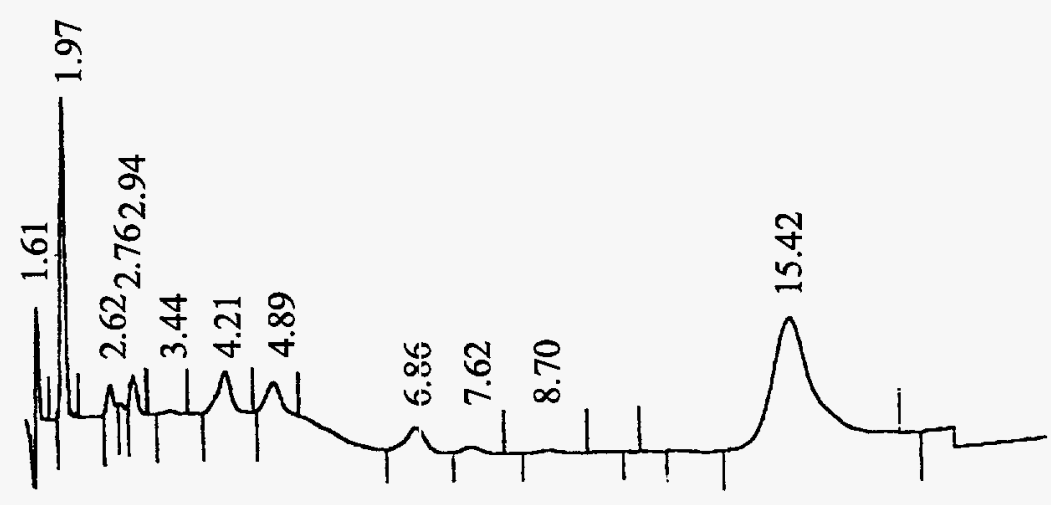

Fig. 15. Gas Chromatograms Showing the Relative Organic Content of the Gas Phase for Polyethylene at $100^{\circ} \mathrm{C}$. (a) Unirradiated and (b) Irradiated for 1 Month with a 6-mCi Am-241 Foil

The concentration of organics in the gas phase were also substantially increased at $100^{\circ} \mathrm{C}$. There were upwards of 12 distinguishable VOC peaks in the gas phase, and total concentrations were as high as $0.5 \mathrm{~mol} \%$. Dominant peaks were ethylene, derivatives of propylene, and what has been tentatively identified as acetone (15.42 minute retention time).

\section{Irradiation of $\mathrm{PVC}$ at $100^{\circ} \mathrm{C}$}

Experiments WSRC-46 to -53 pertained to the irradiation of polyvinylchloride at $100^{\circ} \mathrm{C}$. Strong discoloration, where the material turned from clear to black, occurred in both irradiated and unirradiated experiments. Black specs were frequently noted on the surface of the vessel wall and were presumably organic condensates or "ash" due to the PVC degradation. These materials, though highly discolored, were still flexible and had not lost all their plasticity by the end of the experiment. 
The gas phase compositions as a function of time are tabulated in Tables A.23 through A.26. Examples of concentration profile are given in Fig. 16. Gas chromatograms, as a function of dose rates are given in Fig. 17. As was the case for polyethylene at this temperature, the formation of hydrogen and carbon dioxide was not always linear with time. This was influenced by the large change in the oxygen concentration during the course of the experiment and the thermallyinduced destabilization of the plastic material. For this reason again, it was not always appropriate to present gas generation data in terms of radiolytic yield values. Less oxygen, only about half, was lost in the PVC experiments compared to those with PE.

(a)

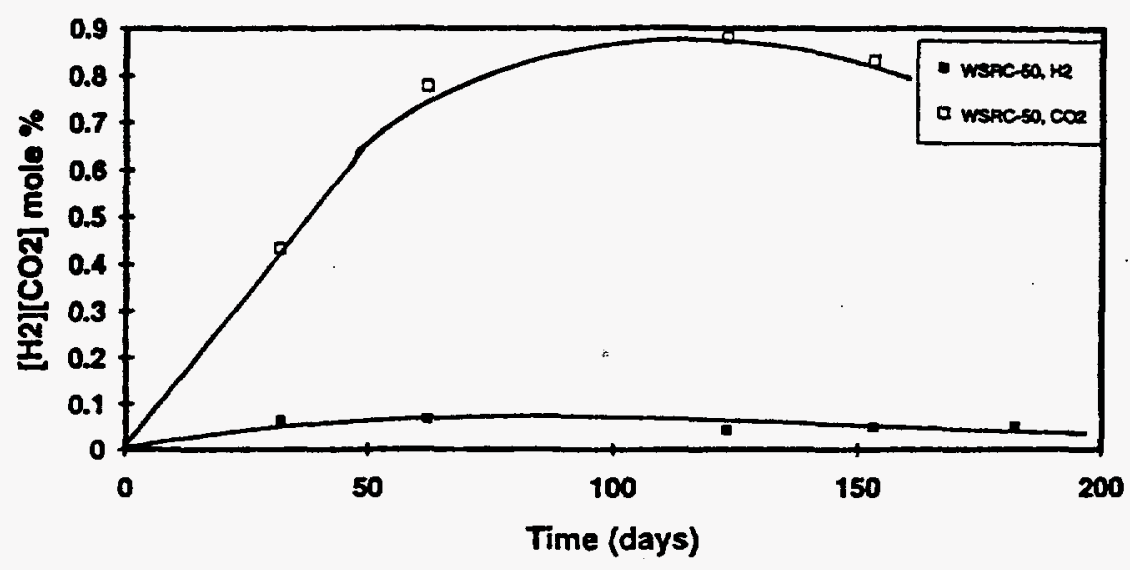

(b)

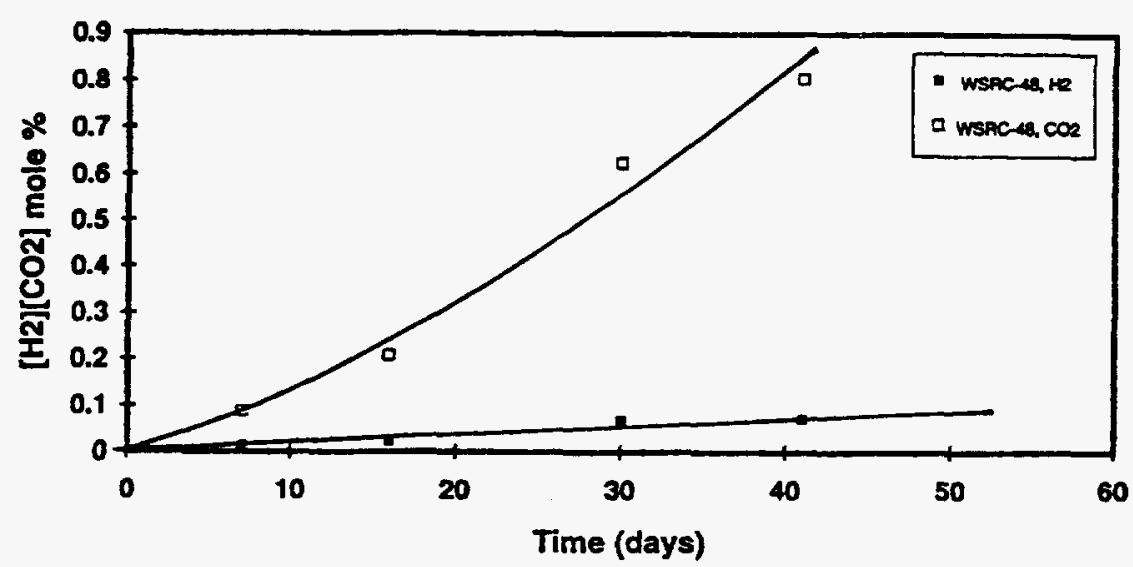

Fig. 16. Concentration of Hydrogen (a) and Carbon Dioxide (b) for Irradiated Polyvinylchloride at $100^{\circ} \mathrm{C}$ 
(a)

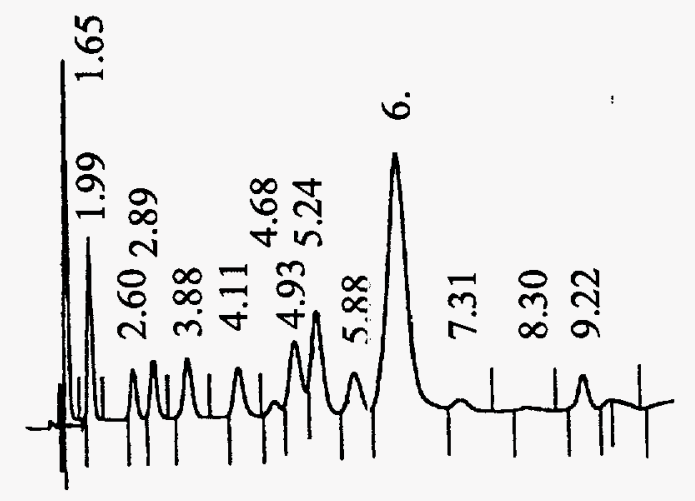

(b)

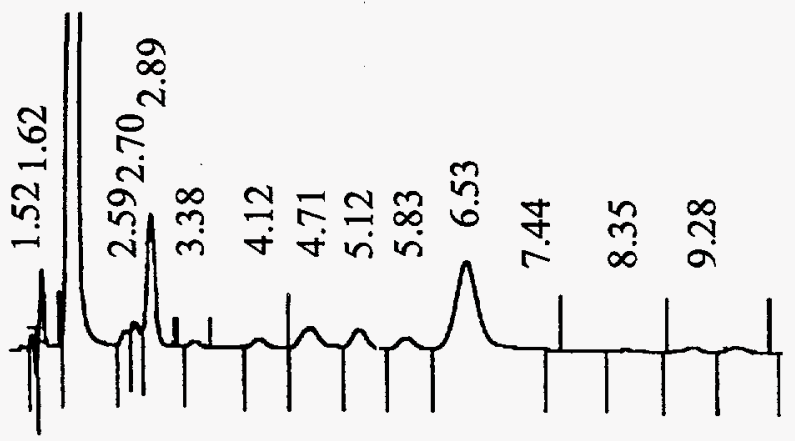

(c)

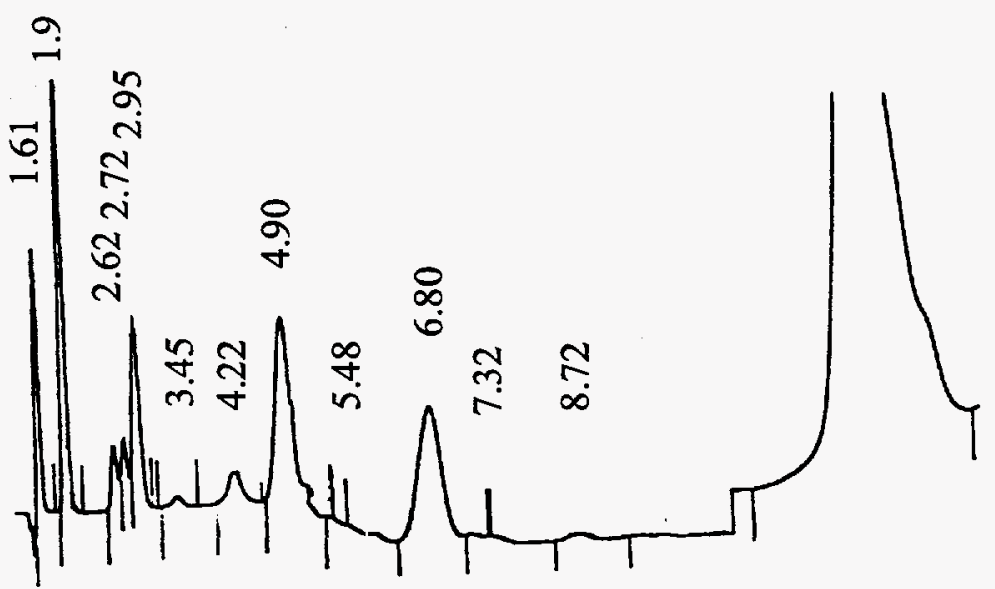

Fig. 17. Gas Chromatograms Showing the Relative Organic Content of the Gas Phase for Polyvinylchloride at $100^{\circ} \mathrm{C}$. (a) Unirradiated, (b) Irradiated for 1 Month with a $0.6-\mathrm{mC}$ i Am-241 Foil, and (c) $1-\mathrm{Month}$ with a 6-mCi Am-241 Foil. 
In the unirradiated blank experiment, WSRC-54, significant alteration of the gas phase occurred. The oxygen content was reduced to $8.4 \mathrm{~mol} \%$, and hydrogen formation was observed $(0.41 \mathrm{~mol} \%)$. Both carbon monoxide $(0.52 \mathrm{~mol} \%)$ and carbon dioxide $(0.69 \mathrm{~mol} \%)$ were generated. Over sixteen distinguishable peaks were observed in the chromatograms, corresponding to approximately $4 \mathrm{~mol} \%$ of the gas phase. The dominant organic peak was probably acetone (>80\% of the gas phase). Significant weight loss $(-0.152 \mathrm{~g})$ was also observed.

In the variable dose rate experiments, hydrogen formation was linear with irradiation time corresponding to yields of $\mathrm{G}\left(\mathrm{H}_{2}\right)$ equaling $1.2 \pm 0.2$ and $1.0 \pm 0.1$ for the 6- and 3-mCi alpha foils, respectively. At lower dose rates and longer times, hydrogen formation went through a maximum at about two months and decreased in concentration with time.

Carbon dioxide, as well as oxygen, concentration trends were not always reproducible. In the shorter, higher dose-rate experiments, concentration trends that sometimes increased and sometimes decreased were observed. Apparent yields range from 7 to greater than $10 \mathrm{molec} / 100 \mathrm{eV}$. Overall oxygen depletion was more than an order of magnitude greater than the formation of carbon dioxide. The fate of oxygen in the PVC system has not been fully established, although it is most likely associated with organic condensates rather than alteration of the PVC material itself.

Hydrochloric acid production was also greatly accelerated at $100^{\circ} \mathrm{C}$. Apparent yields were greater than $20 \mathrm{molec} / 100 \mathrm{eV}$ and did not systematically depend on dose rate, absorbed dose, or time. In fact, an increase in the dose rate appears to lower the amount of $\mathrm{HCl}$ generated. Radiolytic and thermal processes, with respect to $\mathrm{HCl}$ production, are too strongly coupled to establish a purely radiolytic yield.

The weight loss incurred was in the range of $0.05-0.18 \mathrm{~g}$ per plastic sample. This correlated more with time than absorbed dose, but was not proportional to experiment length. This may indicate that the plasticizer was being depleted or substantially altered, resulting in a slow down in the overall rate of reaction. For the lowest two dose rates investigated, which lasted 6 months, there was a decrease in weight loss of about $30 \%$ for a drop of two in absorbed dose. This is consistent with a predominantly thermal mechanism and agrees with the significant weight loss noted in the unirradiated experiments.

The organic gas phase data also reflects the strong coupling between radiolytic and thermal processes. In both the irradiated and unirradiated system, a multiplicity of peaks were noted (up to 18). Total organic content was as high as 3-5 mol \%. Increased diversity and concentration of organic transients were evident in the irradiated systems. 


\section{SUMMARY OF OBSERVATIONS AND DISCUSSION}

Our yield data compliment past studies in two ways: First, they are specific to the materials used at WSRC in packaging TRU waste. Since the same materials are used in other DOE facilities, the data generated may apply to these sites as well. Second, the data generated relate to the expected conditions (i.e., air environment, alpha particle irradiation, temperatures to $100^{\circ} \mathrm{C}$ ) during the $60-\mathrm{d}$ shipping period for TRU waste. Only a few studies have utilized alpha particle irradiation at elevated temperature, and fewer still were performed in an anoxic environment. Our observations for each of these issues are discussed in this section.

Our work addressed, in part, five issues related to radiolytic gas generation in TRU waste. These are (1) total pressure buildup, (2) general compositional trends, (3) the effect of dose rate on gas generation, (4) the effect of temperature on net yield and (5) the effect of plastic material type on gas generation.

\section{A. Buildup of Pressure Due to Irradiation of Polyethylene and Polyvinylchloride}

One of the key issues we set out to address was the issue of total pressure buildup due to alpha particle degradation of the plastic material. Radiolytic processes can add to total pressure by gas generation, but they can also lower total pressure by consuming gases present in the initial air. Change in the total pressure is a combination of these two effects that is specific to the initial environment, dose rate, and temperature at which the experiment is performed.

In all the experiments we performed, there was no increase in the total system pressure. This was readily explained by our data. Oxygen removal for each dose rate, type of plastic, and temperature was greater than the contribution to the total pressure by the hydrogen, organics, and carbon oxides generated. At 30 and $60^{\circ} \mathrm{C}$, net change in total pressure was small. At $100^{\circ} \mathrm{C}$, however, thermal/radiolytic processes that removed oxygen were greatly accelerated relative to gas generation. Here, substantial decreases in total pressure were observed.

Our results contrast with other longer-term experiments performed, where oxygen was rapidly depleted and net pressure buildup was observed. Those results, although relevant to the longterm storage of waste in the WIPP, do not relate to the transportation issue, since dose rates and exposure times are much less. Given that (1) the initial atmosphere in the waste drum is air, (2) the transport vessels are sealed for a short time span, (3) there are activity limits/restrictions on TRU waste and, (4) temperatures are usually below $50^{\circ} \mathrm{C}$, radiolytic processes are expected to help lower the pressure in the sealed waste drum. Pressure buildup due to radiolytic processes, in this context, is likely to be a non-issue for most TRU waste. For the specialized TRU wastes that may have an unusually high activity content and temperature, the overall effect of radiolysis needs to be evaluated on a case-by-case basis.

\section{B. Compositional Trends in the Gas Phase}

Our data mainly relate to compositional trends in the gas phase. It is important, however, to note that all the experiments performed were on previously unirradiated material. Gas production, in this case, was significantly influenced by the plasticizer present in the material irradiated. 
In our work, we emphasized the formation of hydrogen, carbon dioxide, and hydrochloric acid (PVC only), since these were the predominant gaseous products expected. The "best value" yields are summarized in Table 13. These data need to be qualified as initial yields until we can fully account for the effects of the plasticizer on the gas generation noted.

\begin{tabular}{|c|c|c|c|}
\hline \multicolumn{4}{|c|}{$\begin{array}{l}\text { Table 13. Best Value Radiolytic Yields for Hydrogen, Carbon Dioxide, and Hydrochloric Acid as a } \\
\text { Function of Irradiation Conditions }\end{array}$} \\
\hline \multirow{2}{*}{$\begin{array}{c}\text { Plastic Material and } \\
\text { Temp, }{ }^{\circ} \mathrm{C}\end{array}$} & \multicolumn{3}{|c|}{ Radiolytic Yields, molec/100 eV } \\
\hline & Hydrogen & Carbon Dioxide & Hydrochloric Acid \\
\hline PE1 (initial) @ 30 ${ }^{\circ} \mathrm{C}$ & $2.3 \pm 0.3$ & $2.4 \pm 0.3$ & NA \\
\hline PE1 (long-term)@ $30^{\circ} \mathrm{C}$ & $1.2 \pm 0.1$ & $3.0 \pm 0.1$ & NA \\
\hline PE2 (long-term) @ 30 ${ }^{\circ} \mathrm{C}$ & $1.8 \pm 0.2$ & $4.3 \pm 0.3$ & NA \\
\hline PE1 (initial) @60 ${ }^{\circ} \mathrm{C}$ & $1.8 \pm 0.3$ & $2.6 \pm 0.3$ & NA \\
\hline $\mathrm{PE} 1$ (initial) @ $100^{\circ} \mathrm{C}$ & $\leq 3$ & ND & NA \\
\hline PVC1 (initial) @ $30^{\circ} \mathrm{C}$ & $0.61 \pm 0.03$ & $0.8 \pm 0.1$ & $0.46 \pm 0.05$ \\
\hline PVC1 (long-term) @ $30^{\circ} \mathrm{C}$ & $0.55 \pm 0.02$ & $0.86 \pm 0.02$ & $0.42 \pm 0.05$ \\
\hline PVC2 (long-term) @ $30^{\circ} \mathrm{C}$ & $0.36 \pm 0.03$ & $0.9 \pm 0.1$ & $0.39 \pm 0.04$ \\
\hline PVC1 (initial) @60 ${ }^{\circ} \mathrm{C}$ & $0.51 \pm 0.05$ & $0.96 \pm 0.1$ & $0.85 \pm 0.1$ \\
\hline PVC1 (initial) @ $100^{\circ} \mathrm{C}$ & $1.2 \pm 0.2$ & ND & ND \\
\hline
\end{tabular}

The 30 and $60^{\circ} \mathrm{C}$ results we obtained for polyethylene compare well with those in existing literature [5-8] using low LET radiation as the source of ionizing radiation. The same major products were observed. The yield for hydrogen was somewhat lower than the values of 3.5 to 5.0 molec/100 eV typically reported in gamma/beta irradiation studies. Carbon dioxide was expected as a product because we used an oxygen-containing atmosphere [6,8]. In our experiments, we cannot differentiate between gaseous oxidation of organics to carbon dioxide and direct oxidation of carbon in the plastic. The large weight gains noted are indicative of oxygen uptake in the system, which was consistent with oxygen depletion noted in the gas phase data and that reported by others $[6,8]$.

In the PVC irradiations, there was also qualitative agreement between our results and those obtained with low LET radiation. We found the same key products, hydrogen, carbon dioxide and hydrochloric acid, that were identified by others. The hydrogen yields observed at 30 and $60^{\circ} \mathrm{C}$ were comparable to those reported in the low LET studies $\left(\mathrm{G}\left(\mathrm{H}_{2}\right)=1 \mathrm{vs} .0 .7 \mathrm{molec} / 100 \mathrm{eV}\right.$ for alpha particles). There was no direct comparison between low and high LET carbon dioxide formation because it is associated with the presence of oxygen and the plasticizer. Carbon dioxide formation in our experiments was much higher than that observed in longer-term high absorbed dose experiments [9]. It was also significantly higher than that expected at $100^{\circ} \mathrm{C}$, due to the large contribution of thermal process to gas generation. At 30 and $60^{\circ} \mathrm{C} \mathrm{HCl}$ production was within the 
broad range of values reported for high LET systems. The apparent yields noted at $100^{\circ} \mathrm{C}$, however, were significantly higher than expected due to the large thermal contribution noted. The weight change (e.g., loss) we observed was in the same direction as reported in the low LET studies [2]. We could not compare the magnitude of the weight change because there were no directly comparable results.

The results reported herein do not appear to agree with alpha irradiation results published elsewhere [9]. We found (1) carbon dioxide and hydrogen formation were approximately the same, compared with a 98:0.6 ratio, (2) essentially no temperature effect between 30 and $60^{\circ} \mathrm{C}$ and, (3) our net yields were twice as high. The differences in these results are due to the differences in gas phase composition (primarily the presence of oxygen) and our current emphasis on initial rather than longterm gas generation trends.

We also obtained qualitative information on gaseous species other than carbon dioxide, hydrogen, and hydrochloric acid. Carbon monoxide was present at concentrations of up to $10 \%$ of the carbon dioxide concentration in the final gas phase analyses made. The presence of carbon monoxide was related to the relative oxygen-to-carbon dioxide ratio and to temperature. It was present at the greater concentrations when significant oxygen depletion had occurred (e.g., at $100^{\circ} \mathrm{C}$ ). It was also qualitatively established that halogenated hydrocarbons were being generated when PVC was irradiated. This finding was expected, since chloride and organics are present in these systems and radiolytic processes are not well controlled. We did not however quantify the data on the halogenated hydrocarbon content of the gas phase.

Lastly, the organic composition of the gas phase was established for most of the experiments performed. The organic content of the gas phase, particularly at $100^{\circ} \mathrm{C}$, was greater than that anticipated, based on existing reports. The FII) gas chromatography analysis established that a wide variety of alkenes, alkanes, along with alcohols and ketones, were being generated. The cumulative concentration of VOCs in the post-irradiation gas phases increased, ranging from $<0.01 \mathrm{~mol} \%$ at $30^{\circ} \mathrm{C}$ to as high as $3-5 \mathrm{~mol} \%$ for $\mathrm{PVC}$ at $100^{\circ} \mathrm{C}$. At 30 and $60^{\circ} \mathrm{C}$ VOC production was predominantly radiolytic in nature. At $100^{\circ} \mathrm{C}$, however, thermal and radiolytic process were strongly coupled with thermal, not radiolytic, processes predominant for PVC.

\section{Effect of Dose Rate on Gas Generation}

The effect of dose rate on radiolytic processes is often not clearly delineated and may be sometimes misrepresented in data reported in the literature. To reach the same absorbed dose, the lowering of the dose rate requires longer-term experiments. It is important when interpreting data to factor in the increased environmental interactions that necessarily occur when experiments that differ in duration are compared.

To help clarify this issue, the data are: interpreted in terms of true and apparent dose-rate effects. True dose-rate effects are defined as changes in yield due to increased overlap between the tracks and spurs that are generated radiolytically on a molecular level. These overlaps were not expected in our experiments because (1) a high. LET radiation was used (dense track formation) and (2) only a factor of 20 in dose rate was being investigated. 
Apparent dose-rate effects result from coupling time-dependent interactions between the plastic material and the environment with radiolytic processes. The effects noted are caused by changes in the yield due to differences in experiment duration. These changes occur mainly because of greater thermal contributions to the net change observed. If they are additive, they can be factored out. Apparent dose-rate effects can also occur because of changes in the availability of reactants relative to the rate at which radiolytic processes are occurring. For example, in the plastic irradiations, both the diffusion of oxygen into the material and the depletion of plasticizer in the material affected the overall compositional trends noted in the gas phase.

In the variable dose-rate experiments performed, there was no clear evidence for true doserate effects. When gas generation was mostly radiolytic (e.g., $\mathrm{PE}$ at 30 and $60^{\circ} \mathrm{C}$ ) or when it appeared to be additively coupled to thermal effects (e.g., PVC at 30 and $60^{\circ} \mathrm{C}$ ), the yields of the various gases generated were essentially unchanged as the dose rate was varied. This is consistent with expectations based on the high LET nature of the incident radiation.

However, a number of apparent dose-rate effects were noted. Extending the highest dose-rate experiments at $30^{\circ} \mathrm{C}$ from one month to four resulted in a significant lowering of hydrogen, carbon dioxide, and (for PVC only) $\mathrm{HCl}$ yields. Since the only change in these experiments is irradiation time and, hence, absorbed dose, this suggests that either the materials are being degraded to a steadystate composition that is less radiolytically degradable and/or a key contributor to the net gas generation observed (i.e., the plasticizer) is being depleted. Based on the data obtained so far, the depletion of the plasticizer is the most likely contributing factor.

In the experiments at 30 and $60^{\circ} \mathrm{C}$, there were also some apparent dose-rate effects due to the presence of both thermal and radiolytic contributions to the gas generation observed. The thermal component, although slightly more pronounced in the PVC material, was small compared to the radiolytic contribution at the higher dose rates. The lower dose-rate experiments (including the unirradiated experiments) could be used to establish the thermal contribution, while the higher ones are used to establish the dependence on absorbed dose.

Apparent dose-rate effects were most pronounced in the experiments performed at $100^{\circ} \mathrm{C}$. This is readily indicated by the nonlinearity noted in the longer-term experiments performed. Not only is the plasticizer being depleted in these experiments, but the bulk composition, and, most importantly, the oxygen concentration, are not constant. This uneven supply of oxygen to the plastic material resulted in large changes in the rate of carbon dioxide production and perhaps also of hydrogen formation. Yields determined in a more constant environment are needed to avoid this complexity and provide more meaningful gas generation rates at these elevated temperatures.

\section{Effect of Temperature on Gas Generation}

There was little difference in gas generation from either plastic between 30 and $60^{\circ} \mathrm{C}$. Significant effects, however, were noted at $100^{\circ} \mathrm{C}$, as just discussed. Apparent initial yields of hydrogen increased with temperature from 1 to 3 molec/100 eV for both PVC and PE. Apparent yields of carbon dioxide were greatly accelerated by increased temperature, owing to the coupling of radiolytic and thermal effects. For $\mathrm{PVC}, \mathrm{HCl}$ production was increased by more than a factor of 20 with temperature. At $100^{\circ} \mathrm{C}$, it was not possible to determine purely radiolytic yields. 
The most significant finding from the $100^{\circ} \mathrm{C}$ experiments was the extent of coupling between radiolytic and thermal effects. The important contribution of thermal processes is readily apparent in the case of PVC, since significant changes are induced by thermal processes alone. Once in the gas phase, the volatile organic species are likely to undergo a wide array of both radiolytic and thermal reactions, leading to the increased diversity of gaseous species noted in our experiments. This process can include reactions with hydrogen, carbon dioxide, and oxygen and affect their net yields. Radiolytically-induced reactions in the gas phase cannot be excluded, even though, in our experiments, only a small volume percentage of the gas phase was exposed to significant levels of ionizing radiation (3-mm gap between the alpha particle foil and the plastic material).

A more subtle effect was noted when polyethylene was irradiated at $100^{\circ} \mathrm{C}$. Although there was little change in the unirradiated sample, even a small amount of radiation produced relatively large changes in weight gain and the organic content of the gas phase. Based on this observation, it appears that radiolytically-induced processes are adding to the net change in gas phase composition through nonlinear reaction pathways (e.g., chain reactions) that effectively magnify what would otherwise be characterized as a thermal effect.

\section{E. Gas Generation as a Function of Plastic Material Variability}

Gas generation versus plastic material was studied in two ways: (1) between two different plastics (PE and PVC) and (2) between two types of the same plastic (e.g., PE1 and PE2). The two plastics were compared in the variable-dose-rate experiments performed at all temperatures. The types of PE and PVC were compared in the four-month, material-specific experiments with irradiation at $30^{\circ} \mathrm{C}$. There were a number of experimentally significant differences in gas generation between PE and PVC. Hydrogen yields were a factor of two lower for PVC. Carbon dioxide buildup also differed by a factor of two. Oxygen depletion was consistently higher for PE than for PVC. Hydrochloric acid was only generated from irradiated PVC. Weight gain was always noted for PE and weight loss for PVC. Lastly, the overall effect of increased temperature was more pronounced for PVC than PE.

Experimentally significant differences in the gas generation were noted for types of the same plastic. They were discussed in more detail in Section III.B.3. In general, a difference of factors of two in hydrogen generation were noted for both the polyethylene and polyvinyl set of data. Carbon dioxide formation differed significantly between PE1 and PE2 but not between PVC1 and PVC2. Hydrochloric acid production was the same for both PVCs irradiated.

The differences noted within a particular plastic, although experimentally significant, are all within a factor of two and are not likely to be important in overall gas generation. The differences noted between PVC and PE, however, are significant since unique products (primarily $\mathrm{HCl}$ ) are observed, and the dependence of gas generation on temperature for the two materials vary significantly. Modeling of these data is needed to more quantitatively evaluate the effect of these differences. 


\section{FUTURE DIRECTION OF THE WORK}

Although a number of questions were answered in part by the work just reported, the following questions remain:

1. What are the threshold temperatures at which substantial increases in the gas generation rate due to coupled radiolytic-thermal degradation of WSRC-specific plastic are initiated?

2. What is the long-term gas generation profile of "reacted" plastic material?

3. Are there other materials/plastics present in WSRC TRU waste that have substantially different gas generation properties?

4. What is the gas generation rate in actual Pu-waste mixtures?

5. How can we incorporate the more basic data we are generating to model gas generation in TRU-waste drums (i.e., model validation)?

These questions may be pursued in future research activities. 


\section{ACKNOWLEDGMENTS}

The authors wish to acknowledge the important role of Marshall Looper, Dave Hobbs, and Dan McCabe, all at Westinghouse Savannah River Company, for the guidance and support provided to this project.

This work was supported in part by both operations funds from Westinghouse Savannah River Company (WSRC) and the Buried Waste Integrated Demonstration Project. Work was performed under contract W-31-109-ENG-38 at Argonne National Laboratory. 


\section{REFERENCES}

1. M. Dole and D. M. Bodily, "Reactive Intermediate in the Radiation Chemistry of Polyethylene," Adv. Chem. Ser. 66, 31-43 (1967).

2. A. Chapiro, Radiation Chemistry of Polymeric Systems, Interscience Publishers, New York (1962).

3. A. Charlesby, Radiation Chemistry, "Radiation Chemistry of Polymers," Farhatziz and M. A. J. Rodgers, Eds., VCH Publishers, New York, pp. 451-475 (1987).

4. J. W. T. Spinks and R. J. Woods, Introduction to Radiation Chemistry, Chapter 9, John Wiley and Sons, New York (1976).

5. M. Dole, Report of Symposium IX, "Chemistry and Physics of Radiation Dosimetry," U.S. Army Chemical Center, MD, p. 120 (1950).

6. A. Charlesby, Proc. Roy. Soc. (London) $\underline{\text { A215, }} 187$ (1952).

7. H. Matsuo and M. Dole, "Irradiation of Polyethylene IV. Oxidation Effects," J. Chem. Phys. $\underline{63}, 837$ (1959).

8. N. A. Slovokhotova and T. I. Vsesoyuz, Soveshchariya PO Radiatsionnoi Khim. Academy of Sciences of the U.S.S.R., Moscow, p. 263 (1958).

9. S. T. Kosiewitcz, "Gas Generation from Organic Transuranic Wastes. I. Alpha Radiolysis at Atmospheric Pressure," Nucl. Technol. 54, 92 (1981).

10. S. T. Kosiewicz, B. L. Barraclough, and A. Zerwekh, "Studies of Transuranic Waste Storage under Conditions Expected in the Waste Isolation Pilot Plant," Los Alamos National Laboratory Report LA-7931-PR, 1980.

11. S. T. Kosiewicz and A. Zerwekh, "Studies of Transuranic Waste Storage Under Conditions Expected in the Waste Isolation Pilot Plant," Los Alamos National Laboratory Report LA-8345-PR, 1980.

12. A. Zerwekh, "Gas Generation from Radiolytic Attack of TRU-Contaminated Hydrogenous Waste," Los Alamos National Laboratory Report LA-7674-MS, 1979.

13. M. A. Molecke, "Gas Generation from Transuranic Waste Degradation: Data and Summary Interpretation," Sandia National Laboratories Report SAND79-1245, 1979. 


\section{REFERE'NCES (Contd)}

14. H. A. Friedman, L. R. Dole, T. M. Gillian, and G. C. Rogers, "Radiolytic Gas Generation Rates from Hanford RHO-CAW Slucge and Double-Shell Slurry Immobilized in Grout," Oak Ridge National Laboratory Report ORNL/TM-9412, 1985.

15. N. E. Bibler, "Radiolytic Gas Production from Concrete Containing Savannah River Plant Waste," Savannah River Laboratory Report DP-1464, 1978.

16. A. R. Lappin and R. L. Hunter, Eds., "Systems Analysis, Long-Term Radionuclide Transport, and Dose Assessments, Waste Isolation Pilot Plant (WIPP), Southeastern New Mexico; March 1989," Sandia National Laboratories Report SAND89-0462, 1989.

17. L. H. Brush, "Test Plan for Laboratory and Modeling Studies of Repository and Radionuclide Chemistry for the Waste Isolation Pilot Plant," Sandia National Laboratory Report SAND90-0266, 1990.

18. D. T. Reed and S. Okajima, "Radiation Effects Studies in Support of the Waste Isolation Pilot Plant," Sandia National Laboratory, to be published.

19. D. T. Reed, S. Okajima, L. H. Brush, and M. A. Molecke,"Radiolytically-Induced Gas Production in Plutonium-Spiked WIPP Brine," in Proceedings of the Symp. on Scientific Basis for Nuclear Waste Management XVI, Vol. 294, pp. 431-438, 1992.

20. D. T. Reed, J. Hoh, J. Emery, and D. Hobbs, "Radiolytic Gas Production in the Alpha Particle Degradation of Plastics," in Proceedings of Waste Management 92, Vol. 2, pp. 10811085 (1992). 


\begin{tabular}{|c|c|c|c|}
\hline \multicolumn{4}{|c|}{$\begin{array}{l}\text { Table A.1. Summary of Ethylene Dosimetry Data for the } \\
\text { Various Am-241 Alpha Particle Foils Tested }\end{array}$} \\
\hline Foil Designation ${ }^{\mathrm{a}}$ & $\begin{array}{c}\text { Am-241 Content, } \\
\text { mCi } \\
\end{array}$ & $\begin{array}{c}\text { Duration, } \\
\text { d }\end{array}$ & $\begin{array}{c}\text { Energy Deposition } \\
\text { Rate, } \\
\text { MeV/hx10 }\end{array}$ \\
\hline $75-1$ & 0.3 & 27 & $4: 9$ \\
\hline $75-2$ & 0.3 & 27 & 5.4 \\
\hline $75-3$ & 0.3 & 27 & 5.2 \\
\hline $75-4$ & 0.3 & 27 & 4.9 \\
\hline $75-5$ & 0.3 & 27 & 5.2 \\
\hline $75-6$ & 0.3 & 27 & 4.6 \\
\hline $75-7$ & 0.3 & 27 & 4.9 \\
\hline $75-8$ & 0.3 & 27 & 4.1 \\
\hline $150-2$ & 0.6 & 15 & 9.3 \\
\hline $150-3$ & 0.6 & 15 & 9.6 \\
\hline $750-2$ & 3 & 15 & 53 \\
\hline $750-3$ & 3 & 15 & 43 \\
\hline $1500-1$ & 6 & 2.08 & 95 \\
\hline $1500-2$ & 6 & 2.09 & 95 \\
\hline $1500-3$ & 6 & 2.10 & 116 \\
\hline $1500-4$ & 6 & 2.10 & 96 \\
\hline $1500-5$ & 6 & 2.02 & 103 \\
\hline $1500-6$ & 6 & 2.03 & 100 \\
\hline $1500-7$ & 6 & 2.04 & 107 \\
\hline $1500-8$ & 6 & 2.04 & 104 \\
\hline $1500-9$ & 6 & 2.04 & 99 \\
\hline $1500-10$ & 6 & 2.04 & 115 \\
\hline $1500-11$ & 6 & 2.04 & 99 \\
\hline $1500-12$ & 6 & 2.04 & 104 \\
\hline $1500-13$ & 6 & 6.0 & 86 \\
\hline $1500-14$ & 6 & 6.0 & 83 \\
\hline $1500-15$ & 6 & 6.0 & 112 \\
\hline
\end{tabular}

${ }^{a}$ The number before the hyphen is the foil activity in $\mu \mathrm{Ci} / \mathrm{in}^{2}$. 


\begin{tabular}{|c|c|c|c||}
\hline \multicolumn{5}{|c|}{ Table A.1. Summary of Ethylene Dosimetry Data for the Various } \\
Am-241 Alpha Pqirticle Foils Tested (contd)
\end{tabular}

\begin{tabular}{|c|c|c|c|c|c|c|c|}
\hline \multirow{2}{*}{$\begin{array}{l}\text { Experiment } \\
\text { Designation } \\
\end{array}$} & \multirow[b]{2}{*}{ Plastic } & \multirow[b]{2}{*}{ Temp } & \multicolumn{5}{|c|}{ Gas Phase Composition (mol \%) ${ }^{\mathrm{b}}$} \\
\hline & & & $\mathrm{H}_{2}$ & $\mathrm{O}_{2}$ & $\mathrm{~N}_{2}$ & $\mathrm{CO}$ & $\mathrm{CO}_{2}$ \\
\hline WSRC- 9 & $\mathrm{PE}$ & $30^{\circ} \mathrm{C}$ & $\mathrm{ND}$ & 21.1 & 78.8 & ND & 0.022 \\
\hline WSRC-31 & $\mathrm{PE}$ & $60^{\circ} \mathrm{C}$ & $\mathrm{ND}$ & 21.1 & 78.9 & ND & 0.031 \\
\hline WSRC-45 & $\mathrm{PE}$ & $100^{\circ} \mathrm{C}$ & ND & 20.8 & 79.1 & .006 & .050 \\
\hline WSRC-18 & PVC & $30^{\circ} \mathrm{C}$ & $\mathrm{ND}$ & 21.6 & 78.4 & ND & .020 \\
\hline WSRC-36 & PVC & $60^{\circ} \mathrm{C}$ & ND & 21.1 & 78.9 & ND & .034 \\
\hline WSRC-54 & PVC & $100^{\circ} \mathrm{C}$ & 0.41 & 8.4 & 90.4 & 0.52 & 0.69 \\
\hline \multicolumn{8}{|c|}{$\begin{array}{l}\text { a Experiment duration was eight months. } \\
{ }^{b} \text { Uncertainty is } \pm 0.3 \text { mol } \% \text { for } \mathrm{O}_{2} \text { and } \mathrm{N}_{2} \text { and } \pm .003 \mathrm{~mol} \% \text { for } \mathrm{H}_{2}, \mathrm{CO} \text {, and } \mathrm{CO}_{2} \text {. } \\
{ }^{\mathrm{c}} \mathrm{ND}=\text { not detected, which corresponds to }<10 \mathrm{ppm} \text {. }\end{array}$} \\
\hline
\end{tabular}




\begin{tabular}{|c|c|c|c|c|c|}
\hline \multirow[b]{2}{*}{$\begin{array}{c}\text { Experiment } \\
\text { Number }\end{array}$} & \multirow[b]{2}{*}{$\begin{array}{c}\text { Duration, } \\
\mathrm{d}\end{array}$} & \multicolumn{4}{|c|}{$\mathrm{mol} \%$} \\
\hline & & $\mathrm{O}_{2}$ & $\mathrm{~N}_{2}$ & $\mathrm{H}_{2}$ & $\mathrm{CO}_{2}$ \\
\hline \multirow[t]{4}{*}{1} & 3 & 21.6 & 78.4 & NA & 0.011 \\
\hline & 7 & 21.5 & 78.5 & 0.063 & 0.034 \\
\hline & 14 & 21.1 & 78.8 & 0.048 & 0.081 \\
\hline & 33 & 20.4 & 79.3 & 0.28 & 0.292 \\
\hline \multirow[t]{4}{*}{2} & 3 & NA & NA & NA & NA \\
\hline & 7 & 21.5 & 78.5 & 0.074 & 0.014 \\
\hline & 14 & 21.1 & 78.8 & 0.154 & 0.085 \\
\hline & 33 & 20.5 & 79.2 & 0.30 & 0.270 \\
\hline
\end{tabular}

Table A.4. Gas Phase Composition for Polyethylene at $30^{\circ} \mathrm{C}$ with 3-mCi Am-241 Foils: Experiments WSRC-3 and WSRC-4

\begin{tabular}{||c|c|c|c|c|c|}
\hline \hline \multirow{4}{*}{$\begin{array}{c}\text { Experiment } \\
\text { Number }\end{array}$} & $\begin{array}{c}\text { Duration, } \\
\mathrm{d}\end{array}$ & $\mathrm{O}_{2}$ & $\mathrm{~N}_{2}$ & $\mathrm{H}_{2}$ & $\mathrm{CO}_{2}$ \\
\cline { 2 - 6 } & 7 & 21.7 & 78.3 & .032 & .034 \\
\cline { 2 - 6 } & 22 & 21.5 & 78.4 & .066 & .063 \\
\cline { 2 - 6 } & 36 & 21.2 & 78.7 & 0.123 & .132 \\
\cline { 2 - 6 } & 47 & 20.7 & 79.0 & 0.188 & .231 \\
\cline { 2 - 6 } & 61 & 20.3 & 79.3 & 0.241 & 0.321 \\
\hline \multirow{3}{*}{4} & 7 & 21.7 & 78.3 & .038 & .030 \\
\cline { 2 - 6 } & 22 & 21.5 & 78.4 & .080 & .062 \\
\cline { 2 - 6 } & 36 & 21.1 & 78.7 & 0.146 & .144 \\
\cline { 2 - 6 } & 47 & 20.7 & 79.1 & 0.221 & .253 \\
\cline { 2 - 6 } & 61 & 20.2 & 79.4 & 0.277 & .354 \\
\hline
\end{tabular}


Table A.5. Gas Phase Composition for Polyethylene at $30^{\circ} \mathrm{C}$ with 0.6-mCi Am-241 Foils: Experiments WSRC-5 and WSRC-6

\begin{tabular}{||c|c|c|c|c|c||}
\hline \hline \multirow{3}{*}{$\begin{array}{c}\text { Experiment } \\
\text { Number }\end{array}$} & \multirow{2}{*}{$\begin{array}{c}\text { Duration, } \\
\mathrm{d}\end{array}$} & \multicolumn{5}{|c||}{$\mathrm{mol} \%$} \\
\cline { 2 - 6 } & 31 & $\mathrm{O}_{2}$ & $\mathrm{~N}_{2}$ & $\mathrm{H}_{2}$ & $\mathrm{CO}_{2}$ \\
\cline { 2 - 6 } & 61 & 21.7 & 78.3 & .039 & .029 \\
\cline { 2 - 6 } & 123 & 21.5 & 78.5 & .054 & .044 \\
\cline { 2 - 6 } & 152 & 21.1 & 78.8 & 0.11 & 0.13 \\
\cline { 2 - 6 } & 181 & 20.8 & 79.0 & 0.10 & 0.17 \\
\cline { 2 - 6 } & 31 & 20.6 & 79.2 & 0.12 & 0.22 \\
\cline { 2 - 6 } & 61 & 21.7 & 78.3 & .035 & .038 \\
\cline { 2 - 6 } & 123 & 21.5 & 78.5 & .062 & .064 \\
\cline { 2 - 6 } & 152 & 21.0 & 78.8 & 0.11 & 0.16 \\
\cline { 2 - 6 } & 181 & 20.8 & 79.0 & 0.13 & 0.20 \\
\hline
\end{tabular}

Table A.6. Gas Phase Composition for Polyethylene at $30^{\circ} \mathrm{C}$ with 0.3-mCi Am-241 Foils: Experiments WSRC-7 and WSRC-8

\begin{tabular}{||c|c|c|c|c|c||}
\hline \hline \multirow{3}{*}{$\begin{array}{c}\text { Experiment } \\
\text { Number }\end{array}$} & $\begin{array}{c}\text { Duration, } \\
\mathrm{d}\end{array}$ & $\mathrm{O}_{2}$ & $\mathrm{~N}_{2}$ & $\mathrm{H}_{2}$ & $\mathrm{CO}_{2}$ \\
\cline { 2 - 6 } & 58 & 21.6 & 78.4 & .025 & $\mathrm{~N} / \mathrm{A}$ \\
\cline { 2 - 6 } & 93 & 21.6 & 78.4 & .035 & .034 \\
\cline { 2 - 6 } & 121 & 21.5 & 78.4 & .060 & .050 \\
\cline { 2 - 6 } & 150 & 21.3 & 78.6 & .060 & .066 \\
\cline { 2 - 6 } & 182 & 21.3 & 78.6 & .080 & .089 \\
\hline \multirow{3}{*}{8} & 58 & 21.5 & 78.4 & .030 & .030 \\
\cline { 2 - 6 } & 93 & 21.2 & & .046 & .049 \\
\cline { 2 - 6 } & 121 & 21.2 & 78.8 & .064 & .068 \\
\cline { 2 - 6 } & 150 & 20.9 & 79.0 & .080 & .091 \\
\cline { 2 - 6 } & 182 & 20.8 & 79.1 & .095 & .119 \\
\hline
\end{tabular}




\begin{tabular}{|c|c|c|c|c|c|}
\hline \multicolumn{6}{|c|}{$\begin{array}{l}\text { Table A.7. Gas Phase Composition for Polyvinylchloride at } 30^{\circ} \mathrm{C} \text { with } 6-\mathrm{mCi} \mathrm{Am}-241 \text { Foils: } \\
\text { Experiments WSRC-10 and WSRC-11 }\end{array}$} \\
\hline \multirow[b]{2}{*}{$\begin{array}{l}\text { Experiment } \\
\text { Number }\end{array}$} & \multirow[b]{2}{*}{$\begin{array}{c}\text { Duration, } \\
\quad \mathrm{d}\end{array}$} & \multicolumn{4}{|c|}{$\mathrm{mol} \%$} \\
\hline & & $\mathrm{O}_{2}$ & $\mathrm{~N}_{2}$ & $\mathrm{H}_{2}$ & $\mathrm{CO}_{2}$ \\
\hline \multirow[t]{4}{*}{10} & 3 & 21.6 & 78.4 & NA & 0.0090 \\
\hline & 7 & 21.7 & 78.3 & 0.017 & 0.023 \\
\hline & 14 & 21.3 & 78.7 & 0.032 & 0.042 \\
\hline & 33 & 21.0 & 78.8 & 0.08 & 0.112 \\
\hline \multirow[t]{4}{*}{11} & 3 & NA & NA & NA & NA \\
\hline & 7 & 21.7 & 78.2 & 0.006 & 0.033 \\
\hline & 14 & 21.3 & 78.7 & 0.029 & 0.031 \\
\hline & 33 & 21.2 & 78.7 & 0.07 & 0.092 \\
\hline
\end{tabular}

Table A.8. Gas Phase Composition of Polyvinylchloride at $30^{\circ} \mathrm{C}$ with $3-\mathrm{mCi} \mathrm{Am}-241$ Foils: Experiments WSRC-12 and WSRC-13

\begin{tabular}{||c|c|c|c|c|c|}
\hline \hline \multirow{3}{*}{$\begin{array}{c}\text { Experiment } \\
\text { Number }\end{array}$} & \multirow{2}{*}{$\begin{array}{c}\text { Duration, } \\
\mathrm{d}\end{array}$} & $\mathrm{O}_{2}$ & $\mathrm{~N}_{2}$ & $\mathrm{H}_{2}$ & $\mathrm{CO}_{2}$ \\
\cline { 2 - 6 } & 7 & 21.65 & 78.3 & .009 & .0091 \\
\cline { 2 - 6 } & 16 & 21.6 & 78.3 & .015 & .023 \\
\cline { 2 - 6 } & 30 & 21.4 & 78.5 & .041 & .047 \\
\cline { 2 - 6 } & 41 & 21.4 & 78.5 & .048 & .070 \\
\hline \multirow{3}{*}{13} & 7 & 21.5 & 78.5 & .008 & .016 \\
\cline { 2 - 6 } & 16 & 21.5 & 78.4 & .023 & .031 \\
\cline { 2 - 6 } & 30 & 21.5 & 78.4 & .024 & .056 \\
\cline { 2 - 6 } & 41 & 21.4 & 78.5 & .041 & .083 \\
\hline
\end{tabular}


Table A.9. Gas Phase Composition for Polyvinylchloride at $30^{\circ} \mathrm{C}$ with 0.6-mCi Am-241 Foils: Experiments WSRC-14 and WSRC-15

\begin{tabular}{||c|c|c|c|c|c||}
\hline \multirow{4}{*}{$\begin{array}{c}\text { Experiment } \\
\text { Number }\end{array}$} & $\begin{array}{c}\text { Duration, } \\
\mathrm{d}\end{array}$ & $\mathrm{O}_{2}$ & $\mathrm{~N}_{2}$ & $\mathrm{H}_{2}$ & $\mathrm{CO}_{2}$ \\
\cline { 2 - 6 } & 31 & 21.6 & 78.3 & .015 & .018 \\
\cline { 2 - 6 } & 61 & 21.5 & 78.4 & .011 & .019 \\
\cline { 2 - 6 } & 123 & 21.5 & 78.4 & .021 & .042 \\
\cline { 2 - 6 } & 152 & 21.4 & 78.5 & .027 & .048 \\
\cline { 2 - 6 } & 181 & 21.3 & 78.6 & .032 & .056 \\
\hline \multirow{3}{*}{15} & 31 & 21.7 & 78.3 & .0080 & .009 \\
\cline { 2 - 7 } & 61 & 21.6 & 78.4 & .0080 & .0154 \\
\cline { 2 - 6 } & 123 & 21.6 & 78.4 & .017 & .030 \\
\cline { 2 - 6 } & 152 & 21.5 & 78.5 & .020 & .040 \\
\cline { 2 - 6 } & 181 & 21.4 & 78.5 & .034 & .044 \\
\hline
\end{tabular}

Table A.10. Gas Phase Composition for Polyvinylchloride at $30^{\circ} \mathrm{C}$ with 0.3-mCi Am-241 Foils: Experiments WSRC-16 and WSRC-17

\begin{tabular}{|c|c|c|c|c|c|}
\hline \multirow{2}{*}{$\begin{array}{c}\text { Experiment } \\
\text { Number }\end{array}$} & \multirow{2}{*}{$\begin{array}{c}\text { Duration, } \\
\mathrm{d}\end{array}$} & \multicolumn{4}{|c|}{$\mathrm{mol} \%$} \\
\hline & & $\mathrm{O}_{2}$ & $\mathrm{~N}_{2}$ & $\mathrm{H}_{2}$ & $\mathrm{CO}_{2}$ \\
\hline \multirow[t]{5}{*}{16} & 58 & 21.8 & 78.2 & .005 & .021 \\
\hline & 93 & 21.4 & 78.5 & .008 & .027 \\
\hline & 121 & 21.6 & 78.3 & .010 & .031 \\
\hline & 150 & 21.4 & 78.5 & NA & .039 \\
\hline & 182 & NA & NA & NA & NA \\
\hline \multirow[t]{5}{*}{17} & 58 & 21.7 & 78.2 & .0045 & .020 \\
\hline & 93 & 21.6 & 78.4 & .008 & .025 \\
\hline & 121 & 21.7 & 78.3 & .0074 & .028 \\
\hline & 150 & 21.5 & 78.5 & .010 & .033 \\
\hline & 182 & 21.5 & 78.4 & .011 & .039 \\
\hline
\end{tabular}




\begin{tabular}{|c|c|c|c|c|c|}
\hline \multicolumn{6}{|c|}{$\begin{array}{l}\text { Table A.11. Gas Phase Composition of Polyethylene-1 at } 30^{\circ} \mathrm{C} \text { with 6-mCi Am-241 Foils: } \\
\text { Experiments WSRC-19 and WSRC-20 }\end{array}$} \\
\hline \multirow[b]{2}{*}{$\begin{array}{c}\text { Experiment } \\
\text { Number }\end{array}$} & \multirow[b]{2}{*}{$\begin{array}{c}\text { Duration, } \\
\mathrm{d}\end{array}$} & \multicolumn{4}{|c|}{$\mathrm{mol} \%$} \\
\hline & & $\mathrm{O}_{2}$ & $\mathrm{~N}_{2}$ & $\mathrm{H}_{2}$ & $\mathrm{CO}_{2}$ \\
\hline \multirow[t]{7}{*}{19} & 7 & 21.6 & 78.3 & .052 & .033 \\
\hline & 15 & 21.3 & 78.5 & .11 & .098 \\
\hline & 29 & 20.7 & 78.9 & .20 & .25 \\
\hline & 61 & 19.2 & 79.8 & .37 & .64 \\
\hline & 89 & 18.1 & 80.4 & .49 & .97 \\
\hline & 120 & 17.2 & 80.9 & .57 & 1.3 \\
\hline & 120 & 17.1 & 81.0 & .56 & 1.3 \\
\hline \multirow[t]{7}{*}{20} & 7 & 21.6 & 78.4 & .061 & .031 \\
\hline & 15 & 21.4 & 78.5 & 0.12 & .076 \\
\hline & 29 & 20.9 & 78.9 & 0.21 & 0.194 \\
\hline & 61 & 19.5 & 79.6 & 0.38 & .53 \\
\hline & 89 & 18.6 & 80.1 & 0.47 & .81 \\
\hline & 120 & 17.7 & 80.7 & .55 & 1.10 \\
\hline & 120 & 17.7 & 80.7 & .54 & 1.1 \\
\hline
\end{tabular}




\begin{tabular}{|c|c|c|c|c|c|}
\hline \multicolumn{6}{|c|}{$\begin{array}{l}\text { Table A.12. Gas Phase Composition of Polyethylene-2 at } 30^{\circ} \mathrm{C} \text { with 6-mCi Am-241 Foils: } \\
\text { Experiments WSRC-21 and WSRC-22 }\end{array}$} \\
\hline \multirow[b]{2}{*}{$\begin{array}{l}\text { Experiment } \\
\text { Number }\end{array}$} & \multirow[b]{2}{*}{$\begin{array}{c}\text { Duration, } \\
\mathrm{d}\end{array}$} & \multicolumn{4}{|c|}{$\mathrm{mol} \%$} \\
\hline & & $\mathrm{O}_{2}$ & $\mathrm{~N}_{2}$ & $\mathrm{H}_{2}$ & $\mathrm{CO}_{2}$ \\
\hline \multirow[t]{7}{*}{21} & 7 & 21.3 & 78.6 & .093 & .054 \\
\hline & 15 & 20.9 & 79.0 & 0.18 & .150 \\
\hline & 29 & 20.0 & 79.6 & 0.29 & .363 \\
\hline & 61 & 17.7 & 80.8 & 0.57 & .95 \\
\hline & 89 & 15.8 & 82.0 & 0.76 & 1.50 \\
\hline & 120 & 13.9 & 83.2 & .87 & 2.0 \\
\hline & 120 & 13.9 & 83.2 & .87 & 2.0 \\
\hline \multirow[t]{7}{*}{22} & 7 & 21.4 & 78.6 & .079 & .048 \\
\hline & 15 & 21.0 & 78.9 & 0.15 & 0.14 \\
\hline & 29 & 20.3 & 79.4 & 0.27 & .311 \\
\hline & 61 & 18.3 & 80.4 & 0.50 & 0.81 \\
\hline & 89 & 16.9 & 81.2 & 0.67 & 1.24 \\
\hline & 120 & 15.4 & 82.1 & .78 & 1.7 \\
\hline & 120 & 15.4 & 82.1 & .78 & 1.7 \\
\hline
\end{tabular}




\begin{tabular}{|c|c|c|c|c|c|}
\hline \multirow{2}{*}{$\begin{array}{c}\text { Experiment } \\
\text { Number }\end{array}$} & \multirow{2}{*}{$\begin{array}{c}\text { Duration, } \\
\text { d }\end{array}$} & \multicolumn{4}{|c|}{$\mathrm{mol} \%$} \\
\hline & & $\mathrm{O}_{2}$ & $\mathrm{~N}_{2}$ & $\mathrm{H}_{2}$ & $\mathrm{CO}_{2}$ \\
\hline \multirow[t]{6}{*}{23} & 7 & 21.7 & 78.3 & .012 & .018 \\
\hline & 14 & 21.6 & 78.4 & .024 & .043 \\
\hline & 28 & 21.3 & 78.6 & .054 & .072 \\
\hline & 60 & 20.8 & 78.9 & 0.12 & 0.17 \\
\hline & 88 & 20.4 & 79.2 & 0.18 & .261 \\
\hline & 124 & 19.9 & 79.5 & 0.25 & .390 \\
\hline \multirow[t]{6}{*}{24} & 7 & 21.7 & 78.3 & .012 & .012 \\
\hline & 14 & 21.5 & 78.4 & 0.24 & .030 \\
\hline & 28 & 21.3 & 78.6 & .053 & .077 \\
\hline & 60 & 20.7 & 79.0 & 0.12 & .18 \\
\hline & 88 & 20.3 & 79.3 & 0.19 & .27 \\
\hline & 124 & 19.6 & 79.8 & 0.25 & .40 \\
\hline
\end{tabular}


Table A.14. Gas Phase Composition for Material-Specific Irradiation of Polyvinylchloride-2 at $30^{\circ} \mathrm{C}$ with 6-mCi Am-241 Foils: Experiments WSRC-25 and WSRC-26

\begin{tabular}{||c|c|c|c|c|c||}
\hline \multirow{3}{*}{$\begin{array}{c}\text { Experiment } \\
\text { Number }\end{array}$} & \multirow{4}{*}{$\begin{array}{c}\text { Duration, } \\
\mathrm{d}\end{array}$} & $\mathrm{O}_{2}$ & $\mathrm{~N}_{2}$ & $\mathrm{H}_{2}$ & $\mathrm{CO}_{2}$ \\
\cline { 2 - 6 } & 7 & 21.7 & 78.3 & .009 & .018 \\
\cline { 2 - 6 } & 14 & 21.5 & 78.4 & .026 & .043 \\
\cline { 2 - 6 } & 28 & 21.3 & 78.6 & .063 & .072 \\
\cline { 2 - 6 } & 60 & 20.6 & 79.1 & 0.10 & 0.17 \\
\cline { 2 - 6 } & 88 & 20.1 & 79.6 & 0.13 & .261 \\
\cline { 2 - 6 } & 124 & 19.6 & 79.9 & 0.16 & .390 \\
\hline \multirow{3}{*}{26} & 7 & 21.6 & 78.4 & .012 & .022 \\
\cline { 2 - 6 } & 14 & 21.4 & 78.5 & .032 & .046 \\
\cline { 2 - 6 } & 28 & 21.1 & 78.8 & .058 & .095 \\
\cline { 2 - 6 } & 60 & 20.1 & 79.6 & 0.11 & 0.23 \\
\cline { 2 - 6 } & 88 & 19.4 & 80.1 & 0.15 & .36 \\
\cline { 2 - 6 } & 124 & 18.7 & 80.6 & 0.19 & .53 \\
\hline
\end{tabular}

Table A.15. Gas Phase Composition for Polyethylene at $60^{\circ} \mathrm{C}$ with 6-mCi Am-241 Foils: Experiments WSRC-27 and WSRC-28

\begin{tabular}{||c|c|c|c|c|c||}
\hline \hline \multirow{3}{*}{$\begin{array}{c}\text { Experiment } \\
\text { Number }\end{array}$} & \multirow{2}{*}{$\begin{array}{c}\text { Duration, } \\
\mathrm{d}\end{array}$} & \multicolumn{4}{|c|}{$\mathrm{mol} \%$} \\
\cline { 2 - 6 } & 3 & $\mathrm{O}_{2}$ & $\mathrm{~N}_{2}$ & $\mathrm{H}_{2}$ & $\mathrm{CO}_{2}$ \\
\cline { 2 - 6 } & 7 & 21.7 & 78.3 & $\mathrm{NA}$ & 0.013 \\
\cline { 2 - 6 } & 14 & 22.0 & 78.0 & 0.064 & 0.036 \\
\cline { 2 - 6 } & 33 & 21.1 & 78.9 & 0.049 & 0.085 \\
\hline \multirow{3}{*}{28} & 3 & 20.0 & 79.7 & 0.229 & 0.31 \\
\cline { 2 - 6 } & 7 & $\mathrm{NA}$ & $\mathrm{NA}$ & $\mathrm{NA}$ & $\mathrm{NA}$ \\
\cline { 2 - 6 } & 14 & 21.6 & 78.4 & 0.070 & 0.031 \\
\cline { 2 - 6 } & 33 & 21.2 & 78.8 & 0.123 & 0.073 \\
\cline { 2 - 6 } & 19.9 & 79.7 & 0.244 & 0.32 \\
\hline
\end{tabular}




\begin{tabular}{|c|c|c|c|c|c|}
\hline \multicolumn{6}{|c|}{$\begin{array}{l}\text { Table A.16. Gas Phase Composition for Polyethylene at } 60^{\circ} \mathrm{C} \text { with } 0.6-\mathrm{mCi} \text { Am-241 Foils: } \\
\text { Experiments WSRC-29 and WSRC-30 }\end{array}$} \\
\hline \multirow[b]{2}{*}{$\begin{array}{l}\text { Experiment } \\
\text { Number }\end{array}$} & \multirow[b]{2}{*}{$\begin{array}{l}\text { Duration, } \\
\mathrm{d}\end{array}$} & \multicolumn{4}{|c|}{$\mathrm{mol} \%$} \\
\hline & & $\mathrm{O}_{2}$ & $\mathrm{~N}_{2}$ & $\mathrm{H}_{2}$ & $\mathrm{CO}_{2}$ \\
\hline \multirow[t]{5}{*}{29} & 29 & 21.6 & 78.4 & .029 & .015 \\
\hline & 61 & 21.4 & 78.6 & .049 & .041 \\
\hline & 122 & 20.6 & 79.1 & .084 & .113 \\
\hline & 151 & 20.5 & 79.4 & .089 & .152 \\
\hline & 182 & 20.1 & 79.7 & .094 & .186 \\
\hline \multirow[t]{5}{*}{30} & 29 & 21.6 & 78.4 & .029 & .017 \\
\hline & 61 & 21.3 & 78.6 & .048 & .040 \\
\hline & 122 & 20.7 & 79.2 & .072 & .103 \\
\hline & 151 & 20.4 & 79.4 & .077 & .137 \\
\hline & 182 & 20.2 & 79.6 & .084 & .163 \\
\hline
\end{tabular}

Table A.17. Gas Phase Composition for Polyvinylchloride at $60^{\circ} \mathrm{C}$ with 6-mCi Am-241 Foils: Experiments WSRC-32 and WSRC-33

\begin{tabular}{||c|c|c|c|c|c||}
\hline \multirow{3}{*}{$\begin{array}{c}\text { Experiment } \\
\text { Number }\end{array}$} & $\begin{array}{c}\text { Euration, } \\
\mathrm{d}\end{array}$ & $\mathrm{O}_{2}$ & $\mathrm{~N}_{2}$ & $\mathrm{H}_{2}$ & $\mathrm{CO}_{2}$ \\
\cline { 2 - 6 } & 3 & 21.6 & 78.4 & $\mathrm{NA}$ & 0.010 \\
\hline \multirow{3}{*}{32} & 7 & 21.5 & 78.4 & 0.021 & 0.021 \\
\cline { 2 - 6 } & 14 & 21.3 & 78.7 & 0.02 & 0.044 \\
\cline { 2 - 6 } & 33 & 21.0 & 78.8 & 0.064 & 0.124 \\
\hline \multirow{3}{*}{33} & 3 & $\mathrm{NA}$ & $\mathrm{NA}$ & $\mathrm{NA}$ & $\mathrm{NA}$ \\
\cline { 2 - 6 } & 7 & 22.0 & 78.0 & 0.012 & 0.031 \\
\cline { 2 - 6 } & 14 & 21.2 & 78.7 & 0.030 & 0.043 \\
\cline { 2 - 6 } & 33 & 21.0 & 78.9 & 0.068 & 0.119 \\
\hline
\end{tabular}


Table A.18. Gas Phase Composition for Polyvinylchloride at $60^{\circ} \mathrm{C}$ with 0.6-mCi Am-241 Foils: Experiments WSRC-34 and WSRC-35

\begin{tabular}{||c|c|c|c|c|c||}
\hline \multirow{3}{*}{$\begin{array}{c}\text { Experiment } \\
\text { Number }\end{array}$} & \multirow{2}{*}{$\begin{array}{c}\text { Duration, } \\
\mathrm{d}\end{array}$} & $\mathrm{O}_{2}$ & $\mathrm{~N}_{2}$ & $\mathrm{H}_{2}$ & $\mathrm{CO}_{2}$ \\
\cline { 2 - 6 } & 29 & 21.8 & 78.2 & .003 & .022 \\
\cline { 2 - 6 } & 61 & 21.7 & 78.3 & .008 & .036 \\
\cline { 2 - 6 } & 122 & 21.6 & 78.4 & .020 & .060 \\
\cline { 2 - 6 } & 151 & 21.5 & 78.5 & .012 & .071 \\
\cline { 2 - 6 } & 182 & 21.4 & 78.6 & .015 & .081 \\
\hline \multirow{3}{*}{35} & 29 & 21.6 & 78.4 & .005 & .019 \\
\cline { 2 - 6 } & 61 & 21.4 & 78.5 & .009 & .032 \\
\cline { 2 - 6 } & 122 & 21.1 & 78.8 & .017 & .068 \\
\cline { 2 - 6 } & 151 & 20.9 & 79.0 & .021 & .085 \\
\cline { 2 - 6 } & 182 & 20.7 & 79.2 & .035 & .103 \\
\hline
\end{tabular}

Table A.19. Gas Phase Composition for Polyethylene at $100^{\circ} \mathrm{C}$ with 6-mCi Am-241 Foils: Experiments WSRC-37 and WSRC-38

\begin{tabular}{||c|c|c|c|c|c||}
\hline \multirow{3}{*}{$\begin{array}{c}\text { Experiment } \\
\text { Number }\end{array}$} & $\begin{array}{c}\text { Duration, } \\
\mathrm{d}\end{array}$ & $\mathrm{O}_{2}$ & $\mathrm{~N}_{2}$ & $\mathrm{H}_{2}$ & $\mathrm{CO}_{2}$ \\
\cline { 2 - 6 } & 3 & 21.5 & 78.5 & $\mathrm{NA}$ & 0.039 \\
\cline { 2 - 6 } & 7 & 21.4 & 78.6 & $\mathrm{NA}$ & 0.068 \\
\cline { 2 - 6 } & 14 & 19.1 & 80.6 & 0.025 & 0.312 \\
\cline { 2 - 6 } & 33 & 0.9 & 95.8 & 0.4 & 3.3 \\
\hline \multirow{3}{*}{38} & 3 & $\mathrm{NA}$ & $\mathrm{NA}$ & $\mathrm{NA}$ & $\mathrm{NA}$ \\
\cline { 2 - 6 } & 7 & 21.4 & 78.5 & 0.103 & 0.109 \\
\cline { 2 - 6 } & 14 & 19.5 & 80.2 & 0.214 & 0.294 \\
\cline { 2 - 6 } & 33 & 15.9 & 83.1 & 0.354 & 1.02 \\
\hline
\end{tabular}




\begin{tabular}{|c|c|c|c|c|c|}
\hline \multirow{2}{*}{$\begin{array}{c}\text { Experiment } \\
\text { Number }\end{array}$} & \multirow{2}{*}{$\begin{array}{c}\text { Duration, } \\
\mathrm{d}\end{array}$} & \multicolumn{4}{|c|}{$\mathrm{mol} \mathrm{\%}$} \\
\hline & & $\mathrm{O}_{2}$ & $\mathrm{~N}_{2}$ & $\mathrm{H}_{2}$ & $\mathrm{CO}_{2}$ \\
\hline \multirow[t]{5}{*}{39} & 8 & 21.2 & 78.7 & .032 & .099 \\
\hline & 22 & 20.6 & 79.2 & .045 & .175 \\
\hline & 36 & 15.2 & 84.0 & 0.186 & .867 \\
\hline & 47 & 3.88 & 93.2 & .045 & 2.89 \\
\hline & 61 & 2.85 & 94.0 & .040 & 3.14 \\
\hline \multirow[t]{5}{*}{40} & 8 & 21.2 & 78.7 & .035 & .078 \\
\hline & 22 & 20.5 & 79.4 & .045 & .170 \\
\hline & 36 & 12.2 & 86.5 & 0.207 & 1.30 \\
\hline & 47 & 2.48 & 94.3 & 0.35 & 3.25 \\
\hline & 61 & 1.73 & 94.8 & 0.32 & 3.44 \\
\hline
\end{tabular}

Table A.21. Gas Phase Composition for Polyethylene at $100^{\circ} \mathrm{C}$ with 0.6-mCi Am-241 Foils: Experiments WSRC-41 and WSRC-42

\begin{tabular}{||c|c|c|c|c|c||}
\hline \multirow{3}{*}{$\begin{array}{c}\text { Experiment } \\
\text { Number }\end{array}$} & $\begin{array}{c}\text { Duration, } \\
\mathrm{d}\end{array}$ & $\mathrm{O}_{2}$ & $\mathrm{~N}_{2}$ & $\mathrm{H}_{2}$ & $\mathrm{CO}_{2}$ \\
\cline { 2 - 6 } & 30 & 20.7 & 79.2 & .030 & .118 \\
\cline { 2 - 6 } & 61 & 19.4 & 80.3 & .035 & .257 \\
\cline { 2 - 6 } & 121 & 2.76 & 94.4 & 0.32 & 2.86 \\
\cline { 2 - 6 } & 152 & 1.96 & 95.0 & 0.26 & 3.09 \\
\hline \multirow{3}{*}{42} & 30 & 20.6 & 79.3 & .034 & .126 \\
\cline { 2 - 6 } & 61 & 18.8 & 80.8 & .056 & .311 \\
\cline { 2 - 6 } & 121 & 5.78 & 91.8 & 0.20 & 2.42 \\
\cline { 2 - 6 } & 152 & 6.36 & 91.3 & 0.11 & 2.30 \\
\hline
\end{tabular}




\begin{tabular}{|c|c|c|c|c|c|}
\hline \multicolumn{6}{|c|}{$\begin{array}{l}\text { Table A.22. Gas Phase Composition for Polyethylene at } 100^{\circ} \mathrm{C} \text { with } 0.3-\mathrm{mCi} \text { Am-241 Foils: } \\
\text { Experiments WSRC-43 and WSRC-44 }\end{array}$} \\
\hline \multirow[b]{2}{*}{$\begin{array}{l}\text { Experiment } \\
\text { Number }\end{array}$} & \multirow[b]{2}{*}{$\begin{array}{l}\text { Duration, } \\
\mathrm{d}\end{array}$} & \multicolumn{4}{|c|}{$\mathrm{mol} \%$} \\
\hline & & $\mathrm{O}_{2}$ & $\mathrm{~N}_{2}$ & $\mathrm{H}_{2}$ & $\mathrm{CO}_{2}$ \\
\hline \multirow[t]{5}{*}{43} & 60 & 12.3 & 86.6 & .276 & 1.13 \\
\hline & 91 & 1.03 & 95.9 & 0.409 & 3.06 \\
\hline & 120 & 2.27 & 94.9 & .246 & 2.87 \\
\hline & 151 & 3.96 & 93.4 & 0.164 & 2.62 \\
\hline & 181 & 5.64 & 92.2 & .011 & 2.18 \\
\hline \multirow[t]{5}{*}{44} & 60 & 19.6 & 80.2 & .022 & .238 \\
\hline & 91 & 16.8 & 82.6 & .044 & .547 \\
\hline & 120 & .860 & 96.2 & 0.38 & 2.92 \\
\hline & 151 & 2.25 & 94.9 & 0.232 & 2.82 \\
\hline & 181 & 3.59 & 95.0 & 0.13 & 2.45 \\
\hline
\end{tabular}

Table A.23. Gas Phase Composition for Polyvinylchloride at $100^{\circ} \mathrm{C}$ with 6-mCi Am-241 Foils: Experiments WSRC-46 and WSRC-47

\begin{tabular}{|c|c|c|c|c|c|}
\hline \multirow{2}{*}{$\begin{array}{c}\text { Experiment } \\
\text { Number }\end{array}$} & \multirow{2}{*}{$\begin{array}{c}\text { Duration, } \\
\mathrm{d}\end{array}$} & \multicolumn{4}{|c|}{$\mathrm{mol} \%$} \\
\hline & & $\mathrm{O}_{2}$ & $\mathrm{~N}_{2}$ & $\mathrm{H}_{2}$ & $\mathrm{CO}_{2}$ \\
\hline \multirow[t]{4}{*}{46} & 3 & NA & NA & NA & NA \\
\hline & 7 & 20.8 & 79.1 & 0.019 & 0.096 \\
\hline & 14 & 17.7 & 81.9 & 0.053 & 0.35 \\
\hline & 33 & 11.6 & 87.4 & 0.138 & 0.98 \\
\hline \multirow[t]{4}{*}{47} & 3 & NA & NA & NA & NA \\
\hline & 7 & 21.7 & 78.3 & 0.014 & 0.043 \\
\hline & 14 & 17.6 & 82.0 & 0.074 & 0.35 \\
\hline & 33 & 10.9 & 89.1 & 0.174 & 0.021 \\
\hline
\end{tabular}




\begin{tabular}{|c|c|c|c|c|c|}
\hline \multicolumn{6}{|c|}{$\begin{array}{l}\text { Table A.24. Gas Phase Composition for Polyvinylchloride at } 100^{\circ} \mathrm{C} \text { with 3-mCi Am-241 Foils: } \\
\text { Experiments WSRC-48 and WSRC-49 }\end{array}$} \\
\hline \multirow[b]{2}{*}{$\begin{array}{l}\text { Experiment } \\
\text { Number }\end{array}$} & \multirow[b]{2}{*}{$\begin{array}{l}\text { Duration, } \\
\text { d }\end{array}$} & \multicolumn{4}{|c|}{$\mathrm{mol} \%$} \\
\hline & & $\mathrm{O}_{2}$ & $\mathrm{~N}_{2}$ & $\mathrm{H}_{2}$ & $\mathrm{CO}_{2}$ \\
\hline \multirow[t]{4}{*}{48} & 7 & 21.1 & 78.8 & .012 & .087 \\
\hline & 16 & 20.2 & 79.6 & .020 & .206 \\
\hline & 30 & 15.3 & 84.0 & .067 & .624 \\
\hline & 41 & 13.2 & 86.0 & .070 & 0.805 \\
\hline \multirow[t]{4}{*}{49} & 7 & 21.1 & 78.8 & .010 & .081 \\
\hline & 16 & 20.5 & 79.3 & .025 & .173 \\
\hline & 30 & 16.3 & 83.2 & .052 & .53 \\
\hline & 41 & 14.1 & 85.2 & .065 & 0.71 \\
\hline
\end{tabular}

Table A.25. Gas Phase Composition for Polyvinylchloride at $100^{\circ} \mathrm{C}$ with 0.6-mCi Am-241 Foils: Experiments WSRC-50 and WSRC-51

\begin{tabular}{||c|c|c|c|c|c||}
\hline \multirow{3}{*}{$\begin{array}{c}\text { Experiment } \\
\text { Number }\end{array}$} & $\begin{array}{c}\text { Duration, } \\
\mathrm{d}\end{array}$ & $\mathrm{O}_{2}$ & $\mathrm{~N}_{2}$ & $\mathrm{H}_{2}$ & $\mathrm{CO}_{2}$ \\
\cline { 2 - 6 } & 32 & 17.3 & 82.3 & .062 & 0.433 \\
\cline { 2 - 6 } & 62 & 13.0 & 86.2 & .066 & .777 \\
\cline { 2 - 6 } & 123 & 10.1 & 89.0 & .042 & 0.88 \\
\cline { 2 - 6 } & 153 & 9.7 & 89.5 & .049 & .83 \\
\cline { 2 - 6 } & 182 & 8.9 & 90.3 & .050 & .82 \\
\hline \multirow{3}{*}{51} & 32 & 17.7 & 81.9 & .045 & 0.403 \\
\cline { 2 - 6 } & 62 & 12.9 & 86.3 & .056 & .797 \\
\cline { 2 - 6 } & 123 & 8.3 & 90.6 & .053 & 1.1 \\
\cline { 2 - 6 } & 153 & 8.2 & 90.8 & .075 & .98 \\
\cline { 2 - 6 } & 182 & 6.6 & 92.4 & .177 & 1.01 \\
\hline
\end{tabular}


Table A.26. Gas Phase Composition for Polyvinylchloride at $100^{\circ} \mathrm{C}$ with 0.3-mCi Am-241 Foils: Experiments WSRC-52 and WSRC-53

\begin{tabular}{||c|c|c|c|c|c||}
\hline \hline \multirow{3}{*}{$\begin{array}{c}\text { Experiment } \\
\text { Number }\end{array}$} & $\begin{array}{c}\text { Duration, } \\
\mathrm{d}\end{array}$ & $\mathrm{O}_{2}$ & $\mathrm{~N}_{2}$ & $\mathrm{H}_{2}$ & $\mathrm{CO}_{2}$ \\
\cline { 2 - 6 } & 60 & 13.1 & 86.1 & .083 & .836 \\
\cline { 2 - 6 } & 91 & 11.1 & 87.9 & .074 & .954 \\
\cline { 2 - 6 } & 120 & 10.0 & 90.0 & .072 & 1.02 \\
\cline { 2 - 6 } & 151 & 9.7 & 89.3 & .061 & 1.02 \\
\cline { 2 - 6 } & 181 & 9.7 & 89.4 & .053 & .926 \\
\hline \multirow{3}{*}{53} & 60 & 13.5 & 85.8 & .059 & .758 \\
\cline { 2 - 6 } & 91 & 11.8 & 87.3 & .049 & .822 \\
\cline { 2 - 6 } & 120 & 11.0 & 88.2 & .052 & .853 \\
\cline { 2 - 6 } & 151 & 10.7 & 88.4 & .048 & .843 \\
\cline { 2 - 6 } & 181 & 10.6 & 88.6 & .037 & .778 \\
\hline
\end{tabular}


Distribution for ANL-97/7

Internal:
S. B. Aase
J. W. Emery
J. J. Laidler
J. E. Banaszak
J. E. Harmon
D. T. Reed (50)
J. C. Cunnane
C. Jonah
R. E. Einziger
T. R. Krause
A. S. Wagh
TIS File

\section{External:}

DOE-OSTI (2)

ANL-E Library

ANL-W Library

Manager, Chicago Operations Office, DOE

Chemical Technology Division Review Committee Members:

H. U. Anderson, University of Missouri-Rolla, Rolla, MO

E. R. Beaver, Monsanto Company, St. Louis, MO

A. L. Bement, Purdue University, West Lafayette, $\mathbb{I N}$

M. V. Koch, University of Washington, Seattle, WA

R. A. Osteryoung, North Carolina State University, Raleigh, NC

V. P. Roan, University of Florida, Palm Beach Gardens, FL

G. R. St. Pierre, Ohio State University, Columbus, $\mathrm{OH}$

S. Barney, Fluor Daniels, Richland, WA

N. Bibler, Westinghouse Savannah River Company, Aiken, SC

D. Bullen, Iowa State University, Ames, IA

K. Czerwinski, Massachusetts Institute of Technology, Cambridge, MA

D. Hobbs, Westinghouse Savannah River Company, Aiken, SC

D. McCabe, Westinghouse Savannah River Company, Aiken, SC

M. Molecke, Sandia National Laboratory, Albuquerque, NM

R. Moore, Sandia National Laboratory, Albuquerque, NM

R. Van Konynenburg, Lawrence Livermore National Laboratory, Livermore, CA 